\title{
Essays on the impact of market information on stock markets: R\&D, patents and money illusion
}

Kwasi Osei-Yeboah

West Virginia University

Follow this and additional works at: https://researchrepository.wvu.edu/etd

\section{Recommended Citation}

Osei-Yeboah, Kwasi, "Essays on the impact of market information on stock markets: R\&D, patents and money illusion" (2009). Graduate Theses, Dissertations, and Problem Reports. 4510.

https://researchrepository.wvu.edu/etd/4510

This Dissertation is protected by copyright and/or related rights. It has been brought to you by the The Research Repository @ WVU with permission from the rights-holder(s). You are free to use this Dissertation in any way that is permitted by the copyright and related rights legislation that applies to your use. For other uses you must obtain permission from the rights-holder(s) directly, unless additional rights are indicated by a Creative Commons license in the record and/ or on the work itself. This Dissertation has been accepted for inclusion in WVU Graduate Theses, Dissertations, and Problem Reports collection by an authorized administrator of The Research Repository @ WVU.

For more information, please contact researchrepository@mail.wvu.edu. 


\title{
ESSAYS ON THE IMPACT OF MARKET INFORMATION ON STOCK MARKETS: R\&D, Patents and Money Illusion
}

\author{
Kwasi Osei-Yeboah
}

\author{
Dissertation submitted to the \\ College of Business and Economics \\ at West Virginia University \\ in partial fulfillment of the requirements \\ for the degree of
}

Doctor of Philosophy

in

Economics

\begin{abstract}
Ronald Balvers, Ph.D, Chair
Arabinda Basistha, Ph.D.

Alexei Egorov, Ph. D.

Alexander Kurov Ph.D.

Shuichiro Nishioka Ph.D.
\end{abstract}
Department of Economics
Morgantown, West Virginia 2009

Keywords: Asymmetric information, adverse selection, Cumulative Abnormal returns

Copyright 2009 Kwasi Osei-Yeboah 


\title{
ABSTRACT \\ ESSAYS ON THE IMPACT OF MARKET INFORMATION ON STOCK MARKETS:
}

\author{
R\&D, Patents and Money Illusion
}

Kwasi Osei-Yeboah

This dissertation identifies patents and R\&D expenditures as firm-level information variables, and investigates how they affect the pricing of assets in the stock market. In the first essay, the question as to whether patents and R\&D represent adverse selection risk is investigated. Firms investing in patents and R\&D may present an uncertain outcome for investors who do not have the privilege of insider information. This may increase the adverse selection cost for uninformed investors. For the uninformed investor to hold stocks with more private information, he must be compensated for taking on more firm characteristic risk. The empirical results show that patents and R\&D activities imply higher average returns. Further evidence illustrates that the return premiums for patents and $R \& D$ show differences in their information structures. Patents appear to reduce the degree of asymmetric information and lower the extent to which R\&D affects average returns. Patents by a firm appear to represent increased exposure to a priced systematic risk factor. The second paper evaluates abnormal returns from a trading strategy that selects stocks on the basis of previous patents issued to firms. The cumulative abnormal returns due to previously issued patents reflect a revision of the firm's expected returns resulting from future price correction. Evidence presented in the essay suggests the possibility of a systematic-risk-based explanation to the abnormal returns from patent-based trading strategies. The third paper extends the ModiglianiCohn hypothesis to the international context. The paper argues on the basis of increasing interdependence of the world financial markets, and the dominant role played by the US market that, if the US stock market suffers from money illusion, then the developed international markets must also suffer from money illusion. The empirical analysis supports this hypothesis. 


\section{Acknowledgements}

My appreciation goes to Professor Ronald Balvers, my dissertation advisor, and mentor at the College of Business and Economics. Throughout my years in the program, Professor Ronald Balvers has inspired me with many research ideas some of which made it into my dissertation. Professor Ronald Balvers also provided me with exceptional career guidance in nurturing me in my thinking as an economist. I really appreciate all the help and I am very fortunate to have had the opportunity to work with him.

I would also like to thank the remaining members of my dissertation committee, Arabinda Basistha, Alexei Egorov, Alexander Kurov and Shuichiro Nishioka. They were always supportive of my research ideas and greatly helped me to sharpen the quality of this dissertation. I would like to thank all other economics professors in our department who were always friendly and eager to help.

Many thanks go to my parents Elizabeth Yeboah and Alfred Joseph Kwame Yeboah. I am a product of their hard work and sacrifice. I will also like to thank my siblings for their encouragement and support.

Last but not the least is my appreciation and love to my wife Christina. You have sacrificed with me through trying times and I owe it all to you. God richly bless you. 


\section{TABLE OF CONTENTS}

Table of Contents $\quad$ iv

List of Tables $\quad$ v

Chapter 1. General Overview of the Dissertation ................................

1. Reference.............................................................4

Chapter 2. Do Patents and R\&D Represent Adverse Selection Risk?

1. Introduction................................................................... 5

2. Model and Hypotheses...............................................

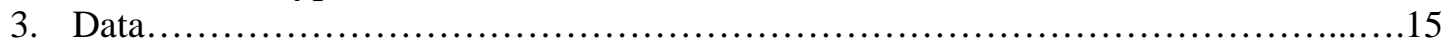

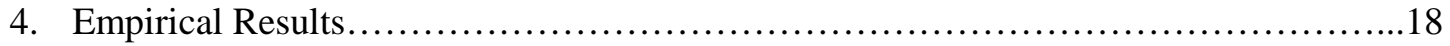

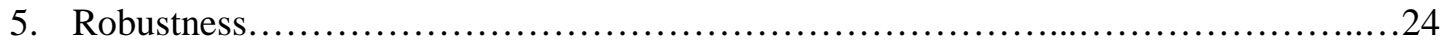

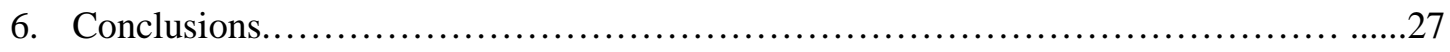

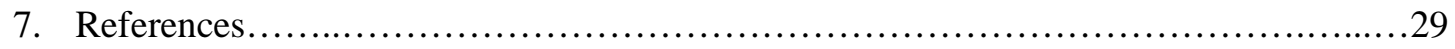

Tables.....................................................................

\section{Chapter 3. Return Predictability Using Firm Issued Patents As Trading Strategies}

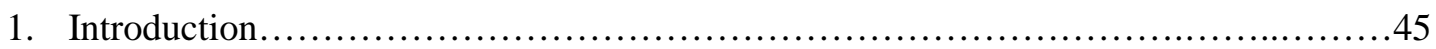

2. The Literature and Hypothesis ..............................................47

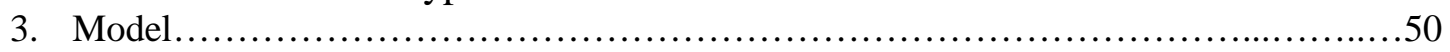

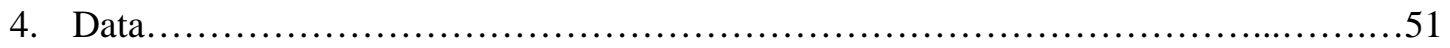

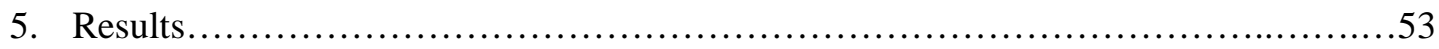

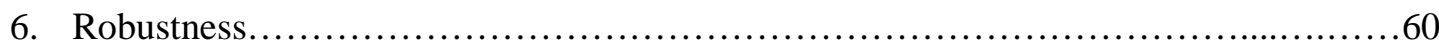

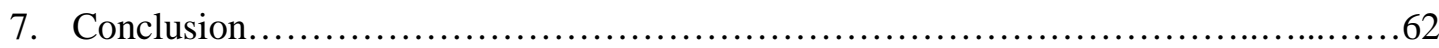

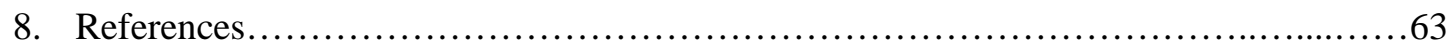

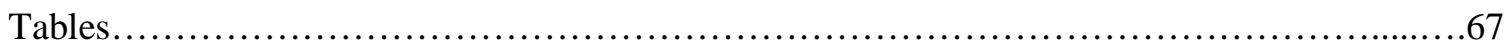

Graphs.............................................................................. 90

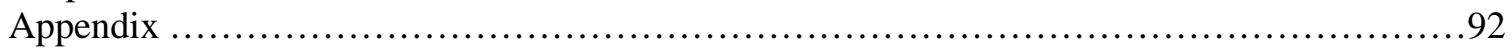

Chapter 4. International Evidence of Money Illusion in the Stock Market

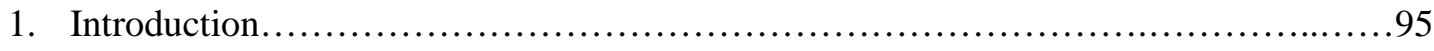

2. Literature Review and Model Description...................................96

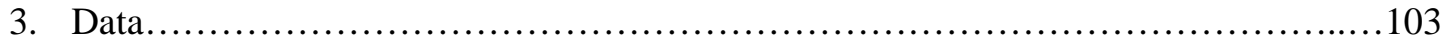

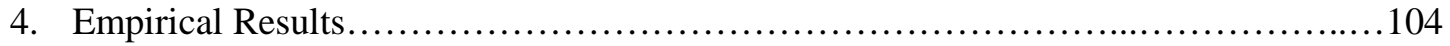

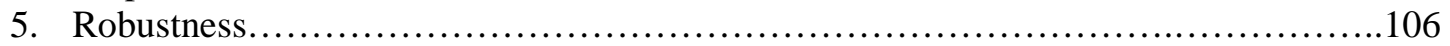

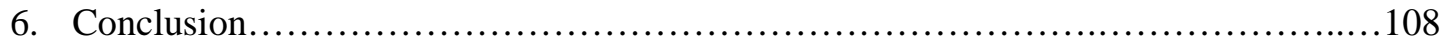

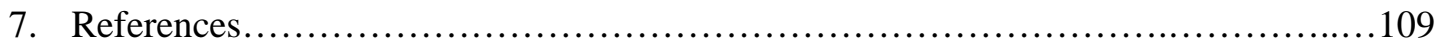

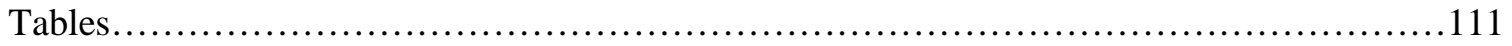




\section{List of tables}

\section{Chapter 2}

Table 2.1 Summary Results of Portfolios.............................................. 34

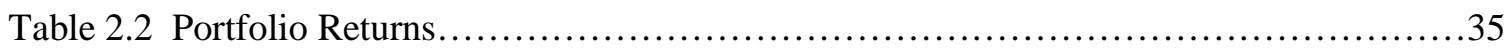

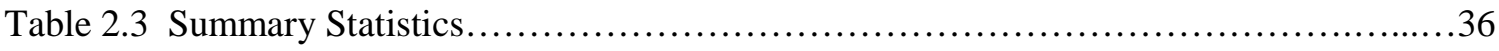

Table 2.4 Cross-sectional Test of Asymmetric Information versus Patent and R\&D.............37

Table 2.5 Cross-sectional Regression of Excess Returns of Individual Firm....................38

Table 2.6 Characteristic Test using all data in sample...................................39

Table 2.7 Robustness: Test of Individual Firm Patent and R\&D and Asymmetric

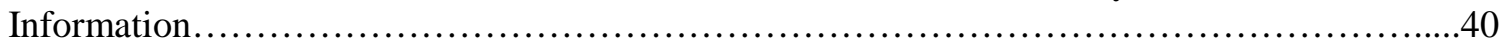

Table 2.8 Robustness: Time Series Regression Results of 25 Portfolios......................41

Table 2.9 Robustness: Characteristic Test of patent variable and parent factor using selected industry portfolios.................................................. 42

Table 2.10 Robustness: Characteristic Test of R\&D variable and R\&D factor

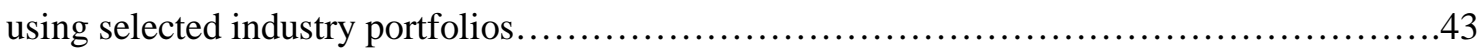

Table 2.11 Robustness: Characteristic Test using individual firms in selected industry.........44

Chapter 3

Table 3.1 Summary Distribution of Earnings per Size by Portfolios........................67

Table 3.2 Summary Distribution of patents among momentum Portfolios...................67

Table 3.3 Average Returns of Patent Portfolios......................................68

Table 3.4 Average Returns of Patent Portfolios......................................69

Table 3.5 Uncorrected Average Returns and Corrected Average Returns

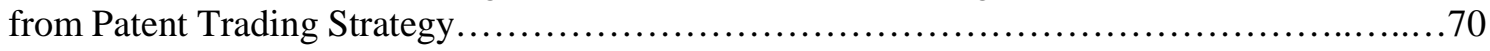

Table 3.6 Average Returns from Patent Trading Strategy Corrected for

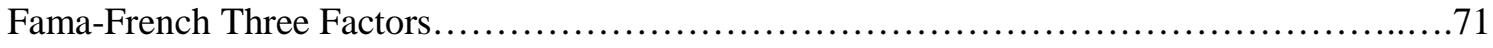

Table 3.7 Average Returns from Patent Trading Strategy Corrected for Fama-French Three Factors and Momentum Factor....................................... 
Table 3.8 Average Returns from Patent Trading Strategy Corrected for

Fama-French Three Factors and Patent Risk Factor.

Table 3.9 Average Returns from Patent Trading Strategy Corrected for

Fama-French Three Factors, Momentum Factor and Patent Risk Factor.

Table 3.10 Average Returns from Patent Trading Strategy Corrected for

Patent Risk Factor.

Table 3.11 Average Returns from Patent Trading Strategy Corrected for Market and Patent Risk Factor.... .76

Table 3.12 Uncorrected Average Returns and Corrected Average Returns from Momentum Trading Strategy....

Table 3.13 Average Returns from Momentum Trading Strategy Corrected for Fama-French Three Factors. ... .78

Table 3.14 Average Returns from Momentum Trading Strategy Corrected for Patent Risk Factor. .79

Table 3.15 Average Returns from Momentum Trading Strategy Corrected for Fama-French Three Factors and Patent Risk Factor.

Table 3.16 Average Returns from Momentum Trading Strategy Corrected for Fama-French Three Factors and Momentum Factor....

Table 3.17 Average Returns from Momentum Trading Strategy Corrected for Fama-French Three Factors , Momentum and Patent Risk Factor.

Table 3.18 Average Returns from Momentum Trading Strategy Corrected for Market and Patent Risk Factor...

Table 3.19 Robustness: Average Returns of Patent Portfolios with T-Statistics.

Table 3.20 Robustness: Uncorrected Average Returns and Corrected Average Returns from Citation Trading Strategy...

Table 3.21 Robustness: Average Returns from Citation Trading Strategy

Corrected for Fama-French Three Factors .86

Table 3.22 Robustness: Average Returns from Momentum Trading

Strategy Corrected for Patent Risk Factor. ...

Table 3.23 Robustness: Average Returns from Patent Trading Strategy

Corrected for Market Risk and Patent Risk Factor. .88

Table 3.24 Robustness: Sub-period Monthly Excess Returns .89

\section{Chapter 4}

Table 4.1 Average Inflation for All Data Period and Average Inflation for 
Periods of Positive and Negative Inflation Shocks.

Table 4.2 Mean Excess Returns of data from Morgan Stanley Capital International.

.112

Table 4.3 Regression Results for Developed Countries Using Negative

Inflation Shocks and Using Data Period 1970:01 - 2005:12.......

Table 4.4 Regression Results for Developed Countries Using Positive

Inflation Shocks and Using Data Period 1970:01 - 2005:12........

Table 4.5 Regression Results for Emerging Countries Using Negative

Table 4.6 Regression Results for Emerging Countries Using Positive

Inflation Shocks and Using Data Period 1987:01 - 2005:12..

Table 4.7 Regression Results for Developed Countries Using Negative Inflation Shocks with Fama-French Risk Correction

Table 4.8 Regression Results for Developed Countries Using Positive Inflation Shocks with Fama-French Risk Correction. .

Table 4.9 Regression Results for Emerging Countries Using Negative Inflation Shocks with Fama-French Risk Correction.

Table 4.10 Regression Results for Emerging Countries Using Positive

Inflation Shocks with Fama-French Risk Correction.

Table 4.11 Regression Results for Developed Countries Using Negative

Inflation Shocks and Using Data Period 1987:01 - 2005:12...

Table 4.12 Regression Results for Developed Countries Using Positive

Inflation Shocks and Using Data Period 1987:01 - 2005:12..

\section{List of Graphs}

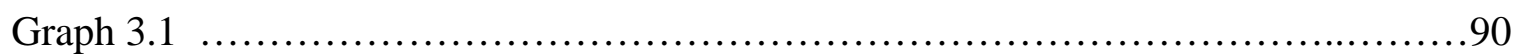

Graph 3.2 ............................................................91 


\section{Chapter 1. General Overview of the Dissertation}

The 1933 securities act, "truth in securities", has two key canons. One, it requires that investors receive financial and other significant information concerning securities being offered for public sale. Two, it prohibits deceit, misrepresentations and other fraud in the sale of securities.

- Securities and Exchange Commission.

The availability of firm-level information matters for stock returns and it is an issue that continues to receive attention in the finance literature. There is a growing body of literature on the role firm-level information plays in our general understanding of how assets are priced on the stock market. Intuitively, one may expect that disclosure of information reduces the uncertainty of the information environment faced by investors, hence lowers the compensation to investors for holding these stocks. Conversely, increased private information may increase the uncertainty faced by investors, and investors must be compensated for holding stocks that allow more private information. Diamond and Verrecchia (1991) show that the reduction in information asymmetry by revealing public information can reduce a firm’s cost of capital. Easley, Hvidkjaer, and O’Hara (2002) show in their model that trading stocks with more possibilities for private information produce higher stock returns.

The issue of interest addressed in the second chapter of the dissertation is the contribution of patents and R\&D spending in the discussion of firm-level information. There has been substantial work done by economists to include $R \& D$ spending as a capital investment in the national account. Many economists believe R\&D is a significant source of economic growth. Work by Fraumeni and Okubo (2005), Okubo et al (2006) of the US Bureau of Economic Analysis (BEA), de Haan (2004) of the Central Bureau of Statistics (CBS) in the Netherlands and other economists at the Australia Bureau of Statistics have published work in support of this effort. Firms commit to R\&D with the hope that the investment would pay off leading to greater profit. The question asked is whether increased R\&D spending of firms changes the information environment of the firm. Many of the investments made by firms in R\&D do not yield any benefit. More so, 
firm do not report progress made in their $R \& D$ activities, partly to protect their investments. From the perspective of an outsider who does not have the benefit of insider information, increased firm R\&D spending increases private information associated with the firm's stock. Patents could be described as a product of firm research and development activities. The firm receives the exclusive right to use (sell) the patent and profit from it for 20 years subject to renewal. However, a key requirement of the United States Patent and Trademark Office is for all information about the patent to be made publicly available. This key requirement may affect the information environment of firms actively engaged in patents. In a sense, the question is whether $R \& D$ and patents represent adverse selection risk and whether this risk is priced in the stock market.

Chapter 2 of this dissertation investigates increases in adverse selection risk for firms investing in patents and R\&D activities. Investment projects with uncertain benefits increase private information and impose an adverse selection cost on uninformed investors. Informed investors could take advantage of superior information to profit from holding stocks with higher private information. Uninformed investors would accordingly require higher overall stock returns to hold stocks with increased private information. I show here that increases in patents and R\&D activities imply higher average returns. The return premium behaves as the characteristics premium noted in Daniel and Titman (1997) but attributable to an adverse selection risk, borne by the uninformed investors. The adverse selection risks due to patent activities display a different information structure as compared to that of the risks of R\&D activities. Patents appear to reduce the degree of asymmetric information and lower the extent to which R\&D affects average returns. Patents by a firm show evidence of representing a priced systematic risk factor.

Chapter 3 continues the discussion on firm-level market information by specifically looking at patents. If the market is unable to make an accurate prediction of the value of firm patents, then there would be future corrections as information becomes less noisy. Future price correction could be captured by implementing trading strategies that select stocks on the basis of previously issued firm patents. The cumulative abnormal returns would reflect a revision of a firm's expected returns resulting from future price correction as in Jegadeesh and Titman (2001) 
Chapter 4 uses the money illusion hypothesis to highlight how information transmission from one market could significantly influence market outcomes in other economies. The chapter extends the Modigliani-Cohn hypothesis to the international context. It argues on the basis of increasing interdependence of the world financial markets, and the dominant role played by the US market that, if the US stock market suffers from money illusion, then the developed international markets must also suffer from money illusion. The empirical analysis supports this hypothesis.

This dissertation lends support to the side of the finance literature that advances the view that information asymmetry may not be fully diversifiable in an economy with large numbers of risky assets, as otherwise suggested by Hughes, Liu, and Liu (2007). Many researchers report empirical evidence showing the relationship between information quality and the cost of capital. Among them, Botosan (1997) and Botosan and Plumlee (2002) examine the relation between the cost of capital and the information disclosure level and find that greater disclosure is associated with a lower cost of equity capital. Francis, LaFond, Olsson, and Schipper (2004) use eight proxies for earnings quality and show that firms with lower earnings quality have a higher cost of capital. The quality of firm's accounting information matters. 


\subsection{Reference:}

Botosan, C., 1997. "Disclosure level and the cost of equity capital”. The Accounting Review 72, 323-349.

Botosan, C., Plumlee, M., 2002. "A re-examination of disclosure level and the expected cost of equity capital”. Journal of Accounting Research 40, 21-40.

Daniel, K. and Titman, S., 1997, "Evidence on the Characteristics of Cross Sectional Variation in Stock Returns”, Journal of Finance, 52, 1-33

de Haan, M. 2004. "Progress Report on R\&D Capitalization: The Netherlands”, paper presented at meeting of Canberra II Group, Washington DC.

Diamond, D. and Verrecchia, R., 1991. "Disclosure, Liquidity and the Cost of Capital", Journal of Finance, 46, 1325 - 1360

Easley, D, Hvidkjaer, S. and O’Hara, M, 2005, "Factoring Information Into Returns", working paper.

Francis, J., LaFond, R., Olsson, P., Schipper, K., 2004. "Cost of equity and earnings attributes”. The Accounting review, 79, 976-1010.

Francis, J., LaFond, R., Olsson, P., Schipper, K., 2005. "The market pricing of accruals quality”. Journal of Accounting and Economics, 39, 295-327.

Fraumeni, B., and Okubo, S. 2005. “ R\&D in National Income Product Account: A First Look at the Effect on GDP” In Carol Corrado, John Haltiwanger and Daniel Sichel, eds. Measuring Capital in the New Economy. NBER Conference on Research in Income and Wealth (Chicago University Press)

Okubo, S., Robbins, C., Sliker, K. D., Schultz, L. and Mataloni, L. 2006. “ BEA’s 2006 R\&D Satellite Account: Preliminary Estimates of R\&D for 1959 - 2002 Effect on GDP and Other Measures” Survey of Current Business, 14 - 27

Hughes, J, Liu, J., Liu, J., 2007. Information, diversification, and cost of capital. The Accounting Review, 82, 705-729.

Jegadeesh, N. and Titman, S., 2001. "Profitability of Momentum Strategies: An Evaluation of Alternative Explanations.” Journal of Finance, 56, 699- 720.

Modigliani, F. and Cohn, R. 1979 "Inflation, Rational Valuation and the market", Financial Analysts Journal, 35, 24-44 


\section{Chapter 2. Do Patents or R\&D Represent Adverse Selection Risk?}

\subsection{Introduction}

The finance literature documents the process by which information affects asset pricing fundamentals. Easley and O’Hara (2004) present an empirical model, where they argue that differences in information between informed and uninformed investors affect the cost of capital. Informed and uninformed investors perceive risk differently, and that affects the risk-return trade-off leading to insider gains. Easley, Hvidkjaer, and O'Hara (2002) also present evidence to show that stocks with higher probabilities of informationbased trading have higher rates of returns. Some attempts have been made to identify the sources of private information. Aboody and Lev (2000) argue that all firm-specific investment decisions serve as drivers of information asymmetry. They empirically tested research and development (R\&D), as an example of such firm-specific driver of information asymmetry. However, it is not clear whether the effect of information on asset pricing models is due to the behavioral or rational views of the investor.

Taking the cue from Easley and O'Hara (2004), I develop the argument that adverse selection risk due to firm-level decisions is a type of asymmetric information risk. This risk cannot be diversified away through portfolio formation, and the market pays a premium. This argument is consistent with Daniel and Titman's (1997) notion of priced firm "characteristics". However, Daniel and Titman (1997) imply that characteristics show up because prices are not determined by an equilibrium asset pricing model but instead by the actions of irrational investors. In this chapter, I show that, even though you get what looks like characteristics, you do have an equilibrium asset pricing model that does give a specific explanation (based on rational investor behavior) for why the characteristic is priced. The adverse selection risk is a one-sided risk ${ }^{1}$ : for given mean return, informed investors do better on average, and for a given mean return, uninformed investors must do worse. To entice regular (uninformed) investors into the market, the

\footnotetext{
${ }^{1}$ One-sided risk - putting your money at risk means you may lose it without compensation on the up side. This type of risk is disliked even by risk neutral investors.
} 
asset needs to have a higher mean return than implied by systematic risk alone. Then the market pays a premium for one-sided risk as a result of adverse selection risk

In this chapter, I empirically show that firm managers' decisions to invest in Research and Development (R\&D) generate adverse selection risk. Increased $R \& D$ increases uncertainty, and the uncertainty ${ }^{2}$ about the outcome of investment generates adverse selection risk. As evidenced in the literature, uncertainty is priced by the market. I further show that increased R\&D spending leads to higher average returns. However, R\&D spending is not priced systematic but priced firm-specific risk.

In this chapter, I address the question suggested by Aboody and Lev (2000) 'Do all corporate investments create information asymmetries?' To address this question, I contrast the effects of patents and R\&D activities of firms on asymmetric information. A number of papers establish a direct relation between patents and R\&D spending [e.g. Pakes and Griliches (1980, 1984) and Griliches, Pakes and Hall (1987)]. The expectation is that patents and $R \& D$ activities share the same information structure; hence they both must generate adverse selection risk due to information asymmetry. Patents could arguably be described as the product of successful R\&D activities and may serve to reduce the degree of asymmetric information so that, in the presence of patent information, uninformed investors may not need to be compensated as much. In addition, the rules governing the issue of patents by US Patent and Trademark Office (USPTO) require full disclosure of information. Though the assignee gets the exclusive use and the right to profit from the product for twenty years subject to renewal, the patent information is made publicly available. Thus, increased patents may not increase adverse selection risk. The evidence put forward in the chapter suggests that R\&D spending may capture the information contained in patents. The relationship between patents and returns turns negative when the $R \& D$ variable is included in the regression model. I show in the chapter that not all firm-level decisions create information asymmetry. Though patents correlate with uncertainty patents are not priced as firm-specific risk.

This chapter bridges an important gap in the literature by establishing a linkage between firm-level decisions and firm-specific risk in explaining equilibrium asset

\footnotetext{
${ }^{2}$ Papers by Hansen and Sargent (1995, 2001, 2003, 2005, and 2006), Anderson, Hansen, and Sargent (2003) among others have shown how uncertainty affects optimal decisions and asset prices.
} 
pricing. The findings in the chapter may also offer an alternative explanation the pricing of idiosyncratic risk in the market.

The remaining sections of the chapter are organized as follows: Section II provides the model and key hypotheses in which the research question is defined. Section III presents the data used for the chapter. Section IV provides the empirical results. Section V presents the robustness of the research findings. Section VI concludes the chapter.

\subsection{Model and Hypotheses}

\subsubsection{Defining the problem}

The chapter proceeds in two directions. First I examine the linkage between the firms' patents and R\&D activities and adverse selection risk. Based on the argument put forward by Easley and O'Hara (2004), increased patents and R\&D activities must lead to

higher average returns. Secondly, I address the question of whether patents and R\&D activities are priced characteristics or priced systematic risk.

The finance literature documents two types of nondiversifiable risk. The first is systematic (two-sided) risk priced by the market [Sharpe (1964), Kaufman and Scott (2003), Fama and French (1992, 1993)]. Two-sided risk is empirically evaluated for instance by considering the Fama-French model or the standard Sharpe-Lintner CAPM formulation. The second is a one-sided risk, as is important for fixed income instruments due to the possibility of default but as also postulated for equity instruments by Easley and O'Hara (2004), who indicate that for given mean returns, if informed investors can do better on average, uninformed investor must do worse. Thus in a multi-asset rational expectation equilibrium setting with informed and uninformed investors, private and public information, uninformed investors consistently perform worse. For uninformed investors to be enticed into the market, and be properly compensated for holding assets with one-sided and nondiversifiable risk, the assets have to offer a higher overall mean return than implied by systematic risks alone. Easley, Hvidkyaer and O’Hara (2002) estimate the probability of information-based trading (PIN) as a proxy for asymmetric information and they present evidence that the PIN is positively and significantly related to mean returns. Jones and Slezak (1999) also present a theoretical model of the 
asymmetric information effect on asset returns in which the variance of news and liquidity shocks over time affect agent portfolio holdings, and hence affect asset returns.

The first research question addressed in this chapter is: Do all firm-level decisions that affect the information balance between insiders and outsiders generate adverse selection risk? This chapter looks at two firm-level decisions; one is firm-level decision to invest in R\&D and the other is the decision to apply for patents. Patents and R\&D activities share close similarities in their information structure, since potentially they may increase the investment opportunities of the firm. Pakes and Griliches $(1980,1984)$ and Griliches, Pakes and Hall (1986) find evidence to show that there exist a significant relationship between R\&D and patent application. The information about their value and productivity is not shared with the public, and for an uninformed investor, holding stocks with more R\&D spending or more patents may be taking additional risk. According to Aboody and Lev (2000), all such firm-level decisions must have higher average returns. In this regard, increased firm spending on $R \& D$ and patents increases private information. Insiders with the benefit of good information about firm patents and R\&D would exploit this to their gain ${ }^{3}$. Subsequently, outsiders would have to be compensated for adverse selection risk with a premium in excess of the return-risk trade-off due to systematic risk.

Do patents and $R \& D$ activities share the same information structure? According to Aboody and Lev (2000), patents and R\&D must share the same information structure on the basis of the similarities between them. In this chapter, the effect of firm-level decision is investigated to be influenced by the nature of the information structure. In spite of the similarities between patents and R\&D, they may not share the same information structure. It is without a doubt that R\&D spending may increase firm's asymmetric information risk to outsiders [Easley and O’Hara (2004)]. Aboody and Lev (2000) explain that the information about the value and productivity of firm's R\&D investment are not shared with the public. The US Patent and Trademark Office (USPTO) requires that all information about patents must be made public. The assignee gets exclusive use of the product for 20 years subject to renewal, but the information is

\footnotetext{
${ }^{3}$ Studies by Lorie and Niederhoffer (1968), Jaffe (1974) and Finnerty (1976) all document varying levels of insider gains from private information ranging from 3 to 30 percent over a period of about three years.
} 
made public. Coca-Cola for instead, keeps a tight-lip on its Coke formula; the company would not patent it because it does not want to share the formula with competitors. Kentucky Fried Chicken would not patent its chicken recipe because they do not want to reveal the formula, as would be required by USPTO.

The difference between $R \& D$ and patents may not only be because of the willingness to disclose information, but by the differences in the nature of their economic activities. Hence, the two variables may affect uncertainty differently. All private R\&D expenditures can plausibly be treated as investment because these expenditures are all undertaken with the expectation of a commercial return and may obtain such returns. Hence, R\&D may be described as an investment input and may not always add value to the firm. Patents may more likely be described as an asset [like intangible assets such as trademarks, etc.]. McCarthy and Schneider (1995) present a significant positive relationship between goodwill and the market value of a firm. Choi, Kwon and Lobo (2000) conclude that the level of intangible assets reported on the balance sheet is positively related to market valuation of firms' equity. Therefore patents are an output of investment and may add value to the firm. In view of these differences, patents and $R \& D$ may convey different information.

I hypothesize:

Hypothesis 1: A higher level of patents received and $R \& D$ spending by a firm raises average returns on the firm's equity.

As argued by Easley and O’Hara (2004), assets with greater private information would cause uninformed investors to demand higher returns to hold stocks. Increased uncertainty raises the average returns of stocks. R\&D spending by firms provides more private information to insiders, but increases the uncertainty for outsiders. Insiders may benefit from private information because they can rebalance their portfolios and hold stocks with more good information about the success of R\&D activity. Outsiders are disadvantaged and for the market to entice them to hold stocks with more private information, they ought to be compensated with an additional premium. Outsiders are 
therefore faced with more adverse selection risk due to increased $R \& D$ activities as a result of firm managers’ decisions.

There may be a systematic risk based explanation to increased average returns on firm's equity due to higher level of patents received by a firm and R\&D spending. According to Merton, anything that changes the investment opportunities of a firm may be priced as systematic risk. The patent and $R \& D$ factors may proxy for systematic changes in aggregate technology growth, which changes investment opportunities.

The next question of interest is: Is the risk associated with increased patents and $R \& D$ priced as one-sided, two-sided, or no risk? The literature documents that $\mathrm{R} \& \mathrm{D}$ risk matters in asset pricing and that it is unlikely to be systematic risk. According to Daniel and Titman (1997), firm-level decisions generate a "characteristic" effect on asset returns. Aboody and Lev (2000) also argue that lack of market exchange for firm level characteristics like $R \& D$ makes it impossible to evaluate a market proxy for these risk factors.

Hypothesis 2: A higher level of patents received and $R \& D$ spending by a firm generates “characteristic risk” as defined by Daniel and Titman (1997)

This research question is a follow-up on the first hypothesis. It is argued here that adverse selection risks due to firm-level decisions command a premium, and this is priced onesided risk. The hypothesis argues that an increase in adverse selection risk due to an increase in firm issued patents and $R \& D$ expenditure reflects higher average return and this may be firm characteristic risk. This question is empirically evaluated by running the characteristic model put forward by Daniel and Titman (1997). If the hypothesis reflects a characteristic view, then the R\&D level and patent level variables should perform better than the $R \& D$ and patent factors ${ }^{4}$ for explaining mean returns.

Hypothesis 3: A higher level of patents received and $R \& D$ spending by a firm is priced as systematic risk consistent with Merton (1973).

\footnotetext{
${ }^{4}$ The R\&D factor is estimated using the Fama-French factor formulation
} 
Similarly, hypothesis 3 evaluates the systematic view. If patents and R\&D spending are priced according to Merton's framework, then the factors would perform better than the characteristic variables. The intuition behind this hypothesis is that patents and R\&D spending would influence the productivity growth of firms, thereby increasing investment opportunities.

The motivation behind the research question is to explore the sensitivity of the information structures of patents and R\&D to asset pricing. Lev and Souigiannis, (1996, 1999) argue that more R\&D lowers mean returns since they appear to explain the FamaFrench value premium. Thus increased R\&D spending implies more growth options and so less value. In this chapter, I look at firm R\&D activities directly affecting the balance of information between private and public information. Chen, Golstein and Jiang (2007) argue that managerial investment decisions are influenced by private information reflected in stock prices. R\&D activities are, among other things, investment decisions of managers. It can be empirically demonstrated that $R \& D$ spending leads to increased mean returns. This effect is different from that hypothesized by Lev and Souigiannis (1999); indeed it is one-sided risk as explained in detail in Easley and O'Hara (2004).

Easley and O'Hara (2004) show that uninformed traders cannot diversify asymmetric information (one-sided) risk by holding more stocks of different firms. They end up holding more of stocks with bad news, and too little of stocks with good news. The risk associated with uninformed investor portfolio holding is one-sided risk, but not two-sided risk. The standard separation theorem does not hold here since uninformed and informed investors perceive different risk and returns. Thus private information induces one-sided risk and in equilibrium, investors require compensation for this risk. Jaffe (1974), Finnerty (1976), Seyhun (1986, 1998), Rozeff and Zaman (1988), Lin and Howe (1990), and Jeng, Metrick and Zeckhauser (1999) present evidence from US data to show that insiders are better informed and earn positive abnormal returns from trading activities. According to Easley and O'Hara (2004), any firm decision that increases asymmetric information may have a cross-sectional effect on returns. Increases in firm R\&D and patent activities may lead to increased asymmetric information. Insiders have a better sense of the growth opportunities or success of firm R\&D and patent activities. We 
can test the significance of $R \& D$ and patent variables on required returns as described in Easley and O’Hara (2004).

\subsubsection{Model Discussion}

I present a brief description of the basic idea behind the empirical model as detailed by Easley, Hvidjkaer and O’Hara (2002) in the Lintner (1969) setup below.

Consider a two-period $(t+1)$ consumption-based asset pricing model with two states $s=1,2$ at date $t+1$. There are two assets with state contingent payoffs. Asset one pays 3 units of single consumption good in state 1 and zero in the other state; asset 2 pays 3 units in state 2 and nothing in state 1. We assume an economy with one unit of each asset and consider two traders indexed $i=1,2$. Each trader is endowed with one unit of the consumption good and with one-half of the available assets. Traders have log-utility of consumption at dates $t$ and $t+1$, and discount future utility with discount factor $0<\rho<1$. Trader i's belief ${ }^{5}$ about the distribution of states tomorrow is $q^{i}=\left(q_{1}^{i}, q_{2}^{i}\right)$. Trader $i$ chooses current consumption and asset purchases $\left(c_{t}^{i}, \alpha_{1}^{i}, \alpha_{2}^{i}\right)$ to maximize his expected utility of current and future state contingent on consumption $\left(c_{t}^{i}, c_{t+1}^{i}(1), c_{t+1}^{i}(2)\right)$,

$$
\operatorname{In}\left(c_{t}^{i}\right)+\rho\left[q_{1}^{i} \operatorname{In}\left(c_{t+1}^{i}(1)\right)+q_{2}^{i} \operatorname{In}\left(c_{t+1}^{i}(2)\right)\right]
$$

Subject to his budget constraints

$$
\left.\begin{array}{l}
c_{t}^{i}=w_{t}^{i}-p_{1} \alpha_{1}^{i}-p_{2} \alpha_{2}^{i} \\
c_{t+1}^{i}(1)=3 \alpha_{1}^{i} \\
c_{t+1}^{i}(2)=3 \alpha_{2}^{i}
\end{array}\right\}
$$

Where $w_{t}^{i}=1+\left(p_{1}+p_{2}\right) / 2$ is the wealth at date $t$.

3 scenarios are evaluated from this model.

1. If both traders have common beliefs $q$, then equilibrium asset prices are $p_{s}^{*}=2 q_{s} \rho$. The shadow risk-free rate of return is $3 / 2 \rho^{-1}$ and the expected payoff would be $3 q_{s}$.

\footnotetext{
${ }^{5}$ Beliefs are exogenous in the Lintner (1969) model and are not affected by market prices.
} 
2. If traders differ in their beliefs, then the equilibrium price could be evaluated as $p_{s}=2 \bar{q}_{s} \rho$ where $\bar{q}_{s}=1 / 2\left(q_{s}^{1}+q_{s}^{2}\right)$ is the average belief about the probability of state $s$. According to Easley, Hvidjkaer and O'Hara (2002), this is an example of the Lintner (1969) generalization of the CAPM to heterogeneous beliefs. Here, the traders choose to hold idiosyncratic risk. This happens because each trader believes that the asset is mispriced and is willing to accept some risk in order to take advantage of perceived mispricing.

3. If trader 1 is correct about his belief, then the expected returns on asset $s$ is $3 q_{s}^{1}$, and asset prices are not correct, thus are not equal to expected returns divided by risk-free rate. In this case, there is a positive excess return (expected return divided by price minus the risk-free rate) on one asset and negative excess return on the other asset. In this simplified model, even though there is no market-wide risk, there will be three units of the good in the next period. The adverse selection issues that arise will cause the trader with better information to hold a better portfolio and the trader with bad information will hold a worse portfolio. As pointed out by Easley, Hvidjkaer and O'Hara (2002), diversification will not eliminate this one-sided risk. The informed trader overweighs his investment in the assets with positive excess return. This shows that if investors perceive different risk-return tradeoff, they may choose to hold idiosyncratic risk.

I relate the above model to R\&D spending and patent activities. Looking at an illustrative example of Mylan Pharmaceutical drug research program, not much could be learned from their research spending compared to an FDA approved Bayer drug if you are an outsider. Insiders at Mylan may know what they hope to achieve, at what stage is the research and the likely success of the research program. However, if the FDA approves the drug, and more so if the drug hits the market, information becomes public and insiders may not have information advantage over outsiders. As stated by Aboody and Lev (2000), if a drug company's research fails to pass clinical tests, that information is not shared with others. In a similar fashion, firm's patent ${ }^{6}$ activity may contain private

\footnotetext{
${ }^{6}$ USPTO classifies patents into three criteria

1. Utility patents, thus for new and useful process, machine, article of manufacture, or composition of matter, or any new and useful improvement.
} 
information. The patent application process requires full public disclosure of information and a guarantee of exclusive right. Outsiders may be uninformed about the nature of the patent, but an industry competitor may gain valuable information and be able to mimic the product. This may suggest any of the three things: 1 . Patents may increase private information, 2. Patents may reduce private information or 3. Patents may not have any effect at all on private information. Patents may also have the potential of creating a spillover situation where firms in the same industry may benefit from patents of competitors. Empirical evidence by Pakes and Griliches $(1980,1984)$ and Griliches, Pakes and Hall (1986) show significant co-movement in R\&D activities and patent application. Patents and R\&D activities may share the same or signal different asymmetric information. Patent may provide information that reduces the adverse selection risk of $\mathrm{R} \& \mathrm{D}$ activities. These are some of the questions this chapter hopes to explore.

If patents and $R \& D$ can proxy for information asymmetry, then increases in patents and R\&D activities would increase adverse selection risk. Based on the above model, the hypotheses could empirically be tested by running time series and crosssectional regression of excess returns on $R \& D$ and patent variables. From Easley, Hvidjkaer and O'Hara (2002), I estimate 25 portfolio betas $\left(\hat{\beta}_{m k t}\right)$ from the time series regression in equation 3.

$$
R_{t}^{p}-R^{f}{ }_{t}=\alpha^{p}+\beta_{1}^{p} M K T_{t}+\beta_{2}^{p} M K T_{t-1}+\varepsilon_{t}
$$

$\hat{\beta}_{m k t}$ is the average of the two coefficients (betas) in equation 2.3. The use of contemporaneous and lagged market index is to correct for biases arising from nonsynchronous trading, as suggested by Dimson (1979). The estimated betas are then used in the cross-section regression together with patent (PATLEV) and R\&D (RDMAT) variables to evaluate the effect of $R \& D$ and patents as proxies of asymmetric information. PATLEV is the ratio of the number of patents to Total Assets for each firm in a month, where the Total Asset is in units of millions. RDMAT is the ratio of R\&D expenditure of

2. Design patents, thus for invention of a new, original and ornamental design for an article of manufacture.

3. Plant patents, thus for the invention of or discovery and asexually reproduces any distinct and new variety of plant. 
a firm to the Total Assets. Each firm is assigned the beta from the portfolio to which it belongs. In equation 4, I run firm-level cross-sectional regression. As a robustness check, I estimate individual firm betas from firm-level time series regression in equation 3. In this framework, I use the Black, Jensen and Scholes (1972) approach where I assume a constant beta for each firm across time. For each month in the sample period 1970:01 2001:12, I ran the following cross-sectional regression:

$$
R^{i}-R^{f}=\gamma_{0}+\gamma_{1} \hat{\beta}^{i}{ }_{m k t}+\gamma_{2} S I Z E^{i}+\gamma_{3} B M^{i}+\gamma_{4} R D^{i}+\eta^{i}
$$

From equations (2.3) and (1.4), MKT is the excess market return, $R_{t}^{i}$ is the return of stock $i$ in month $t$ and $R^{f}$ is the risk free rate. If patent and $R \& D$ variables induce asymmetric information and adverse selection (one-sided) risk, then $\gamma_{4}$ would be positive and significant. The implication of this test is that increases in patents and R\&D activities may increase the private information of informed investors who can earn abnormal returns. But to entice uninformed investors, assets must offer higher mean returns in excess of what otherwise would have been earned for taking systematic risk. A situation that presents adverse selection risk corresponds to higher mean returns.

Durnev, Morck, and Yeung (2004) use a measure $\psi_{i}{ }^{7}$ to proxy for the asymmetric information variable, which is based on Roll (1988) and Morck, Yeung, and Yu (2000).

$$
\psi_{i}=1-R_{i}^{2}
$$

Where $R_{i}^{2}$ is the R-square $\left(R s q_{i}\right)$ from a CAPM first pass time series regression. I estimate $\psi_{i}$ for all 25 portfolios and run a cross-sectional regression of $\psi_{i}$ against patent and R\&D variables. I also estimate firm level $\psi_{i}$, by estimating $R_{i}^{2}$ from firm level time series. I then run a cross-sectional regression of estimated $\psi_{i}$ against the patent and $\mathrm{R} \& \mathrm{D}$ level variables.

\footnotetext{
${ }^{7}$ Chen, Goldstien and Jiang (2007) use $\left(1-R_{i}^{2}\right)$ to proxy for asymmetric information. Easley and O’Hara (2004) use PIN and other papers use $\frac{\log \left(R s q_{i}\right)}{\left(1-R s q_{i}\right)}$
} 


\subsection{Data}

To test the various questions put forward in this chapter, I start by constructing patent and R\&D variables. Patent data from Bronwyn $\mathrm{Hall}^{8}$ data library is merged with the COMPUSTAT annual data file and the Center for Research in Security Prices (CRSP) monthly data file. Although the United States Patent and Trademark Office (USPTO) have patent data covering the periods 1790 - 1976 and 1976 - 2007 on their website, it is difficult to extract and convert them for use in any meaningful analysis. However, the NBER ${ }^{9}$ and Bronwyn Hall have an on-going project to effectively merge all patent data to COMPUSTAT firms. Bronwyn $\mathrm{Hall}^{10}$ provides patent data already linked to COMPUSTAT (gvkeys) firms that covers the periods from 1969 - 2001. The downloaded patent data are grouped into monthly issued patents for all the firms covered in the sample. With the compustat 'gvkey', the patent data is merged to an already merged compustat and CRSP data. The COMPUSTAT annual data is used instead of the quarterly frequency because the $\mathrm{R} \& \mathrm{D}$ data are reported more accurately on an annual basis [Chan, Lakonishok and Sougiannis (2001)] and the annual frequency avoids seasonal issues. All price data and value data are converted to 2000 constant US Dollars. This is to control for time-varying changes in price. The CRSP monthly returns data cover NYSE, AMEX and NASDAQ stocks. Stocks priced lower than one dollar are eliminated from the sample. I exclude real estate investment trusts, stocks of companies incorporated outside the US, and closed-end funds. Stocks with less than three years continuous monthly data are also excluded. These data cleaning measures are consistent with acceptable practices in the literature [Easley et al (2002)]. The final sample consists of an unbalanced panel of COMPUSTAT and CRSP firms merged with patent data, covering the period 1970:01 to 2001:12. There are in all 151,525 firm month data points used in the sample and a total of 3,741 firms.

The size of a firm is measured as the log of market value of equity, which equals the stock price of the stock at the end of June of year $t$ times the total shares outstanding. Following Fama and French (1992), the book-to-market equity ratio (BE/ME) at time $t$ is calculated by dividing book equity (BE) at the fiscal ending of year $t-1$ by market equity

\footnotetext{
${ }^{8}$ http://www.econ.berkeley.edu/ bhhall/index.html

${ }^{9}$ http://www.nber.org/patents/

${ }^{10}$ http://emlab.berkeley.edu/users/bhhall/bhdata.html
} 
(ME) at December of year $t-1$. The book-to-market equity ratios at time $t$ are matched by the stock returns from July of year $t$ to June of year $\mathrm{t}+1$. Therefore there is at least a 6 months' lag between accounting data and market data. This allows for enough time for the firms' accounting information to be released and fully disseminated in the market. The book value of equity is defined as the Total Assets minus Total Liability minus Preferred Stock plus Deferred Taxes plus Convertible Debt. This definition is based on the Kayhan and Titman (2007) formulation. The patent variable (PATLEV) and R\&D variable (RDMAT) are constructed as follows. PATLEV is the ratio of the number of patents to Total Assets for each firm in a month. RDMAT is the ratio of R\&D expenditure of a firm to the Total Assets, as done in Lev and Sougiannis (1996). Some papers suggest that $R \& D$ ought to be capitalized to take into account its amortized value. I estimate alternative capitalized R\&D (RDCAP1 ) ${ }^{11}$ variables that are used as robustness check [Lev and Sougiannis (1996)].

There is noise in the patent and R\&D data. Patents are described as an output of investment. This description is true if patents are viewed as the product of successful R\&D. However, there are instances in the finance data where certain firms have patents but have no R\&D spending. These firms buy patents previously assigned to original owners or inventors. Some firms also report R\&D spending but they do not have a single patent issued to them. A close inspection of the patent data shows that a significant number of non-public firms and institutions (including Universities and Colleges) are granted patents. Typically, these non-public and institutions patent the product of their research activities and they sell the patent to publicly-traded companies. Patents that are bought by firms may be described as an input investment instead of an investment output. R\&D also has its associated noise. There may be differences across firm in reported R\&D spending. Different firms may treat R\&D related expenditure differently. Hall and Long (1999) use the confidential RD-1 survey conducted by the Bureau of the Census for the National Science Foundation and the data on R\&D spending reported to the Securities and Exchange Commission by firms on their 10-Ks to show discrepancies in industrial R\&D reporting. In view of these underlying issues and no direct link between a firm's

\footnotetext{
${ }^{11}$ Lev and Sougiannis (1996) formulation $R D C_{i t}=\alpha_{1} \frac{R D_{i t}}{T A_{t}}+\alpha_{2} \frac{R D_{i t-1}}{T A_{t-1}}+\alpha_{3} \frac{R D_{i t-2}}{T A_{t-2}}+\alpha_{4} \frac{R D_{i t-3}}{T A_{t-3}}$ where RDC is the $R \& D$ capital, $R D$ is the R\&D expenditure and TA is Total Assets
} 
R\&D and its patents in the data, this chapter relies on the overall statistical relation between the two key variables.

The first set of 25 portfolios is formed by using book-to-market value and size. The sorting process follows the description discussed on Kenneth French's data site ${ }^{12}$. The excess returns of the 25 portfolios are regressed on excess market returns and other key asset pricing factors [e.g. Fama and French (1993)], and I follow the Black, Jensen and Scholes (1974) method. Thus I estimate 25 market betas from the first stage (first pass) of the regression, and I assign the betas to corresponding firms in the portfolio. The second set of portfolios is formed based on industry criteria. Two portfolios are formed based on high R\&D intensive two-digit sic-code industries (28, 35, and 36), and low R\&D intensive industries $(20,24$, and 33). The selection of high $R \& D$ intensive industries is based on Chan, Lakonishok and Sougiannis $(2001)^{13}$, but I limit the criteria to two-digit sic-code industries. The criteria for selecting the three low R\&D intensive industries are: 1. Industries should be in the manufacturing category, 2. Industries should have R\&D expenditure at all data points, and 3. Industries should closely match the high $R \& D$ intensive industries. The selection of the low R\&D intensive classification is such that it would be comparable to the high R\&D intensive industries. Following Easley et al. (2002), I introduce the volume of stocks traded, and size as control variables.

\subsection{Empirical results}

\subsubsection{Summary Analysis}

Table 1 presents a summary report of the 25 portfolios used in the study. Portfolios are formed by sorting firms on the basis of size and book-to-market value. Firms are first sorted into 5 size ${ }^{14}$ quintiles and within each size quintile, sorted into 5 book-to-market ${ }^{15}$ quintiles to form 25 portfolios. The main variables of interest are RDMAT and PATLEV. As explained in the previous section, RDMAT is the ratio of R\&D expenditure to Total Assets, and PATLEV is the ratio of the number of patents to Total Assets for each firm in

\footnotetext{
${ }^{12}$ http://mba.tuck.dartmouth.edu/pages/faculty/ken.french/

${ }^{13}$ In Chan, Lakonishok and Sougiannis (2001), they use a combination of three-digit and two-digit sic-code indurties.

${ }^{14}$ Firm size is computed as the log of market value of equity, where market equity is CRSP price multiply by the shares outstanding

${ }^{15}$ COMPUSTAT data; sum of (Data6,-Data181,-Data10,Data35,Data79)
} 
a month, where the Total Asset is scaled by a millionth. RDCAP1 is used as an alternative measure of $R \& D$ intensity to check for robustness. The summary results provide a snap-shot of how the main variables (RDMAT, EXRET, PATLEV, RDCAP1) are distributed and how general characteristics of the data relate to the literature. Low book-to-market (growth) firms on average have lower mean excess returns than high book-to-market (value) firms. This finding is consistent with the value premium hypothesis documented by Rosenberg, Reid and Lanstein (1985) and Lakonishok, Shleifer and Vishny (1994). The sample considers firms investing in patents and R\&D activities, and such firms tend to be large firm and especially in technology-oriented industries. Large-sized firms on average have higher returns than small-sized firms. This is contrary to what is generally reported in the literature [eg. Fama and French (1993)]. However, Zhang (2008) reports that in recent time, the size effect has changed and in most cases has reversed. The summary results on patent distribution also show that patents are heavily concentrated among large-sized firms. These may contribute to the reverse size-return effect reported in the data sample used for this study. The table reveals some linkage between patents (PATLEV) and excess returns. Large-sized firms and value firms tend to have more patents than small-sized firms and glamour firms. Table 2.1 may suggest cross-sectional linkages between the variables. Thus value firm on average have higher returns, higher number of issued patents, and they spend more on R\&D.

Previous works by Easley, Hvidjkaer and O’Hara (2002) and Aboody and Lev (2000) relate private information to firm size. They find evidence to suggest that private information tends to have a greater impact on price for small stocks than for large stocks. Table 2.2 presents summary results of returns of size-patent portfolios and size-R\&D portfolios. In Panel A, firms are sorted into 5 size quintiles and within each size quintile, high and low patent portfolios returns are generated. On average returns increase from small-sized to large-sized portfolios, both for low and high patent. Similarly, in Panel B, firms are sorted into 5-size quintiles and within each size quintile, high, medium and low R\&D portfolio returns are generated. A similar trend is observed as in Panel A, average returns increase from small-sized to large-sized portfolios.

The two key proxies of asymmetric information under consideration in this chapter are PATLEV and RDMAT. Pakes and Griliches $(1980,1984)$ and Griliches, 
Pakes and Hall (1986) show significant correlation between R\&D expenditure and patents. The correlation matrix in Table 2.3 panel B shows 65\% correlation between PATLEV and RDMAT. According to Grewal, Cote, and Baumgartner (2004), correlation of over $80 \%$ are extreme to worry about collinearity. The $65 \%$ correlation between the two variables may not be large enough to worry about multicollinearity in the crosssectional models.

\subsubsection{Main results}

The first hypothesis in this chapter addresses the question whether firm issued patents and R\&D spending affect the information balance between insiders and outsiders, and whether these activities generate adverse selection risk. As a first check of the hypothesis,

patents and $R \& D$ are investigated to find out whether they contribute to increased private information. Aboody and Lev (2000) argue that all firm-level investment decisions must generate private information. By contrasting patents and $R \& D$, I investigate whether the two firm-level investment decisions share similar information structure. The next check would be to establish that stocks with increased private information offer higher average returns. As argued by Easley and O’Hara (2004), investors must be compensated for holding stocks with more insider information, in excess of the rationally expected returns for systematic risk.

\subsubsection{Relationship between Patents and $R \& D$, and asymmetric information}

Papers by Hansen and Sargent (1995, 2001, 2003, 2005, and 2006), Anderson, Hansen, and Sargent (2003) among others have shown how variance risk affects optimal decisions and asset prices. Prior research establishes a linkage between r-square as a measure of variance risk and private information. Durnev, Morck, Yeung, and Zarowin (2003) and Durnev, Morck, and Yeung (2004) present evidence using United States data to suggest that prices of low r-square stocks contain more public information. Morck, Yeung and Yu (2000), estimate $\left(1-R_{i}^{2}\right)$ to proxy for asymmetric information. Where $R_{i}^{2}$ is the estimated Rsquare for each firm, and it is estimated from the time series regression of excess returns against the excess market portfolio and Fama-French three factors. The estimated $\left(1-R_{i}^{2}\right)$, which is used to proxy for asymmetric information variable is then regressed against PATLEV and RDMAT. According to the expectation of the first 
hypothesis, if patents and $R \& D$ spending generate more private information, then PATLEV and RDMAT would correlate with $\left(1-R_{i}^{2}\right)$.

The results in Table 2.4 panel A show that the $R \& D$ variable (RDMAT) is positively and significantly related to $\left(1-R_{i}^{2}\right)$. This suggests that increasing $\mathrm{R} \& \mathrm{D}$ may increase the asymmetric information risk. The results in Table 2.4 panel $\mathrm{C}$ show a positive relation between PATLEV and $\left(1-R_{i}^{2}\right)$, even when volume is controlled for in the model. Easley, Hvidkjaer and O’Hara (2002) introduce size as a control variable. Aboody and Lev (2000) report that size and volume may proxy for asymmetric information. In panel B, volume is controlled for, to make sure that the correlation between patents and $\mathrm{R} \& \mathrm{D}$, and $\left(1-R_{i}^{2}\right)$ is not capturing volume effects. When volume is controlled for in the respective models with PATLEV and RDMAT, both continue to be correlated with $\left(1-R_{i}^{2}\right)$. However, when PATLEV, RDMAT and VOL are introduced as independent variables in the model, PATLEV becomes negatively related to the asymmetric information proxy. RDMAT is still positive and significant. It is quite clear that patent and R\&D variables show significant correlation with the proxy for asymmetric information.

\subsubsection{Are Patents and $R \& D$ spending determinants of Asset Returns?}

Following Easley, Hvidkjaer and O'Hara (2002), for each month in the sample period 1970:01 - 2001:12, I run the cross-sectional regression model described in equation 2.4. Under the hypothesis, this model test whether RDMAT and PATLEV induce adverse selection risk and whether the risk is priced. To begin the analysis, two approaches are used to estimate firm betas. The first estimates portfolio betas from 25 equally-weighted portfolios formed based on size and book-to-market value. Post-ranking portfolio betas are estimated for the full period of the sample. Excess portfolio returns are regressed on contemporaneous and lagged excess market returns, as described in equation 2.3. The cross-sectional regressions are run with individual stocks, so individual stocks are assigned the beta of the portfolio to which they belong. This approach is used to allow for comparability with previous work in the literature [Easley, Hvidkjaer and O'Hara 
(2002)]. The second approach to estimating stock beta runs the Fama-McBeth time series regression and estimate individual betas for all the stocks in the sample.

Table 2.5 present the results of the cross-sectional regression, testing whether patents and $R \& D$ activities, generate adverse selection risk. The results are based on the empirical model $R^{i}-R^{f}=\gamma_{0}+\gamma_{1} \hat{\beta}^{i}{ }_{m k t}+\gamma_{2} S I Z E^{i}+\gamma_{3} B M^{i}+\gamma_{4} R D^{i}+\eta^{i}$. The hypothesis is that higher risk of information related to patents and $\mathrm{R} \& \mathrm{D}$ translate into higher required returns, so the interest is a significantly positive average coefficient on RDMAT or PATLEV. The results show that PATLEV is significant at the $90 \%$ confidence level in model 1. However, PATLEV is not significant when RDMAT is included in the analysis as reported in model 3. RDMAT is seen to be significant at the $99 \%$ confidence level. The results from the cross-sectional regression show that a $10 \%$ increase in $R \& D$ spending as a percentage of Total Asset, may lead to a monthly increase of $0.02 \%$ in excess returns. This translates to about $2.4 \%$ annually and economically it is significant. This may provide an indication that patents and $R \& D$ do not share the same information structure.

\subsubsection{Characteristic test of the Patents and $R \& D$ variables}

The second research question (hypothesis II) evaluates whether the associated increase in returns due to an increase in patents and $R \& D$ spending is market compensation for firmspecific adverse selection risk. To allow for comparability with previous work, I follow the cross-sectional set-up of Easley, Hvidkjaer and O’Hara (2002). Fama and French (1992) identify market beta, size, and book-to-market as determinants of cross-sectional variation in returns. Market beta is estimated using the following approach. Time series regression of individual ${ }^{16}$ firms based on the Black, Scholes and Jensen (1972) formulation is run and market betas estimated. The estimated firms' betas together with PATLEV and RDMAT are used as the determinants in the cross-sectional regression. The results presented and discussed in Table 2.6 show that RDMAT significantly influence returns. According to Jagannathan and Wang (1998), in a cross-sectional framework, if a model is correctly specified, it may be sufficient to test the significance

\footnotetext{
${ }^{16}$ In the next section, the betas are estimated from 25 portfolios sorted by size and BM, and individual firms are assigned the beta for their respective portfolios. Because the portfolio compositions change each year, the individual stock betas vary over time.
} 
of the coefficients by using the t-values to accept whether a variable is priced as firm characteristics. .

Daniel and Titman (1997) argue that in a cross-sectional model, the firmcharacteristic variable must perform better than the systematic factor variable. I run the Daniel and Titman (1997) model with PATLEV and RDMAT, the firm-characteristic variables, and PATFACT ${ }^{17}$ and RDFACT, the systematic factor variable for patents and R\&D respectively. Table 2.6 model 1 presents results based on PATLEV and PATFACT. The results show that the patent factor performs better than the characteristic patent variable. On the other hand, model 2 shows that RDMAT perform better than RDFACT. According to Daniel and Titman (1997), the firm-specific R\&D variable (RDMAT) must be priced as a characteristic and the patent variable must be priced as a systematic risk.

\subsubsection{Systematic test of the Patent factor and the $R \& D$ factor}

The third hypothesis proposes that the associated increase in returns from increases in patents and R\&D spending is market compensation for systematic risk. In an intertemporal economy, the changes in technology prospects may affect consumption and investment opportunities, and lead to systematic technology risk in asset pricing. Merton (1973) posits that any economic variable related to future investment opportunities may act as a risk factor in determining expected asset returns. Given the fact that many investment opportunities are driven by new technologies, we would expect to see a risk factor representing the effect of technology uncertainty on asset returns as a result of firm patents and R\&D spending. The results in Table 2.6 show that the patent factor (PATFACT) is positive and significant at the 95\% confidence level. However, the R\&D factor (RDFACT) shows a negative correlation with excess returns.

\subsubsection{Contrast between patents and $R \& D$ as adverse selection risk.}

The combination of the three hypotheses suggests that firm-level decisions that will lead to an increase in private information must be priced one-sided, but decisions that will reduce private information are not. This is a modification of what Aboody and Lev (2000) proposed. They argue that all corporate investments create information

\footnotetext{
${ }^{17}$ The patent $(R \& D)$ factor is estimated by shorting assets with low patents (R\&D) and longing assets with high patents (R\&D).
} 
asymmetry. Firms' investments in $R \& D$ and patents are two examples of corporate investments. The main focus of this chapter is to specifically discuss and contrast the two corporate investment variables, patents and R\&D. Though in Table 2.4 patents (PATLEV) and R\&D (RDMAT) are both significantly related to the estimate of the asymmetric information variable $\left(1-R_{i}^{2}\right)$, the characteristic test suggests they may be priced differently. The asymmetric information test may suggest similarities in the information structure of patents and $\mathrm{R} \& \mathrm{D}$ spending since they both correlate with $\left(1-R_{i}^{2}\right)$. However, when the analysis controls for volume $\left(\mathrm{VOL}^{18}\right)$ of stocks traded, patents and $\left(1-R_{i}^{2}\right)$ becomes negatively related whiles RDMAT is still positive.

According to the Daniel and Titman's model, patents may be priced systematic and $R \& D$ priced characteristic. Patents and $R \& D$ factors are estimated based on the zerocost investment portfolio return methodology. PATFACT and RDFACT are returns on equal-weighted, zero-cost, factor-mimicking portfolios for patents and R\&D. According to the Merton's framework, anything that changes the investment opportunities of a firm may be priced systematic. PATFACT and RDFACT may proxy for systematic changes in technology, which changes investment opportunities. The cross-sectional regression results in Table 2.6 show that RDMAT is significantly related to returns, while RDFACT is not. However, in the case of patents, PATFACT is significant while PATLEV is not. These results provide evidence that adverse selection risk due to $R \& D$ investments support the characteristics perspective. However, instead of this coming from a behavioral view, it is here fully consistent with rational behavior by all investors. The patent variable on the other hand, works better as a proxy for systematic risk than as firmlevel adverse selection risk.

\subsection{Robustness}

A number of robustness checks are conducted to test whether minor changes in the underlying assumption may affect the stated hypotheses. The first hypothesis proposes that patents and $\mathrm{R} \& \mathrm{D}$ activities generate adverse selection risk, and investors are

\footnotetext{
${ }^{18}$ Easley, Hvidkjaer and O’Hara (2002) noted that there is substantial interest in the role of volume in explaining asset-price behavior. It is important to control for the possibility of PATLEV and RDMAT being proxied by the effect of volume in the results.
} 
rewarded with higher average returns for holding such stocks. Thus, patents and R\&D activities must generate increased private information, and this is priced by the market. First, I check the robustness of the asymmetric information test of patents and R\&D variables. In this robustness check, instead of running a time series regression of individual firms to estimate the r-squares and betas, I run the time series regression of the 25 portfolios. Each firm is then assigned the r-square and beta of their corresponding portfolios.

Results presented in Table 2.7 show that RDMAT is positive and significantly related to the asymmetric information variable. However, PATLEV is not related to the asymmetric information variable. In the main results it was realized that the private information generated by patents may proxy for volume, since controlling for volume made patent insignificant. The results here suggest that small changes in the estimation of r-squares and market betas do not significantly change the outcome. The robustness analysis confirms that R\&D investments may proxy for increased private information due to increased adverse selection risk.

The next hypothesized issue is whether the adverse selection risk is priced. Based on Easley, Hvidkjaer and O'Hara (2002)'s approach, I form 25 value-weighted portfolios sorted by book-to-market and size. Thus in place of the equally-weighted, value-weighted portfolios are used to run the time series regression to estimate the market betas. The analysis discussed in sub-section ii is re-run with the estimated betas from the time series regression using value-weighted instead of equally-weighted portfolios. The results ${ }^{19}$ are consistent with that of the equal weighted portfolio formation. I also use equally weighted portfolios instead of individual firms to test the time varying effects of PATLEV and RDMAT on mean returns. The result is reported in Table 8, and it shows that RDMAT is significant while PATLEV is not.

The second hypothesis proposes that the adverse selection risk due to patents and R\&D activities are priced-characteristic. This is tested by performing the characteristic test described in Daniel and Titman (1997). The robustness of these results is tested by making minor variations in the sample data. A sub-sample of three CRSP two-digit sic code of high R\&D intensive industries and low R\&D intensive industries are used. The

${ }^{19}$ Results are not included but are available upon request 
three high $R \& D$ intensive portfolios are formed by sorting firms on the basis of two-digit SIC codes. The selected industries are SIC codes 28,35 , and 36. The selection of high R\&D intensive industries is based on Chan, Lakonishok and Sougiannis $(2001)^{20}$, but I limit the criteria to two-digit SIC code industries in this robustness analysis. Another three low R\&D intensive industries are selected based on the following criteria: 1 . Industries should be in the manufacturing category, 2. Industries should have R\&D expenditure at all data points and 3. Industries should closely match the high R\&D intensive industries. The selection of the low R\&D intensive classification is such that they would be comparable to the high R\&D intensive industries.

Table 2.9 presents characteristic test results of patent variables (PATLEV and PATFACT) for high and low R\&D intensive industries. On average, for low R\&D intensive industry, both PATFACT and PATLEV are not significantly related to mean returns. In the high R\&D segment, both PATLEV and PATFACT are on average significant and positive. PATFACT is significant at the $95 \%$ confidence level, while PATLEV is significant at the $90 \%$ confidence level. Table 2.10 present the characteristic test results of the R\&D variables (RDMAT and RDFACT) for high and low R\&D intensive industries. For the low R\&D intensive, on average RDMAT is positively related to mean returns but this is not significant. However, RDFACT is negatively related and significant at the 99\% confidence level. In the case of high R\&D intensive industries, RDMAT is significant at the $95 \%$ while RDFACT is not significant. If the momentum factor is included in the explanatory variables, RDMAT's significance level increases from 95\% to 99\%. Daniel and Titman's characteristic test proposes that firm-specific characteristics must perform better than market systematic factor. The results in Table 2.10 and 2.11 provide evidence in support of $\mathrm{R} \& \mathrm{D}$ activities being priced as firm-specific adverse selection risk.

I also use RDCAP1 ${ }^{21}$ in place of RDMAT for robustness check. This tests whether minor changes in the estimation of key variable would affect the outcome of the hypothesis, but the hypotheses listed in the chapter continues to hold.

\footnotetext{
${ }^{20}$ In Chan, Lakonishok and Sougiannis (2001), they use a combination of three-digit and two-digit sic-code industries.

${ }^{21}$ RDCAP1 is the capitalized R\&D variable formulated based on Chan, Lakonishok and Sougiannis (2001), where the ratios are expressed as R\&D to Total Asset.
} 


\subsection{Conclusion}

The analysis in this chapter addresses three main issues related to firm patents and $R \& D$ activities. These questions could be restated as "Do patents and R\&D spending represent adverse selection risk and are they priced as characteristic or systematic risk?” The first part of the question addresses the linkages between patents and $\mathrm{R} \& \mathrm{D}$, and adverse selection risk. The evidence presented shows that $R \& D$ activities generate uncertain benefits that increase private information. More private information imposes adverse selection risk on investors and the market compensates these investors with higher mean returns. Similarly, patents also generate uncertain benefits that increase private information and this is compensated for with higher mean returns. An underlying issue investigated in the chapter is whether the two key variables share the same information structure. The introduction of the two variables jointly in the empirical model show that the impact of patents diminishes. The empirical relation between patents and equity returns becomes negative, while the $R \& D$ variable continues to be significant with reduced economic impact. Thus $\mathrm{R} \& \mathrm{D}$ may be riskier before the introduction of patents and the effect of patents reduces the private information in a firm's R\&D spending. This may provide an indication of differences in the information structure of patents and $R \& D$ spending.

The second part of the research question explores the contrast in the information structure of patents and R\&D further. I show that the compensation for risk associated with increased R\&D activities is firm-specific and different from market-determined systematic risk. This is in line with Daniel and Titman's (1997) and Jagannathan and Wang's (1998) “characteristics” argument. The evidence supports a modified characteristics perspective, because instead of it coming from a behavioral view, it is fully consistent with rational behavior by all investors. The evidence in support of firmspecific characteristic risk for patents is very weak. There is stronger evidence of systematic priced risk for patents. Thus patents may proxy for higher sensitivity to aggregate technology growth which is a Merton factor. This may enforce the argument on the differences in the information structure of patents and $R \& D$ spending. These differences could be explained by the requirement by USPTO for assignees to disclose all patent information. There is however no such requirement for firms to disclose 
information about specific R\&D spending and stages of development of R\&D activities. The differences in the information structure may also be explained in terms of differences in the economic nature of the two variables. R\&D is an investment input while patents may be viewed as an investment output.

The findings in this chapter lend support to the body of literature on asset pricing that argues in favor of one-sided (adverse selection) risk priced in the market. Thus as firms increase their R\&D activities, insiders with private information can take advantage at the expense of outsiders who only have public information. For the market to attract outsiders to trade in the firm's stock, it must offer higher returns in excess of the systematic risk-return tradeoff. As R\&D activities increase, stocks offer higher mean returns due to asymmetric information risk. This chapter complements the existing literature on information-based trading risk that calls for a rethinking of asset pricing models. The results support the notion that not all idiosyncratic risks are diversified away through portfolio formation.

The evidence presented in the chapter accepts the hypothesis that a higher level of patent and $R \& D$ spending raises average returns. The increase in average returns associated with R\&D spending is due to characteristic risk and that of patents is due to systematic risk. 


\subsection{References}

Aboody, D., and Lev, B. 2000, “Information Asymmetry, R\&D, and Insider Gains”, Journal of Finance 55, 2747-2766

Anderson, E.W., Hansen, L. P., and Sargent, T. J. 2003, “A Quartet of Semigroups for Model Specification, Robustness, Prices of Risk, and Model Detection,” Journal of the European Economic Association, 1, 68-123.

Black, F.; Jensen, M. C.; and Scholes, M. 1972, “The Capital Asset Pricing Model: Some Empirical Tests”. In Studies in the theory of capital markets, ed. Michael Jensen, pp. 79-121. New York: Praeger.

Chan, L. Lakonishok, J and Sougiannis, T, 2001, “The Stock Market Valuation of Research and Development Expenditures”. The Journal of Finance. 2431-2456.

Chen, Qi, Goldstein, I. and Jiang, W., 2007, "Price Informativeness and Investment Sensitivity to Stock Price,” Review of Financial Studies, V20, 620-650.

Choi, W. W., Kwon, S. S. and Lobo, G. J. 2000. "Market Valuation of Intangible Assets.” Journal of Business Research, 49, 35-45.

Daniel, K. and Titman, S., 1997, "Evidence on the Characteristics of Cross Sectional Variation in Stock Returns”, Journal of Finance, 52, 1-33

Dimson, E. 1979, “Risk Measurement When Shares are Subject to Infrequent Trading?”, Journal of Financial Economics, 7, 197-226.

Durnev, A., Morck, R. and Yeung, B. 2000, "Does Firm-specific Information in Stock Prices Guide Capital Allocation?”, National Bureau of Economic Research Working Paper No. 8093.

Durnev, A., Morck, R. and Yeung, B. 2004. "Value Enhancing Capital Budgeting and Firm-specific Stock Returns Variation”, Journal of Finance, forthcoming.

Durnev, A., Morck, R., Yeung, R. and Zarowin, P. 2003, "Does greater firm-specific return variation mean more or less informed stock pricing?”, Journal of Accounting Research 41, 797-836.

Easley, D, Hvidkjaer, S. and O’Hara, M. 2002. “Is Information Risk a Determinant of Asset Returns?” Journal of Finance. 57, 2185-2221.

Easley, D, Hvidkjaer, S. and O’Hara, M, 2005, “Factoring Information Into Returns”, working paper. 
Easley, D., Kiefer, N. M and O’Hara , M. 1997a, "The Information Content of The Trading Process”, Journal of Empirical Finance 4, 159-186.

Easley, D. and O'Hara, M. 2004, "Information and The Cost of Capital”, Journal of Finance 59,1553-1583.

Fama, E., and French, K. 1993, "Common Risk Factors in Returns on Stocks and Bonds", Journal of Financial Economics 33, 3-56.

Finnerty, J., 1976, “Insiders and Market Efficiency”, Journal of Finance 31, 1141-1148.

Grewal, R., Cote, J. A. and Baumgartner, H. 2004. "Multicollinearity and Measurement Error in Structural Equation Models: Implications for Theory Testing," Marketing Science, 23 (4), 519-29.

Griliches, Z., 1995, "R\&D and Productivity: Econometric Results and Measurement Issues", in Paul Stoneman, ed.: Handbook of the Economics of Innovation and Technological Change Blackwell, Oxford!.

Griliches, Z. , Pakes, A., and Hall, B.H. 1987. "The Value of Patents as Indicators of Inventive Activity.” In P. Dasgupta and P. Stoneman, eds., Economic Policy and Technological Performance, Cambridge, England: Cambridge University Press,

Hall, B. H and Long, W. 1999 "Differences in Reported R\&D Data on the NSF/Census RD-1 Form and the SEC 10-K Form: A Micro-data Investigation" Working Paper.

Hansen, L. P. and Sargent, T. J. 1995, "Discounted Linear Exponential Quadratic Gaussian Control”, IEEE Transactions on Automatic Control, 40, 968-971.

Hansen, L. P. and Sargent, T. J. 2001, "Acknowledging Misspecification in Macroeconomic Theory”, Review of Economic Dynamics, 4, 519-535.

Hansen, L. P. and Sargent, T. J. 2003, "Robust Control of Forward-Looking Models", Journal of Monetary Economics, 50, 581-604.

Hansen, L. P. and Sargent, T. J. 2005, "Robust Estimation and Control Under Commitment”, Journal of Economic Theory, 124, 258-301.

Hansen, L. P. and Sargent, T. J. 2006, "Recursive Robust Estimation and Control Without Commitment”, Working Paper.

Hansen, L. P., Sargent, T. J., and Tallarini, Jr., T. D. 1999, "Robust Permanent Income and Pricing”, Review of Economic Studies, 66, 873-907. 
Jagannathan, R. and Wang, Z. 1998, “An Asymptotic Theory for Estimating Beta-Pricing Models Using Cross-Sectional Regression”., Journal of finance, 53, 1285-1309.

Jaffe, J., 1974, “Special Information and Insider Trading”, Journal of Business 47, 410428.

Jeng, L. A. Metrick, A. and Zeckhauser, R., 1999, "The Profits to Insider Trading: A Performance-Evaluation Perspective”, NBER Working Paper No. 6913

Jones, C., and Slezak, S. 1999, "The Theoretical Implications of Asymmetric Information on the Dynamic and Cross-Sectional Characteristics of Asset Returns," Working Paper, University of North Carolina at Chapel Hill.

Kaufman G. G. and Scott, K. E. 2003, "What is Systematic Risk, and Do Bank Regulators Retard or Contribute to it?”, The Independent Review. Vol 8 \#3. pp. $371-391$

Kayhan, A. and Titman, S. 2007, "Firms' histories and their capital structure”, Journal of Financial Economics 83, 1-32

Lakonishok, J., and I. Lee 2000. “Are Insider Trades Informative?” Review of Financial Studies,14:79-111.

Lakonishok, J., Shleifer, A. and Vishny, R 1994, "Contrarian Investment, Extrapolation, and Risk.” Journal of Finance, 49, 1541-1578.

Lev, B. 2001. "Intangibles: Management, Measurement and Reporting”, The Brookings Institution Press, UK.

Lev, B., and Sougiannis, T. 1996, "The Capitalization, Amortization and Value Relevance of R\&D,” Journal of Accounting and Economics 21, 107-138.

Lev, B. and T. Sougiannis. 1999. "Penetrating the book-to-market black box: the R\&D effect”. Journal of Business Finance \& Accounting 26. 419-449.

Lin, Ji-Chai and. Howe, John S, 1990, "Insider Trading in the OTC Market”, Journal of Finance 45, 1273-1284.

Lintner, John. 1965. "The Valuation of Risk Assets and the Selection of Risky Investments in Stock Portfolios and Capital Budgets.” Review of Economics and Statistics. 47:1, 13-37.

Lintner, J. 1969, “The aggregation of investor's diverse judgements and preferences in purely competitive security markets", Journal of Financial and Quantitative Analysis 4, 347-400. 
McCarthy, M. G. and Schneider, D. K. 1995. "Market Perception of Goodwill: Some Empirical Evidence.” Accounting and Business Research, 26, 69-81.

Merton, R., 1973, “An Intertemporal Asset Pricing Model,” Econometrica 41, 867-887.

Morck, R., Yeung B., and Yu, W. 2000. "The Information Content of Stock Markets: Why do Emerging Markets Have Synchronous Stock Price Movements?”, Journal of Financial Economics, 59, pp. 215-238

Pakes, A. and Griliches, Z. 1984. "Estimating Distributed Lags in Short Panels with an Application to the Specification of Depreciation Patterns and Capital Stock Constructs," Review of Economic Studies LI(2): 243—262.

Pakes, A. and Griliches, Z.. 1980. "Patents and R\&D at the Firm Level: A First Look," National Bureau of Economic Research Working Paper \#561, In R \& D. Patents and Productivity 1984. Z. Griliches (ed.): 55-72. Chicago: University of Chicago Press.

Rosenberg, B., Reid, K. and Lanstein, R., 1985, "Persuasive Evidence of Market Inefficiency”, Journal of Portfolio Management 11, 9-17.

Roll, R. 1984. "A Simple Implicit Measure of the Effective Bid-Ask Spread in an Efficient Market.” Journal of Finance, 39:1127-1139.

Ross, S, 1989, "Information and Volatility: The No-arbitrage Martingale Approach to Timing and Resolution Irrelevance”. The Journal of Finance 44, 1-17.

Rozeff, M. S. and Zaman, M. A., 1988, "Market Efficiency and Insider Trading: New Evidence”, Journal of Business 61, 25-44.

Scherer, F., M. 2003, “Technology Flows Matrix Estimation Revisited," Economic Systems Research, 327-358.

Seyhun, H. N., 1986, "Insiders' Profits, Costs of Trading, and Market Efficiency", Journal of Financial Economics 16, 189-212.

Seyhun, H. N., 1992, “The Effectiveness of the Insider-trading Sanctions”, Journal of Law and Economics 35, 149-182.

Seyhun, H. N., 1998, “Investment Intelligence from Insider Trading”, MIT Press.

Sharpe, W. F. 1964. "Capital Asset Prices - A Theory of Market Equilibrium Under Conditions of Risk". Journal of Finance XIX (3): 425-42.

Stoll, H., 1978, The Pricing of Security Dealer Services: An Empirical Study of NASDAQ stocks, Journal of Finance 33, 1153-1172. 
Zhang, X. F., 2006, "Information Uncertainty and Stock Returns", Journal of Finance, Vol. 61, No. 1,

Zhang, C. 2008, "Decomposed Fama-French Factors for the Size and Book-to-market Effects" Working paper 


\section{Table 2.1}

\section{Summary Results of Portfolios}

From 1970.01 to 2001.12, at the beginning of each month, stocks are sorted into 5 portfolios on the basis of firm size. Within each size portfolios, stocks are subsequently sorted into 5 book-to-market quintiles. The size of a firm is measured by the log of market value of equity, which equals the stock price of the stock at the end of June of year $t$ times the total shares outstanding. Following Fama and French (1992), the bookto-market equity ratio (BE/ME) at time $t$ is calculated by dividing book equity (BE) at the fiscal ending of year $t-1$ by market equity (ME) at December of year $t-1$. The book-to-market equity ratios at time $t$ are matched by the stock returns from July of year $t$ to June of year $t+1$. SIZE is the size of a firm and it is measured as the log of market value of equity, which equals the stock price of the stock at the end of June of year $t$ times the total shares outstanding. Following Fama and French (1992), the book-to-market equity ratio (BE/ME) at time $t$ is calculated by dividing book equity (BE) at the fiscal ending of year $t-1$ by market equity (ME) at December of year $t-1$. PATLEV is the ratio of the number of patents to Total Assets for each firm in a month, where the Total Asset is scaled by a millionth. RDMAT is the ratio of R\&D expenditure of a firm to the Total Assets. The excess returns are CRSP monthly returns. Compustat annual data is merged with CRSP to generate monthly frequency for the sample data.

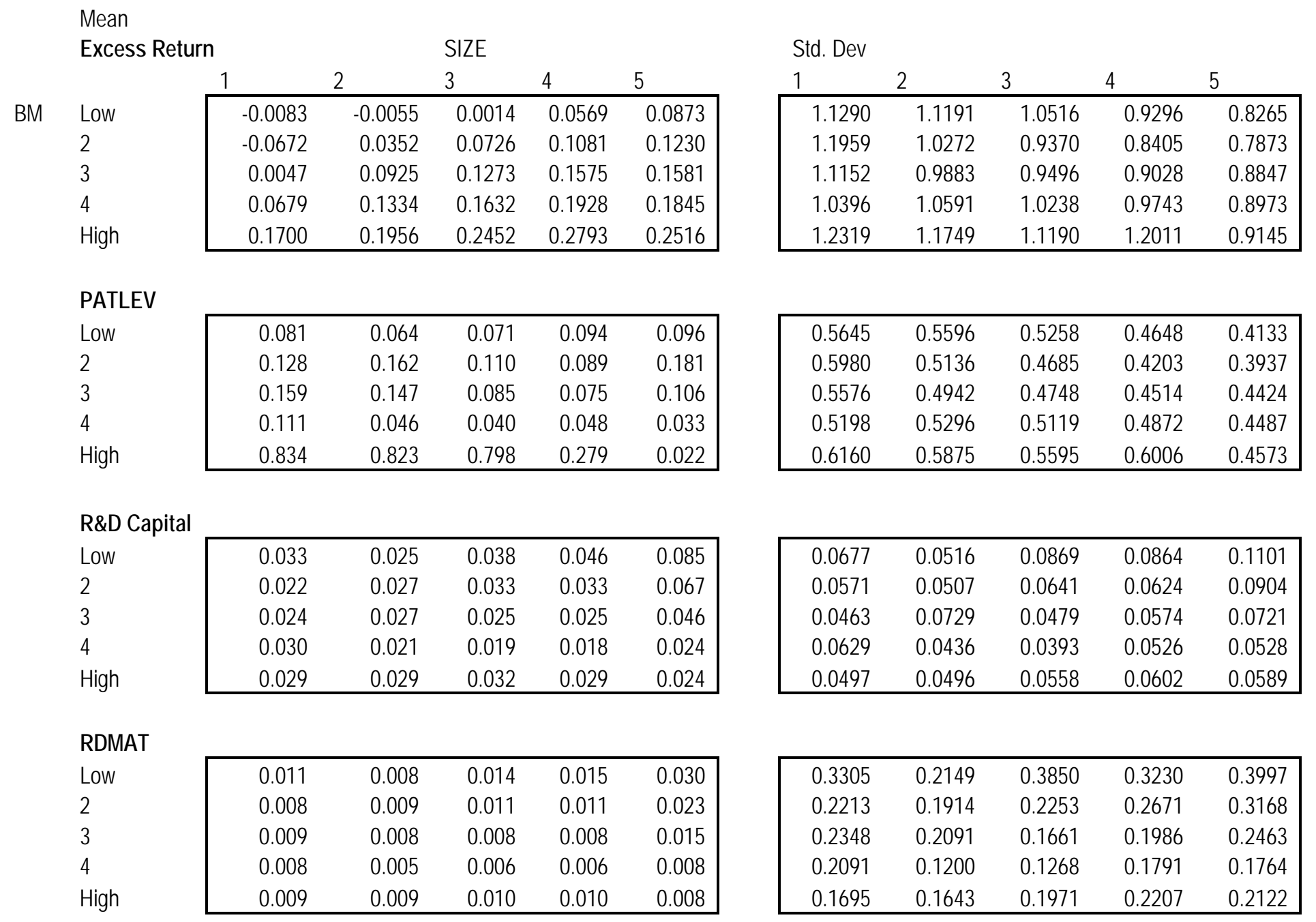




\section{Table 2.2}

\section{Portfolio Returns}

Table 2 contains summary results for portfolio of stocks sorted by size and the patent variable and also size and the R\&D variable. Size is measured as the log of market value of equity, which equals the stock price of the stock at the end of June of year $t$ times the total shares outstanding. PATLEV is the ratio of the number of patents to Total Assets for each firm in a month, where the Total Asset is scaled by a millionth. $R D M A T$ is the ratio of $R \& D$ expenditure of a firm to the Total Assets. Panel A reports average returns of portfolios sorted by size and PATLEV. Panel B reports average returns of portfolio sorted by size and within size sorted by RDMAT. Panel $C$ reports average number of stocks in each portfolio for SIZE/PATLEV. Panel D reports average number of stocks in each portfolio for SIZE/RDMAT. The sample used is CRSP/ CUMPUSTAT data merged with patent data from Bronwyn Hall website, and the period of the data is from 1970:01 - 2001:12.

\begin{tabular}{|c|c|c|c|c|c|c|}
\hline SIZE/PATLEV & Low & High & SIZE/RDMAT & Low & Medium & High \\
\hline \multicolumn{3}{|l|}{ Panel A: } & \multicolumn{4}{|l|}{ Panel B: } \\
\hline \multicolumn{3}{|l|}{ Average returns } & \multicolumn{4}{|c|}{ Average return } \\
\hline Small & 0.073 & 0.107 & Small & 0.039 & -0.020 & 0.159 \\
\hline 2 & 0.115 & 0.121 & 2 & 0.084 & 0.116 & -0.008 \\
\hline 3 & 0.169 & 0.200 & 3 & 0.121 & 0.144 & 0.161 \\
\hline 4 & 0.402 & 0.521 & 4 & 0.463 & 0.572 & 0.455 \\
\hline Large & 1.017 & 1.123 & Large & 1.103 & 0.873 & 1.185 \\
\hline
\end{tabular}

\begin{tabular}{|c|c|c|c|c|c|c|}
\hline SIZE/PATLEV & Low & High & SIZE/RDMAT & Low & Medium & High \\
\hline \multicolumn{3}{|l|}{ Panel C } & \multicolumn{4}{|l|}{ Panel D } \\
\hline \multicolumn{3}{|c|}{ Number of stocks } & \multicolumn{4}{|c|}{ Number of stocks } \\
\hline Small & 34.77 & 35.49 & Small & 32.50 & 31.78 & 33.05 \\
\hline 2 & 38.12 & 40.94 & 2 & 33.82 & 35.60 & 34.98 \\
\hline 3 & 43.35 & 48.16 & 3 & 36.51 & 37.17 & 37.75 \\
\hline 4 & 54.35 & 63.26 & 4 & 42.95 & 44.44 & 43.96 \\
\hline Large & 121.42 & 212.41 & Large & 111.01 & 108.45 & 170.28 \\
\hline
\end{tabular}


Table 2.3

\section{Summary Statistics}

Table is summary statistics of key variables used in the study. The sample used is CRSP/ CUMPUSTAT data merged with patent data from Bronwyn Hall website, and the period of the data is from 1970:01 2001:12. RET is the monthly return data from CRSP returns and RDMAT is the R\&D spending of firms divided by Total Assets. PATLEV is the ratio of the number of patents to Total Assets for each firm in a month, where the Total Asset is scaled by a millionth. SIZE is the size of a firm and it is measured as the $\log$ of market value of equity, which equals the stock price of the stock at the end of June of year $t$ times the total shares outstanding. Following Fama and French (1992), the book-to-market equity ratio (BE/ME) at time $t$ is calculated by dividing book equity $(\mathrm{BE})$ at the fiscal ending of year $t-1$ by market equity (ME) at December of year $t-1$. VOL is the volume of stocks traded in a month.

\section{$\underline{\text { Panel A }}$}

\begin{tabular}{lrrrr}
\hline \multicolumn{1}{c}{ Variable } & \multicolumn{1}{c}{ Mean } & Std. Dev. & \multicolumn{1}{c}{ Min } & \multicolumn{1}{c}{ Max } \\
\hline \hline & & & & \\
RET & 0.0164 & 0.155 & -0.8476 & 12.5 \\
RDMAT & 0.0124 & 0.026 & 0 & 0.5426 \\
PATLEV & 0.0419 & 3.669 & 0 & 0.8251 \\
BM & 4.5764 & 3.218 & 0.1565 & 134.13 \\
SIZE & 2.8574 & 1.953 & 1.2376 & 3.5952 \\
VOL & 4.4365 & 2.648 & 0 & 7.4133 \\
\hline
\end{tabular}

$\underline{\text { Panel B }}$

Correlation Matrix of Key Independent Variables

\begin{tabular}{|l|rrr|}
\hline RDMAT & 1.000 & & \\
PATLEV & 0.621 & 1.000 & \\
VOL & 0.418 & 0.618 & 1.000 \\
\hline & RDMAT & PATLEV & VOL \\
\hline
\end{tabular}




\section{Table 2.4}

\section{Cross-sectional Test of Asymmetric Information versus Patent and R\&D}

In the first pass, portfolio excess returns are regressed on market, SMB and HML factors. Each individual firm is assigned with betas of the portfolio that the firm belongs to. In the second pass, asymmetric information variable defined as INF $=\left(1-R^{2}\right)$. is regressed cross-sectionally against PATLEV, and $R D M A T$, and the results are averaged across time. $R^{2}{ }_{i}$ is the estimated r-square from the first pass regression. PATLEV is the ratio of the number of patents to Total Assets for each firm in a month, where the Total Asset is scaled by a millionth. RDMAT is the ratio of $\mathrm{R} \& \mathrm{D}$ expenditure of a firm to the Total Assets. VOL is the log of the volume of stocks of a firm traded in a month. The sample used is CRSP/ CUMPUSTAT data merged with patent data from Bronwyn Hall website, and the period of the data is from 1970:01 - 2001:12.

\begin{tabular}{|c|c|c|c|c|}
\hline Panel A & RDMAT & & & RSQ \\
\hline & $\begin{array}{l}0.15306 \\
(98.33)^{\star \star \star}\end{array}$ & & & 0.3329 \\
\hline \multirow[t]{2}{*}{$\mathrm{B}$} & PATLEV & & & \\
\hline & $\begin{array}{l}0.013 \\
(4.39)^{\star \star \star}\end{array}$ & & & 0.3106 \\
\hline \multirow[t]{2}{*}{$\mathrm{C}$} & RDMAT & VOL & & $R S Q$ \\
\hline & $\begin{array}{l}0.11476 \\
(140.06)^{\star \star \star}\end{array}$ & $\begin{array}{l}0.0023 \\
(14.129)^{\star \star \star}\end{array}$ & & 0.4143 \\
\hline \multirow[t]{2}{*}{$\mathrm{D}$} & PATLEV & $\mathrm{VOL}$ & & $R S Q$ \\
\hline & $\begin{array}{l}0.00619 \\
(18.52)^{\star \star \star}\end{array}$ & $\begin{array}{l}0.0033 \\
(15.22)^{\star \star \star}\end{array}$ & & 0.2813 \\
\hline \multirow[t]{2}{*}{$E$} & PATLEV & RDMAT & & $R S Q$ \\
\hline & $\begin{array}{l}0.00183 \\
(10.19)^{\star \star \star}\end{array}$ & $\begin{array}{l}0.1114 \\
(21.86)^{\star \star \star}\end{array}$ & & 0.3917 \\
\hline \multirow[t]{2}{*}{$\mathrm{F}$} & PATLEV & RDMAT & VOL & $R S Q$ \\
\hline & $\begin{array}{l}-0.0013 \\
(-6.84)^{\star * \star}\end{array}$ & $\begin{array}{l}0.1181 \\
(91.73)^{\star \star \star}\end{array}$ & $\begin{array}{l}0.0018 \\
(13.51)^{\star \star \star}\end{array}$ & 0.458 \\
\hline
\end{tabular}




\section{Table 2.5}

\section{Cross-sectional Regression of Excess Returns of Individual Firm}

In the first pass, portfolio excess returns are regressed on market, SMB and HML factors. Each individual firm is assigned with betas of the portfolio that the firm belongs to. In the second pass, individual stocks' expected excess returns are regressed on factor betas from the first pass and the characteristic variable. PATLEV and RDMAT are the characteristic variables used in the analysis. EXRET is the CRSP monthly returns minus risk free rate, BETA is the estimated market factor from the first pass. SIZE is the size of a firm and it is measured as the log of market value of equity, which equals the stock price of the stock at the end of June of year $t$ times the total shares outstanding. Following Fama and French (1992), the book-tomarket equity ratio (BE/ME) at time $t$ is calculated by dividing book equity (BE) at the fiscal ending of year $t-1$ by market equity (ME) at December of year $t-1$. PATLEV is the ratio of the number of patents to Total Assets for each firm in a month, where the Total Asset is scaled by a millionth. RDMAT is the ratio of $\mathrm{R} \& \mathrm{D}$ expenditure of a firm to the Total Assets. RSQ is the estimate r-square from the cross-sectional regression. The sample used is CRSP/ CUMPUSTAT data merged with patent data from Bronwyn Hall website, and the period of the data is from 1970:01 - 2001:12 Results is based on the model;

$R^{i}-R F=\gamma_{0}+\gamma_{1} \hat{\beta}^{i}{ }_{m k t}+\gamma_{2} \operatorname{SIZE}^{i^{i}}+\gamma_{3} B M^{i}+\gamma_{4} R D M A T^{i}+\eta^{i}$

\begin{tabular}{|c|c|c|c|c|c|c|c|}
\hline EXRET & CONSTANT & BETA & PATLEV & RDMAT & SIZE & $B M$ & RSQ \\
\hline \multirow[t]{2}{*}{ Model 1} & 1.082 & 1.037 & 0.042 & & 0.0057 & 0.0049 & 0.356 \\
\hline & $(2.59)^{\star \star}$ & $(4.16)^{\star \star \star}$ & $(1.84)^{\star}$ & & $(2.57)^{\star \star}$ & $(0.258)$ & \\
\hline \multirow[t]{2}{*}{ Model 2} & 1.116 & 1.391 & & 0.1985 & 0.0052 & 0.006 & 0.296 \\
\hline & $(2.18)^{\star \star}$ & $(2.74)^{\star *}$ & & $(3.09)^{\star \star \star}$ & $(2.07)^{\star \star}$ & $(0.065)$ & \\
\hline \multirow[t]{2}{*}{ Model 3} & 1.064 & 1.16 & -0.0043 & 0.167 & 0.0022 & 0.0041 & 0.453 \\
\hline & $(1.88)^{\star}$ & $(3.18)^{\star \star \star}$ & $(-1.13)$ & $(3.17)^{\star \star \star}$ & $(1.85)^{\star}$ & $(0.543)$ & \\
\hline
\end{tabular}




\section{Table 2.6}

\section{Characteristic Test using all data in sample}

In the first pass, portfolio excess returns are regressed on market, SMB and $H M L$ factors. Each individual firm is assigned with betas of the portfolio that the firm belongs to. In the second pass, individual stocks' expected excess returns are regressed on factor betas from the first pass and characteristic variable. PATLEV and RDMAT are the characteristic variables used in the analysis. The sample used is CRSP/ CUMPUSTAT data merged with patent data from Bronwyn Hall website, and the period of the data is from 1970:01 - 2001. The test is based on Daniel and Titman's characteristic model, where model 1 and 2 present the results comparing patent factor with patent levels and model 3 and 4 compare the results of the R\&D factor and R\&D intensity. BETA is the estimated market beta from the $1^{\text {st }}$ pass, SIZE is the size of a firm and it is measured as the log of market value of equity, which equals the stock price of the stock at the end of June of year $t$ times the total shares outstanding. Following Fama and French (1992), the book-tomarket equity ratio (BE/ME) at time $t$ is calculated by dividing book equity (BE) at the fiscal ending of year $t-1$ by market equity (ME) at December of year $t-1$. EXRET is CRSP monthly returns minus risk free rate and RDMAT is the ratio of $\mathrm{R} \& \mathrm{D}$ expenditure to Total Assets. RDFACT is a $\mathrm{R} \& \mathrm{D}$ factor variable estimated by shorting assets with low R\&D expenditure and long assets with high R\&D expenditure. PATLEV is the ratio of the number of patents to Total Assets for each firm in a month, where the Total Asset is scaled by a millionth. PATFACT is a patent factor variable estimated by shorting assets with low patent issues and long assets with high patent issue. According to Daniel and Titman (1997), if an asset is priced characteristic, then the characteristic variable must perform better than the factor variable in a crosssectional regression of with both variables. The sample used is CRSP/ CUMPUSTAT data merged with patent data from Bronwyn Hall website, and the period of the data is from 1970:01 - 2001:12.

\begin{tabular}{|c|c|c|c|c|c|c|c|}
\hline EXRET & CONSTANT & BETA & SIZE & $B M$ & PATFACT & PATLEV & $R S Q$ \\
\hline Model 1 & $\begin{array}{l}0.013 \\
(2.88)^{\star \star}\end{array}$ & $\begin{array}{l}1.041 \\
(5.17)^{\star \star \star}\end{array}$ & $\begin{array}{l}0.219 \\
(11.56)^{\star \star \star}\end{array}$ & $\begin{array}{l}0.361 \\
(15.45)^{\star \star \star}\end{array}$ & $\begin{array}{l}0.071 \\
(2.81)^{\star \star}\end{array}$ & $\begin{array}{l}0.138 \\
(1.105)\end{array}$ & 0.357 \\
\hline EXRET & CONSTANT & BETA & SIZE & $B M$ & RDFACT & RDMAT & $R S Q$ \\
\hline Model 2 & $\begin{array}{l}0.053 \\
(3.84)^{\star \star \star}\end{array}$ & $\begin{array}{l}1.042 \\
(6.07)^{\star \star *}\end{array}$ & $\begin{array}{l}0.392 \\
(14.73)^{\star \star \star}\end{array}$ & $\begin{array}{l}0.336 \\
(13.32)^{\star \star \star}\end{array}$ & $\begin{array}{l}-0.044 \\
(-1.74)^{*}\end{array}$ & $\begin{array}{l}0.0234 \\
\left((2.66)^{\star \star}\right.\end{array}$ & 0.346 \\
\hline
\end{tabular}




\section{Table 2.7}

\section{Robustness: Test of Individual Firm Patent and R\&D and Asymmetric Information}

From 1970.01 to 2001.12, at the beginning of each month, stocks are sorted into 5 portfolios on the basis of firm size. Within each size portfolios, stocks are subsequently sorted into 5 book-to-market quintiles. In the first pass, portfolio excess returns are regressed on market, $S M B$ and $H M L$ factors. $R^{2}$ is the estimated r-square from time series regression of 25 the portfolios and it is used to estimate the asymmetric information variable $I N F=\left(1-R^{2}\right)$. Individual firms are assigned the betas from the first pass and these are used to test whether PATLEV and RDMAT correlate with ${ }_{\left(1-R^{2}\right)}$. PATLEV is the ratio of the number of patents to Total Assets for each firm in a month, where the Total Asset is scaled by a millionth. RDMAT is the ratio of R\&D expenditure of a firm to the Total Assets. SIZE is the size of a firm and it is measured as the log of market value of equity, which equals the stock price of the stock at the end of June of year $t$ times the total shares outstanding. The sample used is CRSP/ CUMPUSTAT data merged with patent data from Bronwyn Hall website, and the period of the data is from 1970:01 - 2001

$I N F_{i t}=a_{i}+b_{i} B{ }^{2} A_{i t}+c_{1} S I Z E_{i t}+c_{2} P A T L E V_{i t}+\varepsilon_{i t}$, where INF $=\left(1-R^{2}\right)$

\begin{tabular}{|c|c|c|c|c|c|c|}
\hline INF & CONSTANT & BETA & PATLEV & SIZE & PATLEV/SIZE & $R S Q$ \\
\hline & 1.0127 & -0.5265 & 0.00182 & -0.042 & -0.031 & 0.7195 \\
\hline & $(42.19)^{\star \star \star}$ & $(-18.2165)^{\star \star \star}$ & $(1.041)$ & $(-32.427)^{\star \star \star}$ & $(-1.018)$ & \\
\hline \multirow[t]{3}{*}{ INF } & CONSTANT & BETA & RDMAT & SIZE & RDMAT/SIZE & RSQ \\
\hline & 1.19245 & -0.41889 & 43.912 & -0.04799 & -1.7032 & 0.8012 \\
\hline & $(49.292)^{\star \star \star}$ & $(-19.1759)^{\star \star \star}$ & $(1.9644)^{\star}$ & $(-17.596)^{\star \star \star}$ & $(-2.16)^{\star \star}$ & \\
\hline
\end{tabular}

Where t-values are in parenthesis 


\section{Table 2.8}

\section{Robustness: Time Series Regression Results of 25 Portfolios}

From 1970.01 to 2001.12, at the beginning of each month, stocks are sorted into 5 portfolios on the basis of firm size. Within each size portfolios, stocks are subsequently sorted into 5 book-to-market quintiles. The excess portfolio returns are regressed against excess market, Fama-French size and value factors. PATLEV is the ratio of the average number of patents to Total Assets for each portfolio in a month, where the Total Asset is scaled by a millionth. and PATGW is a measure of patent shock estimated by the percentage deviation of patent from 6 month moving average. RDMAT measures the ratio of R\&D expenditure of firms to the total assets. The sample used is CRSP/ CUMPUSTAT data merged with patent data from Bronwyn Hall website, and the period of the data is from 1970:01 - 2001

\begin{tabular}{|c|c|c|c|c|c|c|c|}
\hline & Model 1 & Model 2 & Model 3 & Model 4 & Model 5 & Model 6 & Model 7 \\
\hline \multirow[t]{2}{*}{ CONSTANT } & 0.016 & 0.012 & -0.032 & -0.04 & -0.051 & -0.04 & 0.4623 \\
\hline & $(2.16)^{\star \star}$ & $(2.17)^{\star \star}$ & $(-0.65)$ & $(-0.83)$ & $(-1.06)$ & $(-0.80)$ & $(13.97)^{\star \star \star}$ \\
\hline \multirow[t]{2}{*}{ EX-MARKET } & 0.981 & 0.913 & 0.956 & 0.9564 & 0.956 & 0.957 & 0.916 \\
\hline & $(185.30)^{\star \star \star}$ & $(187.40)^{\star \star \star}$ & $(185.50)^{\star \star \star}$ & $(184.86)^{\star \star \star}$ & $(183.65)^{\star \star \star}$ & $(182.45)^{\star \star \star}$ & $(189.95)^{\star \star \star}$ \\
\hline \multirow[t]{2}{*}{$S M B$} & 0.414 & 0.428 & 0.505 & 0.505 & 0.506 & 0.504 & \\
\hline & $(25.15)^{\star \star \star}$ & $(29.26)^{\star \star \star}$ & $(34.26)^{\star \star \star}$ & $(34.10)^{\star \star \star}$ & $(34.32)^{\star \star \star}$ & $(34.39)^{\star \star \star}$ & \\
\hline \multirow[t]{2}{*}{$H M L$} & 0.382 & 0.385 & 0.4321 & 0.432 & 0.432 & 0.431 & \\
\hline & $(30.18)^{\star \star \star}$ & $(31.27)^{\star \star \star}$ & $(38.21)^{\star \star \star}$ & $(38.15)^{\star \star \star}$ & $(38.05)^{\star \star \star}$ & $(38.04)^{\star \star \star}$ & \\
\hline \multirow[t]{2}{*}{ PATLEV } & -0.215 & 0.021 & & & & -0.295 & -4.492 \\
\hline & $(-1.13)$ & $(0.90)$ & & & & $(-0.52)$ & $(-2.43)^{\star \star}$ \\
\hline \multirow[t]{2}{*}{ RDMAT } & - & & 0.075 & 0.095 & 0.126 & 0.224 & \\
\hline & - & & $(4.012)^{\star \star \star}$ & $(3.73)^{\star \star \star}$ & $(1.82)^{\star}$ & $(2.10)^{\star \star}$ & \\
\hline \multirow[t]{2}{*}{ PATGW } & 0.004 & - & - & 0.003 & -0.0002 & -0.012 & -0.026 \\
\hline & $(0.35)$ & - & - & $(0.20)$ & $(-0.015)$ & $(-0.907)$ & $(-1.18)$ \\
\hline $\mathrm{R} 2$ adjusted & 0.718 & 0.682 & 0.742 & 0.7423 & 0.7425 & 0.7425 & 0.6355 \\
\hline
\end{tabular}




\section{Table 2.9}

\section{Robustness: Characteristic Test of patent variable and parent factor using selected industry portfolios}

In the first pass, portfolio excess returns are regressed on market, SMB and HML factors. Each individual firm is assigned with betas of the portfolio that the firm belongs to. In the second pass, individual stocks' expected excess returns are regressed on factor betas from the first pass and characteristic variable. PATLEV and RDMAT are the characteristic variables used in the analysis. The sample used is CRSP/ CUMPUSTAT data merged with patent data from Bronwyn Hall website, and the period of the data is from 1970:01 - 2001. The test is based on Daniel and Titman's characteristic model, where model 1 and 2 present the results comparing patent factor with patent levels and model 3 and 4 compare the results of the R\&D factor and R\&D intensity. BETA is the market beta factor, SIZE is the size of a firm and it is measured as the log of market value of equity, which equals the stock price of the stock at the end of June of year $t$ times the total shares outstanding. Following Fama and French (1992), the book-to-market equity ratio (BM) at time $t$ is calculated by dividing book equity (BE) at the fiscal ending of year $t-1$ by market equity (ME) at December of year $t-1$. EXRET is CRSP monthly returns minus risk free rate and PATLEV is the ratio of the number of patents to Total Assets for each firm in a month, where the Total Asset is scaled by a millionth. PATFACT is a patent factor variable estimated by shorting assets with low patent issues and long assets with high patent issue. According to Daniel and Titman (1997), if an asset is priced characteristic, then the characteristic variable must perform better than the factor variable in a crosssectional regression of with both variables. The sample of two-digit sic code $(20,24,28,33,35,36)$ used is CRSP/ CUMPUSTAT data merged with patent data from Bronwyn Hall website, and the period of the data is from 1970:01 - 2001:12. The sample is made up of firm in high R\&D intensive industry $(20,24,33)$ and low R\&D intensive industry $(28,35,36)$.

\begin{tabular}{|c|c|c|c|c|c|c|c|}
\hline EXRET & CONSTANT & BETA & SIZE & $B M$ & PATFACT & PATLEV & $R S Q$ \\
\hline SIC 20 & $\begin{array}{l}0.123 \\
(2.16)^{\star \star}\end{array}$ & $\begin{array}{l}0.859 \\
(21.16)^{\star \star \star}\end{array}$ & $\begin{array}{l}-0.015 \\
(-3.21)^{\star \star \star}\end{array}$ & $\begin{array}{l}0.052 \\
(0.86)\end{array}$ & $\begin{array}{l}-0.016 \\
(-4.09)^{\star \star \star}\end{array}$ & $\begin{array}{l}0.143 \\
(2.54)^{\star \star}\end{array}$ & 0.571 \\
\hline SIC 24 & $\begin{array}{l}0.102 \\
(2.29)^{\star \star}\end{array}$ & $\begin{array}{l}1.108 \\
(22.33)^{\star \star \star}\end{array}$ & $\begin{array}{l}0.075 \\
(0.94)\end{array}$ & $\begin{array}{l}0.296 \\
(3.01)^{\star \star \star}\end{array}$ & $\begin{array}{l}-0.0077 \\
(-0.12)\end{array}$ & $\begin{array}{l}-0.183 \\
(-0.8)\end{array}$ & 0.582 \\
\hline SIC 33 & $\begin{array}{l}0.117 \\
(2.22)^{\star \star}\end{array}$ & $\begin{array}{l}1.024 \\
(20.74)^{\star \star \star}\end{array}$ & $\begin{array}{l}0.052 \\
(9.92)^{\star \star \star}\end{array}$ & $\begin{array}{l}0.199 \\
(8.59)^{\star \star \star}\end{array}$ & $\begin{array}{l}0.7239 \\
(7.1)^{\star \star \star}\end{array}$ & $\begin{array}{l}-0.061 \\
(-0.48) \\
\end{array}$ & 0.697 \\
\hline AVERAGE & $\begin{array}{l}0.114 \\
(18.26)^{\star \star \star}\end{array}$ & $\begin{array}{l}0.997 \\
(13.63)^{\star \star \star}\end{array}$ & $\begin{array}{l}0.037 \\
(1.38) \\
\end{array}$ & $\begin{array}{l}0.182 \\
(2.57)^{\star \star}\end{array}$ & $\begin{array}{l}0.233 \\
(0.95) \\
\end{array}$ & $\begin{array}{r}-0.034 \\
(-0.35) \\
\end{array}$ & 0.617 \\
\hline EXRET & CONSTANT & BETA & SIZE & $B M$ & PATFACT & PATLEV & $R S Q$ \\
\hline SIC 28 & $\begin{array}{l}0.153 \\
(2.41)^{\star \star}\end{array}$ & $\begin{array}{l}0.935 \\
(34.66)^{\star \star \star}\end{array}$ & $\begin{array}{l}0.124 \\
(2.99)^{\star \star}\end{array}$ & $\begin{array}{l}0.164 \\
(3.75)^{\star \star \star}\end{array}$ & $\begin{array}{l}0.062 \\
(0.94) \\
\end{array}$ & $\begin{array}{l}0.047 \\
(2.29)^{\star \star}\end{array}$ & 0.803 \\
\hline SIC 35 & $\begin{array}{l}0.165 \\
(2.32)^{\star \star}\end{array}$ & $\begin{array}{l}1.039 \\
(34.61)^{\star \star \star}\end{array}$ & $\begin{array}{l}0.574 \\
(3.43)^{\star \star \star}\end{array}$ & $\begin{array}{l}0.397 \\
(8.22)^{\star \star \star}\end{array}$ & $\begin{array}{l}0.294 \\
(5.52)^{\star \star \star}\end{array}$ & $\begin{array}{l}-0.001 \\
(-0.07) \\
\end{array}$ & 0.827 \\
\hline SIC 36 & $\begin{array}{l}0.174 \\
(2.58)^{\star \star}\end{array}$ & $\begin{array}{l}1.059 \\
(38.37)^{\star \star \star}\end{array}$ & $\begin{array}{l}0.640 \\
(4.99)^{\star \star \star}\end{array}$ & $\begin{array}{l}0.211 \\
(4.75)^{\star \star \star}\end{array}$ & $\begin{array}{l}0.531 \\
(9.67)^{\star \star \star}\end{array}$ & $\begin{array}{l}0.075 \\
(3.94)^{\star \star \star}\end{array}$ & 0.874 \\
\hline AVERAGE & $\begin{array}{l}0.146 \\
(26.96)^{\star \star \star}\end{array}$ & $\begin{array}{l}1.011 \\
(26.30)^{\star \star \star}\end{array}$ & $\begin{array}{l}0.446 \\
(2.75)^{\star \star}\end{array}$ & $\begin{array}{l}0.257 \\
(3.62)^{\star \star \star}\end{array}$ & $\begin{array}{l}0.296 \\
(2.18)^{\star \star}\end{array}$ & $\begin{array}{l}0.040 \\
(1.82)^{*}\end{array}$ & 0.834 \\
\hline
\end{tabular}


Table 2.10

\section{Robustness: Characteristic Test of $R \& D$ variable and $R \& D$ factor using selected industry portfolios}

In the first pass, portfolio excess returns are regressed on market, $S M B$ and $H M L$ factors. Each individual firm is assigned with betas of the portfolio that the firm belongs to. In the second pass, individual stocks' expected excess returns are regressed on factor betas from the first pass and characteristic variable. PATLEV and RDMAT are the characteristic variables used in the analysis. The sample used is CRSP/ CUMPUSTAT data merged with patent data from Bronwyn Hall website, and the period of the data is from 1970:01 - 2001. The test is based on Daniel and Titman's characteristic model, where model 1 and 2 present the results comparing patent factor with patent levels and model 3 and 4 compare the results of the $\mathrm{R} \& \mathrm{D}$ factor and R\&D intensity. BETA is the market beta factor, SIZE is the size of a firm and it is measured as the log of market value of equity, which equals the stock price of the stock at the end of June of year $t$ times the total shares outstanding. Following Fama and French (1992), the book-to-market equity ratio (BM) at time $t$ is calculated by dividing book equity (BE) at the fiscal ending of year $t-1$ by market equity (ME) at December of year $t-1$. EXRET is CRSP monthly returns minus risk free rate and RDMAT is the ratio of R\&D expenditure to Total Assets. RDFACT is a R\&D factor variable estimated by shorting assets with low R\&D expenditure and long assets with high R\&D expenditure. According to Daniel and Titman (1997), if an asset is priced characteristic, then the characteristic variable must perform better than the factor variable in a cross-sectional regression of with both variables. The sample of two-digit sic code (20, 24, 28, 33, 35, 36) used is CRSP/ CUMPUSTAT data merged with patent data from Bronwyn Hall website, and the period of the data is from 1970:01 - 2001:12. The sample is made up of firm in high R\&D intensive industry $(20,24,33)$ and low R\&D intensive industry $(28,35,36)$.

\begin{tabular}{|c|c|c|c|c|c|c|c|}
\hline EXRET & CONSTANT & BETA & SIZE & $B M$ & RDFACT & RDMAT & RSQ \\
\hline SIC 20 & $\begin{array}{l}0.103 \\
(2.11)^{\star \star}\end{array}$ & $\begin{array}{l}0.759 \\
(20.13)^{\star \star \star}\end{array}$ & $\begin{array}{l}-0.100 \\
(-1.96)^{\star}\end{array}$ & $\begin{array}{l}0.092 \\
(1.48) \\
\end{array}$ & $\begin{array}{l}-0.138 \\
(-2.44)^{\star \star}\end{array}$ & $\begin{array}{l}0.496 \\
(2.57)^{\star \star}\end{array}$ & 0.5591 \\
\hline SIC 24 & $\begin{array}{l}0.112 \\
(2.24)^{\star \star}\end{array}$ & $\begin{array}{l}1.309 \\
(21.94)^{\star \star \star}\end{array}$ & $\begin{array}{l}0.033 \\
(0.40) \\
\end{array}$ & $\begin{array}{l}0.186 \\
(1.90)^{\star}\end{array}$ & $\begin{array}{l}-0.258 \\
(-2.84)^{\star \star}\end{array}$ & $\begin{array}{l}0.040 \\
(0.13) \\
\end{array}$ & 0.5906 \\
\hline SIC 33 & $\begin{array}{l}0.101 \\
(2.31)^{\star \star}\end{array}$ & $\begin{array}{l}1.084 \\
(24.01)^{\star \star \star}\end{array}$ & $\begin{array}{l}0.379 \\
(6.19)^{\star \star \star}\end{array}$ & $\begin{array}{l}0.364 \\
(4.91)^{\star \star \star}\end{array}$ & $\begin{array}{l}-0.095 \\
(-1.40) \\
\end{array}$ & $\begin{array}{l}-0.025 \\
(-0.26) \\
\end{array}$ & 0.6596 \\
\hline AVERAGE & $\begin{array}{l}0.105 \\
(31.14)^{\star \star \star} \\
\end{array}$ & $\begin{array}{l}1.051 \\
(6.58)^{\star \star \star}\end{array}$ & $\begin{array}{l}0.104 \\
(0.73) \\
\end{array}$ & $\begin{array}{l}0.214 \\
(2.68)^{\star \star}\end{array}$ & $\begin{array}{l}-0.164 \\
(-3.36)^{\star \star \star} \\
\end{array}$ & $\begin{array}{l}0.170 \\
(1.04) \\
\end{array}$ & 0.6031 \\
\hline EXRET & CONSTANT & BETA & SIZE & $B M$ & RDFACT & RDMAT & RSQ \\
\hline SIC 28 & $\begin{array}{l}0.111 \\
(2.51)^{\star \star \star}\end{array}$ & $\begin{array}{l}0.937 \\
(35.28)^{\star \star \star}\end{array}$ & $\begin{array}{l}0.095 \\
(2.63)^{\star \star}\end{array}$ & $\begin{array}{l}0.126 \\
(2.88)^{\star \star}\end{array}$ & $\begin{array}{l}-0.046 \\
(-1.14) \\
\end{array}$ & $\begin{array}{l}0.076 \\
(2.71)^{\star \star}\end{array}$ & 0.804 \\
\hline SIC 35 & $\begin{array}{l}0.105 \\
(2.34)^{\star \star \star}\end{array}$ & $\begin{array}{l}1.068 \\
(34.73)^{\star \star \star}\end{array}$ & $\begin{array}{l}0.427 \\
(10.24)^{\star \star \star}\end{array}$ & $\begin{array}{l}0.272 \\
(5.40)^{\star \star \star}\end{array}$ & $\begin{array}{l}-0.036 \\
(-0.77) \\
\end{array}$ & $\begin{array}{l}0.018 \\
(0.44) \\
\end{array}$ & 0.8129 \\
\hline SIC 36 & $\begin{array}{l}0.120 \\
(2.41)^{\star \star \star}\end{array}$ & $\begin{array}{l}1.102 \\
(39.04)^{\star \star \star}\end{array}$ & $\begin{array}{l}0.481 \\
(12.59)^{\star \star \star}\end{array}$ & $\begin{array}{l}0.183 \\
(3.92)^{\star \star \star}\end{array}$ & $\begin{array}{l}0.341 \\
(7.99)^{\star \star \star}\end{array}$ & $\begin{array}{l}0.081 \\
(2.76)^{\star \star}\end{array}$ & 0.8638 \\
\hline AVERAGE & $\begin{array}{l}0.112 \\
(25.70)^{\star \star \star}\end{array}$ & $\begin{array}{l}1.036 \\
(20.57)^{\star \star \star}\end{array}$ & $\begin{array}{l}0.334 \\
(2.77)^{\star \star}\end{array}$ & $\begin{array}{l}0.194 \\
(4.56)^{\star \star \star}\end{array}$ & $\begin{array}{l}0.086 \\
(0.68) \\
\end{array}$ & $\begin{array}{l}0.058 \\
(2.89)^{\star \star}\end{array}$ & 0.8269 \\
\hline
\end{tabular}

* 90\% significance level ** 95\% significance level $\quad * * * 99 \%$ significance level

Where t-values are in parenthesis 


\section{Table 2.11}

\section{Robustness: Characteristic Test using individual firms in selected industry}

Table presents result of excess returns regressed against factors and firm level characteristics based on selected industry [sic (20, 24, 28, 33, 35, and 36)] data. The test is based on the Daniel and Titman characteristic test, where time series of individual firms in the selected sub-sample are run and averaged across firms. BETA is the market beta factor, SIZE is the size of a firm and it is measured as the log of market value of equity, which equals the stock price of the stock at the end of June of year $t$ times the total shares outstanding. Following Fama and French (1992), the book-to-market equity ratio (BM) at time $t$ is calculated by dividing book equity (BE) at the fiscal ending of year $t-1$ by market equity (ME) at December of year $t-1$. The dependent variable (EXRET) used in the first and second pass is the excess return of individual firms. RDMAT is the ratio of R\&D expenditure to Total Assets of each firm within an industry portfolio. RDFACT is a $\mathrm{R} \& \mathrm{D}$ factor variable estimated by shorting assets with low $\mathrm{R} \& \mathrm{D}$ expenditure and long assets with high R\&D expenditure. PATLEV is the ratio of the number of patents to Total Assets for each firm in a month, where the Total Asset is scaled by a millionth. PATFACT is a patent factor variable estimated by shorting assets with low patent issues and long assets with high patent issue.

\begin{tabular}{|c|c|c|c|c|c|c|c|}
\hline EXRET & CONSTANT & BETA & SIZE & $B M$ & RDFACT & RDMAT & $R$-squared \\
\hline Model 1 & $\begin{array}{l}0.015 \\
(1.71)^{*}\end{array}$ & $\begin{array}{l}1.028 \\
(45.41)^{\star \star \star}\end{array}$ & $\begin{array}{l}0.313 \\
(8.001)^{\star \star \star}\end{array}$ & $\begin{array}{l}0.277 \\
(7.622)^{\star \star \star}\end{array}$ & $\begin{array}{l}0.0092 \\
(0.2746)\end{array}$ & $\begin{array}{l}0.154 \\
(4.653)^{\star * *}\end{array}$ & 0.318 \\
\hline EXRET & CONSTANT & BETA & SIZE & $B M$ & PATFACT & PATLEV & $R$-squared \\
\hline Model 2 & $\begin{array}{l}0.021 \\
(1.91)^{*}\end{array}$ & $\begin{array}{l}0.982 \\
(40.88)^{\star \star \star}\end{array}$ & $\begin{array}{l}0.308 \\
(6.80)^{\star \star \star}\end{array}$ & $\begin{array}{l}0.365 \\
(9.18)^{\star \star \star}\end{array}$ & $\begin{array}{l}0.107 \\
(2.79)^{* *}\end{array}$ & $\begin{array}{l}-0.0073 \\
(-0.057)\end{array}$ & 0.307 \\
\hline EXRET & CONSTANT & BETA & $B M$ & RDFACT & RDMAT & & $R$-squared \\
\hline Model 3 & $\begin{array}{l}0.024 \\
(1.77)^{\star}\end{array}$ & $\begin{array}{l}1.042 \\
(45.048)^{\star \star \star}\end{array}$ & $\begin{array}{l}0.296 \\
(8.01)^{\star \star \star}\end{array}$ & $\begin{array}{l}-0.0176 \\
(-0.509)\end{array}$ & $\begin{array}{l}0.106 \\
(3.104)^{\star \star \star}\end{array}$ & & 0.305 \\
\hline EXRET & CONSTANT & BETA & $B M$ & PATFACT & PATLEV & & $R$-squared \\
\hline Model 4 & $\begin{array}{l}0.028 \\
(2.01)^{\star \star}\end{array}$ & $\begin{array}{l}1.002 \\
(41.54)^{\star \star \star}\end{array}$ & $\begin{array}{l}0.401 \\
(9.671)^{\star \star \star} \\
\end{array}$ & $\begin{array}{l}0.1082 \\
(2.94)^{* \star}\end{array}$ & $\begin{array}{l}-0.019 \\
(-0.064) \\
\end{array}$ & & 0.294 \\
\hline
\end{tabular}




\section{Chapter 3. Return Predictability Using Firm-Issued Patents}

\subsection{Introduction}

Shiller $(1987,1991)$ provides survey evidence to show that investors sometimes react to each other rather than to economic facts. This accession may lead to investors overreacting or under-reacting to information in the financial market. DeBondt and Thaler (1985, 1987) use contrarian strategies, where firms are sorted based on previous performance by shorting winners and holding losers, to generate positive excess returns. The intuition behind the contrarian view suggests initial high stock prices due to overreaction by investors and subsequent downward price correction over time. Thus prices revert to its trend level after previous overreaction.

Jegadeesh and Titman (1993, 2001) provide evidence to show that momentum strategies, the exact opposite of the contrarian strategies also generate positive returns. The momentum strategies hold winners and short losers over a holding period. The positive abnormal returns from the momentum strategies are explained by the underreaction hypothesis. Thus the market may react partially to information and later experience upward correction as information becomes more widely available. This is also supported by the behavioral hypothesis, since according to Shiller investors react to what others are doing more than what economic facts dictate. This creates the bandwagon effect, where people are inclined to bet on a winner. As more investors are attracted to winners, the effect of increased demand leads to further upward movement in prices, generating positive returns.

Though the overreaction and underreaction hypotheses suggest a contradiction, Balvers and Wu (2006) argue that not only can the two generate positive returns, but they can co-exist in a single financial model to generate positive returns. They argue that the use of contrarian and momentum strategies does not present a contradiction since a contrarian considers a longer-term perspective and momentum looks at a short-term perspective. In this chapter, I investigate the use of firm-issued patents in trading strategies that generate momentum-like abnormal returns. The intuition behind the abnormal returns stems from investors' evaluation of the growth prospect of the firms as 
new information about firms’ patents becomes available. Increases in firm-issued patents may generate more noise, especially for the uninformed investors, since they may not be able to accurately judge the value of firm-issued patents. Overall, market may under-react to the new information about patents leading to future market correct. I use the nonparametric model discussed in Jagadeesh and Titman (1993, 2001) to create 10 decile portfolios sorted by firm-level patents.

This chapter is an extension of the previous chapter [chapter $2^{22}$ ], where the focus was to investigate whether patents and R\&D generate firm-specific adverse selection risk, and whether such risks are priced. Evidence in the chapter does not provide a conclusive answer to whether patents generate a “characteristics” effect due to market reaction to information. This chapter provides an alternative approach to evaluate the information content of firm patents and how it impacts on returns. I show that trading strategies that short stocks with low issued patents and hold stocks with high issued patent generate abnormal returns. The abnormal returns from such trading strategies may very well be explained by a patent risk factor or some underlying risk factor like $R \& D$ risk. The apparent abnormal returns may be generated if return realizations correlate with risk sensitivities due to increases in firm-issued patents or R\&D activities. As noted in Balvers and $\mathrm{Wu}$ (2006), when a persistent increase in systematic risk comes about, returns are initially low as prices adjust but subsequently are higher as expected returns have increased due to the increased reward for risk. The evidence presented in this chapter suggests that the abnormal returns associated with selecting stocks on the basis of their patents may be explained by noise generated by firm patent activities. And such increased noise may be due to investors' under-reaction to patent information and subsequent correction over time. I also provide evidence to show that the momentum profit could be explained by a patent risk factor in a four-factor Fama-French model. The introduction of a patent risk factor reduces the alpha, the abnormal return from the momentum strategy, by half. The "winner" momentum portfolio tends to have higher issued patents and the "loser" portfolio tends to have relatively lower issued patents.

A number of papers explain the momentum profit as compensation for some form of systematic risk. Berk, Green and Naik (1999) demonstrate that the slow turnover in

\footnotetext{
${ }^{22}$ The first paper in my dissertation; 'do Patents or R\&D Represent Adverse Selection Risk?’
} 
firms' projects gives rise to persistence in their systematic risk, making expected returns positively correlated with lagged expected returns. Chordia and Shivakumar (2002) suggest that momentum profits may not come from firm-specific returns, but from different sensitivities of stocks to the time-varying macroeconomic variables. This chapter addresses the issue by investigating any link patent portfolios may have with systematic risk. Thus are high patent portfolios systematically selecting high risk stock? The evidence presented in this chapter suggest that using a trading strategy that select stocks based on firm issued patents generate abnormal returns. The abnormal returns are not an obvious proxy for systematic risk. The explanation for the results may be due to future market correction for noise generated by firm-issued patents.

The rest of the chapter is organized as follows. Section 2 documents the literature and proposes the hypothesis of study in the chapter. Section 3 describes the empirical model used in the analysis. Section 4 provides information about the source of data. Section 5 presents the empirical results. Section 6 presents the robustness analysis and Section 7 concludes the chapter.

\subsection{The Literature and Hypothesis}

Recent papers by Jegadeesh and Titman $(1993,2001)$ and a host of others have showed that stock selection strategies may generate positive excess returns. Jegadeesh and Titman (1993) show that stocks that perform best in prior periods tend to continue to perform well for subsequent periods. The momentum strategies described in their paper short stocks of previous losers and hold stocks of previous winners. The momentum strategy is supported by the behavioral and psychological hypothesis. Thus individuals (investors) see the price of a stock rising and are drawn to invest in it believing that price would rise further. This creates a bandwagon effect as more investors are drawn to invest in the stock and that further raises stock returns. The paper builds on the behavioral hypothesis of Hong and Stein (1999).

Stein (1987) observes that imperfectly informed rational speculators introduce noise as well as information into asset prices, and can make prices carry less information about the state of the economy and be less stable. Stein's idea as encapsulated in the behavioral hypothesis could be applicable to firm-issued patents. I hypothesize that an 
unexpected jump in firm-issued patents may present new information to the market and because some investors are imperfectly informed their reaction may introduce noise as noted by Stein (1987).

\section{Hypothesis 1:}

Imperfectly informed investors react partially to unexpected increases in firm-issued patents. An initial increase in returns is followed by a further increase in a future time period as noise subsides.

The research question addresses the characteristic properties of a firm's unexpected increase in issued patents as an information variable in affecting stock returns. Thus an unexpected jump in firm patents generates a behavioral reaction from the market, as explained by Stein (1987). It takes time for the market to fully learn all information, so price reaction to new information may be under-stated and subsequent correction would lead to upward movement in price. The market may not initially fully price issued patents, leading to upward market correction over time. Hence, one may get positive returns for using a trading strategy based on firm-issued patents.

\section{Hypothesis 2:}

A firm's patent exposure may be priced as systematic risk under the Merton asset pricing framework.

Firm-issued patents may have a systematic risk explanation on the basis of the Merton's framework. According to Merton (1973), anything that changes investment opportunities of firms may be priced. A patent factor may capture aggregate productivity changes that are systematic and the positive returns from patent trading strategies may be priced systematic risk. Higher betas on the patent factor would imply that higher patent firms have more exposure to this particular risk.

\section{Hypothesis 3:}

The level of patent exposure in portfolios of firms explains the documented momentum returns. 
Jegadeesh and Titman (2001) present evidence to show that trading strategy that uses the momentum strategy may generate abnormal returns. They argue that the standard risk adjustment could not explain the momentum profit. The third hypothesis evaluates whether patent exposure is responsible for the perceived momentum returns.

The use of patent data in economic analysis dates back to Schmookler (1966) and Griliches (1984). Schmookler (1966) points out that historical patent data may reflect economically significant information about technological development. Griliches (1984) shows a positive relation between a firm's market value and its patents. Pakes (1985) provides a focus study on the impact of patent and R\&D shocks on equity returns using firm level data over a period of 8 years. Though limited in scope, he finds results to suggest that patent shocks significantly affect equity prices.

Firm-issued patents have not been studied from the point of view of affecting the information structure of firms. Chapter 2 of the dissertation investigates patent data as a source of new information coming into the market, and how such firm-level characteristic effects are priced in the market. This chapter uses the Jegadeesh and Titman (1993) methodology to investigate firm-issued patents as an information variable on stock returns. News of firm-issued patents may signal expected future growth prospects for the firm. The information may be viewed as positive news and stock price would react as such. Hence the market reacts to unexpected news of any new issued patent. I also include a patent citation variable in the analysis. Griliches, Hall and Pakes (1987) point out that patent may face limitations in capturing heterogeneity in economic data. Schankerman and Pakes (1986) instead use patent renewal data, while Hall, Jaffe and Trajtenberg (2003), use patent citation data. The use of patent citations introduces a way to evaluate heterogeneity in the value of patents. Citations may therefore convey economically significant information and may provide an indication of how valuable a firm's patent is. Trajtenberg (1990) investigates the economic significance of citations in a study of the flow of patents in the computed tomography (CT) scanner to the estimated social surplus due to improvement in technology. Lanjouw and Schankerman (2004) use citations as a proxy for patent quality. To address these concerns, I use patent citations as a robustness check. 


\subsection{Model}

Two models of performance measurement are used. The first is the Sharpe-Lintner Capital Asset Pricing Model (CAPM) and the second is the Fama-French 4-factor model. The models are briefly described in this section, and the performance of their estimates on portfolios evaluated using New York Stock Exchange (NYSE), American Stock Exchange (Amex) and Nasdaq stocks. The performance of the Fama and French (1993) 3-factor model is also used for comparative purposes.

The Sharpe-Lintner CAPM builds on the model of portfolio choice developed by Markowitz (1959). Markowitz's model assumes that an investor selects a portfolio at time $t-1$ that produces a stochastic return at time $t$. The model assumes that investors are risk averse and in their choice of portfolio, they care about the mean and variance of their one-period investment return. The algebraic expression for the Sharpe-Lintner CAPM using mean returns from strategies that sort stocks into portfolios based on firm issued patent is

$$
\begin{aligned}
& r_{i}=r_{f}+\beta_{i}\left(r_{m}-r_{f}\right)+\varepsilon_{i} \\
& \beta_{i}=\operatorname{Cov}\left(r_{i}, r_{m}\right) / \sigma_{m}^{2}
\end{aligned}
$$

$r_{i}$ is the expected returns of portfolio $i, r_{m}$ is the expected market returns, $r_{f}$ is the risk free rate and $\beta_{i}$ is the market beta of an portfolio $i$. The empirical formulation of CAPM is given as

$$
r_{i t}-r_{f t}=\alpha_{i}+\beta_{i}\left(r_{m t}-r_{f t}\right)+\varepsilon_{i t}
$$

Where $\alpha_{i}$ is interpreted as the risk-adjusted mean excess returns of a portfolio $i$.

A 4-factor model is constructed using the Fama-French 3-factor model and an additional factor capturing the patent anomaly ${ }^{23}$. The 4-factor model is consistent with a model of market equilibrium with four risk factors.

$$
r_{i t}-r_{f t}=\alpha_{i}+\beta_{i}\left(r_{m t}-r_{f t}\right)+s_{i} S M B_{t}+h_{i} H M L_{t}+p_{i} \text { PATFACT }_{t}+e_{i t}
$$

\footnotetext{
${ }^{23}$ This is motivated by the 3 factor model's inability to explain cross-sectional variation in patent sorted portfolio returns. Carhart (1997) constructs momentum risk factor and use it to explain Jegadeesh and Titman (1993) momentum anomaly.
} 
$\left(r_{i t}-r_{f t}\right)$ is the excess return of the 10 decile portfolios sorted by patents; $r_{f}$ is the riskfree rate taken from Kenneth French's data library; $r_{m}$ is the aggregate market return data from Kenneth French's data library. SMB and $H M L$ are the size and value factors respectively from the Kenneth French data library. PATFACT is the patent factor constructed as equal-weighted average returns of firms with the highest 30 percent 3month lagged patents minus the equal-weighted average returns of firms with the lowest 30 percent 3-month lagged patents. $\alpha_{i}, \beta_{i}, s_{i}, h_{i}$ and $p_{i}$ are model parameters and $e_{i}$ is the error term. $\alpha_{i}$ and $\beta_{i}$ have their usual meaning as explained above. $s_{i}$ is the factor loading on the size factor, $h_{i}$ is the factor loading on the value factor and $p_{i}$ is the factor loading on the patent risk factor.

The models described in equations 3.3 and 3.4, together with the Fama-French 3factor model is run to evaluate to what extent the abnormal profit is explained by known risk factors. Momentum portfolios and momentum factors are estimated and used to evaluate whether momentum profit is as a result of the portfolio systematically picking stocks with high patent risk.

\subsection{Data}

The US Patent and Trademark Office (USPTO) publishes and keeps records of all US and Foreign patents obtained in the US. Patents are classified in three main categories as defined by the USPTO. ${ }^{24}$ Patent data may be freely downloaded from the USPTO website using the file extraction front end search or ftp folder downloads. However, working with USPTO data is tedious. Google also maintains a database on US patent, but bulk download for research purposes is challenging. In this chapter, I use patent data

24 (1) Utility Patents;- thus for new and useful process, machine, article of manufacture, or composition of matter, or any new and useful improvement.

(2) Design patents;- thus for invention of a new, original and ornamental design for an article of manufacture.

(3) Plant patents;- thus for the invention of or discovery and asexually reproduction of any distinct and new variety of plant. 
from the NBER and Bronwyn Hall's website ${ }^{25}$, and they provide a data file that links firm patents to COMPUSTAT gvkeys.

As indicated above, the patent data is taken from Hall's data site and it spans the period 1969 - 2001. The patent data forms part of an on-going NBER project to link all patent assignee to COMPUSTAT cusip numbers. Hall et al. (2001) provide a description of the database on US patents. The selection of firms into the sample may have possible bias implications. For instance if a firm is in the sample and does not currently have a patent, then we know for sure that it will have a patent in the future, which at that point will cause a positive return shock. The rolling sample selection procedure is however used and it selects a firm only after it has received at least one patent.

A sample of firms for the study was constructed by merging patent data taken from Bronwyn Hall's data library, the COMPUSTAT annual data file, and the Center for Research in Security Prices (CRSP) monthly data. From an initial list of 3,970 firms, a final list of about 691 firms is used. The sample of 691 firms is selected based on past patent information. The aggregate number of patents issued to a firm for the previous five years is used as the selection criteria to select a firm into the sample for year six. The years 1969 - 1973 patent information is used to select the sample for the year 1974 and firms with a 5-year total number of patents of 5 or more are selected. Subsequently, 1975 uses patent information for the period 1970 - 1974. Thus the rolling sample procedure for selecting the sample ensures that the sample selection is based on past data information. It also avoids the problem of survivorship bias and at the same time it ensures that young but high patent firms are not left out of the sample

A list of the top $10 \%$ high patent firms is provided in the Appendix Table 3A. A close inspection indicates that most the firms are within computer, electronics, chemicals and other related technology industries. A significant number of the firms in the list are among the top 100 firms of the firms in Fortune 500. The firms in Appendix Table 3A are mostly the firms selected into the first quintile [high patent] portfolio. The table shows the aggregate number of patents issued to each firm and the average return for the period of the sample. The sample mean returns of firms are compared to corresponding Kenneth French industry portfolio returns for the same sample period. With the exception of some

${ }^{25}$ http://emlab.berkeley.edu/users/bhhall/ 
few firms, almost all the firms performed better than the industry portfolio returns. Firms in paper business and electrical equipment industries were the only out-performed by the industry in the list. Siemens AG is the only firm that is not classified as one of Kenneth French's 48 industry portfolios. From the patent data, it is assigned SIC code 9997 which is not assigned to any of the 48 industries. Appendix 3B provides t-statistics based on the firms listed in Appendix 3A and it shows a t-statistic of 5.550. This may provide an indication that firms with very high concentration of issued patents out-perform other firms within the same industry.

The data sample covers the period 1969 - 2001 because patent data from Hall's site is only available for these years. Firms are sorted into portfolios using previous 3-to$12(J)$ months of patents issued to firms and the estimated portfolio returns are based on 3-to-12 $(K)$ months holding period. The patent citation data covers the period 1975 1999, and are used for a robustness check. Griliches, Hall and Pakes (1987) document that patent data may fail to capture heterogeneity in the performance of patents and the use of patent citation could provide a means to correct that.

\subsubsection{Trading Strategies}

The description of the trading strategy follows Jegadeesh and Titman (1993). If stock prices under-react to information, then investment strategies that select stocks based on the event of firm information may generate positive returns. In this study, I investigate the efficiency of the stock market regarding unexpected information on firm-issued patents. The strategy selects stocks based on the past 1, 2, 3 and 4 quarters of firm issued patents and a holding period from 1 to 4 quarters.

At the beginning of each month $t$, stocks are ranked in ascending order on the basis of the firm's issued patents in the past $J$ months. Based on these rankings, ten decile portfolios are formed that are equally-weighted within each decile. The tenth decile is called the "HIGH" decile and the first decile is called the "LOW" decile. In each month $t$, the strategy buys the HIGH portfolio and sells the LOW portfolio, holding this position for $K$ months. Portfolios are rebalanced each month.

\subsection{Results}

3.5.1 Summary Results of Earnings and size 
It is well documented in the literature that returns are driven by changes in underlying fundamentals. Firm earnings, earning surprises and earning announcements have always been a part of finance studies associated with changes in firm underlying fundamentals. Previous studies by Basu (1977) and Dreman and Berry (1995) provide insight into abnormal returns associated with firm earning announcements. La Porta et al. (1997) and Bernard et al. (1997) examine the stock returns around future earnings announcement dates. Skinner and Sloan (2002) argue that the anomaly of the growth stock could be explained by expectational errors of earning performance. Stock returns tend to be high for firms that exceed earning expectation. The literature also documents return predictability based on earnings momentum. For example Jones and Litzenberger (1970) and Chan, Jegadeesh and Lakonishok (1996) investigate the relation between past earnings momentum and future returns. Following Dechow et al. (2003), Compustat data item 172 is used as the earnings variable.

In this sub-section, I investigate the distribution of the portfolio returns of the trading strategies on the level of earnings. The relationship between earnings and stock returns lies at the core of the 'rational bubble' hypothesis where both the level and volatility of stock prices are related to the uncertainty regarding a firm's average future profits [Pastor and Veronesi (2004; 2005)]. Table 3.1 presents a summary distribution of earnings as a ratio of size of firms as they are distributed among the portfolios formed based on patent trading strategies. The sample data covers the period 1970:01 - 2001:12. The results show that portfolios with high issued patents tend to report higher future earnings even after controlling for the size effect.

Small-sized firms tend to be young, highly leveraged and more risky as compared to large-sized firms. Indeed the literature is full of conflicting explanations of the size effect on stock returns. Fama and French (1993) argue that size meets the definition of a pervasive risk factor or state variable. It is well documented in the finance literature that firms with small equity market values earn, on average, higher stock returns than firms with large equity market values [Berk (1995), Banz (1981) and Fama and French (1993)].

The chapter also investigates whether abnormal profit from patent trading strategies may offer an explanation for the momentum profit as reported in Jegadeesh and Titman (1993). Table 3.2 presents a summary distribution of firm-issued patents among 
momentum portfolios. The table shows that the momentum strategies may be consistently picking stocks with higher issued patents. And that the momentum strategies may capture systematic noise from firm patents.

\subsubsection{Returns of Trading Strategies}

The first hypothesis proposes the possibility of generating abnormal returns by adopting a trading strategy that buys and sells stocks on the basis of firm-issued patents. This subsection discusses the average returns of the 10 portfolios formed by sorting firms on the basis of issued patents. Table 3.3 reports the average returns of the different buy and sell portfolios, as well as zero-cost, $\mathrm{HIGH}^{26}$ minus LOW portfolios. The average returns of almost all the zero-cost portfolios are positive and significant at the $99 \%$ confidence level. The most successful zero-cost strategy selects stock based on their previous 3 months patents and then holds the portfolio for 3 months. This strategy yields $0.99 \%$ per month and this is quite comparable to the $1.31 \%$ estimated yield from the momentum strategy in Jegadeesh and Titman (1993). In Jegadeesh and Titman (1993), the momentum strategy that gives the highest zero-cost yield is $J=3$, and $K=12$. Under the patent strategies described in this chapter, the anomaly is most significant during the recent past. People are able to better interpret the information with time. So with time the positive returns begin to decrease as investors are able to make better predictions of the value of patents. Thus with time, the quality of information improves and rational investors make better prediction of idiosyncratic risk from issued patents.

In Table 3.3, the high patent portfolio generates positive returns on average. The positive returns decrease with an increasing $K$ month holding period. The low patent portfolio records low positive returns or in most cases negative average returns. Notwithstanding, the low patent portfolio shows a similar trend as the high patent portfolio, the low patent portfolio generates decreasing returns with an increasing $K$ month holding period. The above results enforce the belief that short history $(J=3$ ) of patent activities may make it more difficult to value the information content of patents as compared to long history of patent activities. Over time, the market learns and makes better prediction of the patent value of firms. Therefore estimation of average returns

\footnotetext{
${ }^{26}$ HIGH refers to portfolio sorted by the highest level of firm-issued patents and LOW refers to portfolio sorted by the lowest level of firm-issued patents.
} 
using the past 3 months patents may yield relatively higher returns than estimation based on the past 12 months patents. Similarly, relatively short holding period may perform better than long holding period as a result of market correction. This enforces the notion that over time, rational investors get better information and make rational decisions.

Figures 3.1 show the cumulative abnormal returns (CAR) for the various buy and sell strategies. The graph uses the spread between the average returns of the various buy and sell strategies and aggregate market return data from Kenneth French's data library. The CARs are estimated in excess of aggregate market returns and for $K=0$ to 60 over the sample period 1970:01-2001:12. The graph shows that the estimated CARs of all the portfolios are on average increasing in $K$ (the holding period). However, the CARs of the high patent portfolio are increasing at a decreasing rate over the holding period. It is observed that the gap between high and low patent portfolios is growing with increasing $K$, peaks at $K=45$ and begins to decrease. The increasing trend of the CAR for the high patent portfolio is what is expected on the basis that as you continue to hold the riskier or higher alpha asset you accumulate more positive returns. The strategy consistently beats market expectations and the positive returns accumulate over the holding period.

The observed result for the low patent portfolio is also growing with increasing $K$. The expectation is that low patent portfolios act as normal firms. Changes in the pattern of patents may not be an important characteristic for them. Any increase in returns may be due to some systematic risk or firm-level characteristic effect. To further investigate why an increasing pattern is observed, a critical look at the data sample is taken. If returns of firms tend to be higher on average than aggregate market returns from Kenneth French's data library, then it is possible to observe growing CARs for low patent portfolios. Equally-weighted aggregate market returns are estimated from the data sample used for this chapter, and the results is reported in the robustness section.

\subsubsection{Trading Strategy Profit Explained by Systematic Risk}

Balvers and $\mathrm{Wu}$ (2006) argue that it may be possible to explain abnormal returns in the framework of unanticipated persistent changes in risks or risk premia. This may happen if a persistent increase in systematic risk comes about, if returns are initially low as prices adjust but subsequently are higher as expected returns have increased due to the increased 
reward for risk. Similarly, if previous return realizations correlate with risk sensitivities, as suggested by Berk et al. (1999), a price pattern resembling the abnormal returns discussed in the previous sub-section may result. The Sharpe-Lintner one-factor model and the Fama-French three-factor model are used to test the second hypothesis, which suggest that the strategies may be systematically picking stocks on the basis of risk. This approach is consistent with Cahart (1997) and Jegadeesh and Titman (2001). They both test for the correlation between risk and the momentum profits.

Jegadeesh and Titman (2001) argue that if the momentum profits proxy for a risk premium, then there would be a positive correlation between portfolio returns and CAPM beta from the standard one-factor or three-factor test. A number of results are presented to evaluate the systematic risk implication of the patent profits. The results in Table 3.5 are in two parts. Panel A are results with no risk correction (raw returns) and Panel B presents risk-adjusted returns using market risk as the correction factor. First, I present the raw excess returns, uncorrected for systematic risk from the trading strategy that uses past 3 month patents and 3 month holding period. In Table 3.5 panel A, the high-patent portfolio (decile 1) has $2.3 \%$ average non-risk-adjusted excess monthly return and the low patent portfolio (decile 10 ) has $1.4 \%$ average non-risk-adjusted excess monthly return. Table 3.5 panel B present results for the one-factor Sharpe-Lintner CAPM. This corrects for market risk and the results show that the high patent portfolio has $2.0 \%$ riskadjusted returns and the low patent portfolio has $1.2 \%$ risk-adjusted returns. Similarly, the Fama-French 3-factor risk-adjusted return for the high patent portfolio is $2.1 \%$ and the low patent portfolio is $1.4 \%$, as reported in Table 3.6. At first sight, it seems the excess returns from patent portfolios are not explained by the risk factors. The evidence in Tables 3.5 and 3.6 show that there are no significant differences in the risk-adjusted returns and the raw returns.

According to Jegadeesh and Titman (2001), if the patent portfolio returns could be explained by risk, then high patent portfolio would have a high CAPM beta and low patent portfolio would have a low CAPM beta. Also, the differences in betas would be statistically significant. From Table 3.5 panel B, the change in beta between high patent and low patent portfolios may account for only $6.09 \%$ of the difference in the unadjusted excess returns. Thus the estimated betas from Tables 3.5 show a slight decreasing trend 
from 0.997 to 0.897 for high patent portfolio to low patent portfolio respectively. These differences in betas may suggest the strategy is systematically picking higher risk stocks in the higher-patent portfolios and vice versa.

\subsubsection{The 4-factor Results}

Following Carhart (1997)'s approach in constructing a momentum factor, I obtain the momentum (MOM) factor and similarly the patent (PATFACT) factor. MOM and PATFACT are returns on equal-weighted, zero-investment, factor mimicking portfolios for 12 months momentum ${ }^{27}$ in stock returns and past 3 months patents respectively. Table 3.7 present results for the 4-factor Carhart model with MOM. The risk-adjusted returns for high patent portfolios reported in Table 3.7 are reduced significantly, as compared to the results in Tables 3.5 and 3.6. For example the risk-adjusted excess return for the decile 1 (the high patent) portfolio reduces from $2.1 \%$ to $1.5 \%$. The low patent portfolio only sees a $0.2 \%$ reduction in risk-adjusted returns excess. This may not be a surprise since top patent portfolios are where more interest would be expected in terms of noise generated by firm issued patents. Stock returns are expected to be more sensitive to patent shocks for high patent portfolios. The introduction of momentum factor also significantly reduces the risk-adjusted returns for the zero-cost portfolio. The riskadjusted return for the zero-cost portfolio drops from $0.7 \%$ monthly return to $0.3 \%$. Table 3.8 also presents results for the 4-factor model but this time with PATFACT. The results with PATFACT are similar to the results with MOM. The risk-adjusted return for the decile 1 portfolio reduces from $2.1 \%$ to $1.4 \%$. The risk-adjusted return for the zero-cost portfolio drops to $0.1 \%$. The 4 -factor model with MOM and PATFACT also levels off the slight differences in the market betas for the portfolios as observed in Tables 3.5 and 3.6.

In Table 3.9, both MOM and PATFCAT are included in the model. No significant changes in risk-adjusted returns are observed as compared to Tables 3.7 and 3.8. The 4factor model and the 5-factor model present some evidence to suggest that the abnormal returns from a patent trading strategy may be explained by patent and momentum factors.

\subsubsection{Patent Risk Factor}

\footnotetext{
${ }^{27}$ The momentum returns are estimated based on the past 12 months of stock returns.
} 
This sub-section specifically investigates whether abnormal returns from patent trading strategies are explained by a patent risk factor. Lakonishok, Shleifer, and Vishny (1994) and La Porta (1996) argue that (value) strategies work because they capture systematic errors in the way investors form expectation about future returns. On the basis of this argument, a patent risk factor must reduce risk-adjusted returns since the patent strategies may be capturing systematic noise associated with investor expectations about returns. Table 3.10 presents results from the time series regression of excess (patent) portfolio returns against PATFACT and a constant. The results in Table 3.10 are compared to the raw portfolio returns in Table 3.5 panel A. The excess returns reduce from $2.2 \%$ to $1.3 \%$ for the high patent portfolio. The zero-cost investment portfolio returns also see a reduction from $0.8 \%$ to $0.1 \%$. Comparing the results in Table 3.11 and Table 3.5 panel B, similar reduction in risk-adjusted returns are observed as in the case of Table 3.10 and Table 3.5 panel A. Overall, PATFACT explains a significant portion of the abnormal returns associated with high patent portfolios from patent strategies.

\subsubsection{Momentum Returns and Patent Factor}

This section investigates the linkage between momentum profits and the patent risk factor as proposed in the third hypothesis. The momentum returns are estimated from the data sample in this study using the Jegadeesh and Titman (1993) methodology. Thus portfolios are formed based on the past 12 months of stock returns and are held for 6 months. According to Jegadeesh and Titman (1993) that gives the most abnormal profit from the various strategies. The patent risk factor is estimated following the outline in Carhart (1997) for estimating a momentum risk factor. From the estimated patent portfolio returns, equal-weighted average of the top 30 percentile minus the equalweighted average of firms with the bottom 30 percentile is used as estimate of patent risk factor. The estimation method is consistent with Fama and French (1993) and Carhart (1997) and is over the sample period 1970:01 - 2001:12.

Table 3.12 panel A presents results of the raw (unadjusted for risk) excess returns

from the momentum strategies. The high momentum portfolio shows $2.6 \%$ monthly unadjusted excess return and the low momentum has 1.5\% monthly unadjusted excess return. The zero-cost investment portfolio generates $1.0 \%$ monthly excess returns from the momentum strategies. The introduction of the market factor to correct for risk reduces 
the monthly excess returns for the high momentum portfolio from $2.6 \%$ to $2.5 \%$. Systematic risk adjustment accounts for $0.2 \%$ of the difference in the unadjusted monthly excess return from using the momentum strategies. This shows that the market risk factor explains very little of the momentum returns. Similarly, using Fama-French 3-factor model to account for risk, show little difference in the risk-adjusted returns of the portfolios [see Table 3.13]. Table 3.14 presents results from a time series regression of the excess portfolio returns on PATFACT and a constant term. The introduction of PATFACT explains a significant portion of the abnormal returns of the high momentum portfolio as compared to the raw excess returns in Table 3.12 panel A. The monthly excess return of the zero-cost investment portfolio becomes negative; virtually all the potential gains disappear!

The four-factor model is used where the fourth factor in the model is the patent and momentum risk factors respectively. The main purpose of this sub-section is to investigate if momentum profits are explained by a patent risk factor or a momentum risk factor. If the fourth factor explains the momentum profit, its introduction must significantly reduce the risk-adjusted returns as captured by the alphas. Table 3.15 and Table 3.16 report the results from the 4-factor model with PATFACT and MOM as the respective fourth factors. The variable of interest is the CAPM alphas and similar to Table 3.14, the risk-adjusted return of the high momentum portfolio reduces significantly. Similar reduction is observed when only the patent factor and market risk factor are used. Table 3.18 shows that apart from the market risk factor, all that is needed is to adjust for a patent risk factor to achieve the same reduction in risk-adjusted returns.

\subsection{Robustness}

This section investigates minor changes to the underlying due to increased noise from firm issued patents, and subsequent market correction in future generates abnormal profits. Evidence presented in the previous section suggests that such is indeed the case. In this section, patent citations are used in place of patents. Griliches, Hall and Pakes (1987) document that patent data may fail to capture heterogeneity in economic data and the use of patent citation could provide a means to correct that. Hall, Jaffe and Trajtenberg (2001) use patent citation data to aid the explanation of the market value by 
patents. They also argue that patent citation is a higher resolution measure of the information stock of traded firms. Thus citation data does not only aid the informational content of patent, but it is in itself an information variable. In this robustness check, I investigate whether the use of the citation variable would present any significant departure from the evidences in the main results.

\subsubsection{Citations}

In this chapter, the patent citation variable is used as an alternative measure of firm-level information. The patent citation is used as the sorting variable to run the trading strategies outlined by Jegadeesh and Titman (1993), thus similar to the patent variable discussed above. Table 3.19 reports positive excess return from holding stocks with high patent citations and selling stocks with low patent citations. The highest return, if citation is the sorting variable for high minus low portfolios, is $0.48 \%$ per month. This is significantly lower than the $0.99 \%$ per month for the patent variable, but nonetheless positive. Table 3.20 panels $\mathrm{A}$ and $\mathrm{B}$, present results of the raw excess returns and risk-adjusted excess returns for the citation strategies respectively. The excess return for the high citation portfolio reduces from $1.6 \%$ to $1.2 \%$ after correcting for market risk (Table 3.20 panel B) and Fama-French 3-factor risk (Table 3.21). This shows that risk-adjustment may have an impact on excess returns from citation strategies. Tables 3.22 and 3.23, which include the PATFACT, also show significant reduction in the risk-adjusted excess returns. The high citation excess return reduces from $1.2 \%$ to $0.8 \%$ per month, as observed from Tables 3.20 and 3.23. The gains from the zero-cost investment portfolio are now significantly reduced, dropping from $0.7 \%$ to $-0.1 \%$. The trend in the citation result is similar to that of the patent results, though the patent variable provides more abnormal returns compared to the citation variable.

\subsubsection{Sample Sub-periods}

Jegadeesh and Titman (2001) argued on the basis of Ross (1983) that the month January may impact the positive returns adversely. They report the zero-cost return for each calendar month of the year and evaluate the effect of seasonality on performance. Following Jegadeesh and Titman (2001), I estimate zero-cost returns for the twelve calendar months. Table 3.24 reports the result of the monthly zero-cost returns for 3 month holding period for the strategies that select stocks based on 3 and 6 month past 
issued patents. November and December tend to exert a strong seasonal impact on the performance of the zero-cost returns.

\subsubsection{CARs corrected for by equally-weighted market returns from sample}

To correct for the observed increasing trend in $K$-month holding period of the low patent portfolio corrected for aggregate market returns from Fama-French. Aggregate market returns are estimated from the data sample used in this chapter. Equally-weighted market returns are estimated from the sample and used to proxy for market returns. Figures 3.1 and 3.2 show that the CARs for the high patent portfolios are increasing with the holding period and the CARs for the low patent portfolios are decreasing with the holding period.

\subsection{Conclusion}

Trading strategies that buy stocks with past high firm-issued patents and sell stocks with past low patents realize significant abnormal returns over the period 1970 - 2001 covered under this study. The highest abnormal return of $0.99 \%$ per month is realized for the strategy that buys based on previous 3 months issued patents and hold for 3 months. The momentum strategy with the highest realized return is a slightly lower $1.31 \%$ for the 12 month/3-month strategy. The evidence suggests that the abnormal return is persistent but dies down with time as the market corrects.

DeLong, Shleifer, Summers and Waldman (1990) explore the positive feedback trader effect on market prices where investors continuously evaluate the short-term and long-term prospects of firms and correct for market prices. Thus markets may correct for under-reaction generated by firm-issued patents over time as investors continuously evaluating firm's short-term and long-term prospects. The evidence equally shows that abnormal returns may be due to systematic risk and is proxied by a patent risk factor. There is not enough evidence to decide between the two effects, systematic or behavioral. The study also provides evidence to suggest that the momentum profit could be explained by patent risk factors. 


\subsection{References}

Ball, R., and Kothari, S. 1989, "Nonstationary Expected Returns: Implications for Tests of Market Efficiency and Serial Correlation in Returns," Journal of Financial Economics 25: 51-74.

Balvers, R. J. and Wu, Y., 2006. "Momentum and mean reversion across national equity markets.” Journal of Empirical Finance 13. 24-48. 25

Banz, R. W., and Breen, W. J. 1986. "Sample Dependent Results Using Accounting and Market Data: Some Evidence.” Journal of Finance, 41, 779-793

Basu, S. 1977. "Investment Performance of Common Stocks in Relation to Their Price Earnings Ratios: A Test of the Efficient Market Hypothesis." Journal of Finance 32, 663-682.

Berk, J. B. 1995a. “A Critique of Size-Related Anomalies.” Review of Financial Studies, 8, 275-286.

Berk, J. B., Green, R.C. and Naik, V., 1999. "Optimal Investment, Growth Options, and Security Returns.” Journal of Finance 54, 1553-1607.

Bernard, V. L., J. Thomas and J. Wahlen. 1997. "Accounting-Based Stock Price Anomalies: Separating Market Inefficiencies from Risk." Contemporary Accounting Research 14, 89-136.

Carhart, M. M., 1997. “On Persistence in Mutual Fund Performance.” Journal of Finance 52, 57-82.

Chan, K. C. 1988. "On the Contrarian Investment Strategy.” Journal of Business, 61, 147-164.

Chan, L. K. C., Jegadeesh, N. and Lakonishok, J., 1996. "Momentum Strategies.” Journal of Finance 51, 1681- 1713.

Chordia, T. and Shivakumar, L. 2002, "Momentum, Business Cycle, and Time-varying Expected Returns”, Journal of Finance, 57, 985-1019.

DeBondt, W. and Thaler, R., 1985. "Does the Stock Market Overreact?” Journal of Finance 40, 793- 805.

DeBondt, W. and Thaler, R., 1987. "Further Evidence of Overreaction and Stock Market Seasonality.” Journal of Finance 42, 557-581. 
Dechow, P., Richardson, S. and Tuna, A., 2003. "Why Are Earnings Kinky? An Examination of the Earnings Management Explanation.” Review of Accounting Studies, 8, 355-384.

DeLong, J. B., Shleifer, A., Summers, L.H. and Waldmann, R.J., 1990. "Positive Feedback Investment Strategies and Destabilizing Rational Speculation.” Journal of Finance 45, 379- 395.

Dreman, D. and Berry, M. 1995. “Overreaction, Underreaction, and the Low-P/E Effect.” Financial Analysts’ Journal 51, 21-30.

Fama, E and French, K, 1993. "Common Risk Factors in the Returns on Stocks and Bonds,” Journal of Financial Economics. 33, 3-56.

Griliches, Z., Pakes, A. and Hall, B. H., 1987. "The Value of Patents as Indicators of Inventive Activity," in Dasgupta, Partha, and Paul Stoneman (eds.), Economic Policy and Technological Performance. Cambridge, England: Cambridge University Press, 97-124.

Griliches, Z. 1984, “R\&D, Patents, and Productivity,” University of Chicago Press.

Hall, B. H., Jaffe, A. and Trajtenberg, M., 2003, "Market Value and Patent Citations: A First Look,” Economics Department, University of California, Berkeley Working Paper E01-304, 67.

Hall, B. H., Jaffe, A. and Trajtenberg, M. 2001. "The NBER Patent Citation Data File: Lessons, Insights and Methodological Tolls.” NBER Working Paper No. 8498. Reprinted as Chp. 13 in Jaffe and Trajtenberg (2002)

Hong, H. and Stein, J.C., 1999. “A Unified Theory of Underreaction, Momentum Trading, and Overreaction in Asset Markets.” Journal of Finance 54, 2143- 2184.

Jegadeesh, N. and Titman, S., 1993. "Returns to Buying Winners and Selling Losers: Implications for Stock Market Efficiency.” Journal of Finance 48, 65-91.

Jegadeesh, N. and Titman, S., 2001. "Profitability of Momentum Strategies: An Evaluation of Alternative Explanations.” Journal of Finance 56, 699- 720.

Jones, C. P. and Litzenberger, R. H. 1970. “Quarterly Earnings Reports and Intermediate Stock Price Trends,” Journal of Finance, 25, 143-148.

La Porta, R., 1996, “Expectations and the Cross-section of Stock Returns,” Journal of Finance 51, 1715- 1742.

La Porta, R., J. Lakonishok, A. Shleifer and R. Vishny. 1997. "Good News for Value Stocks: Further Evidence of Market Efficiency.” Journal of Finance 52, 859-874. 
Lakonishok, J, Shleifer, A. and Vishny, R. 1994, “Contrarian Investment, Extrapolation, and Risk,” Journal of Finance 49, 1541-1578.

Lanjouw, J. O., and Schankerman, M. 2004. "Patent Quality and Research Productivity: Measuring Innovation with Multiple Indicators," Economic Journal, 114, 441465.

Lintner, J., 1965 “The Valuation of Risk Assets and the Selection of Risky Investments in Stock Portfolios and Capital Budgets," Review of Economics and Statistics, 47, 13-37.

Merton, R., 1973, “An Intertemporal Asset Pricing Model,” Econometrica 41, 867-887.

Pakes, A. 1985. "Patents, R and D, and the Stock Market Rate of Return.” Journal of Political Economy, 93: 390-409.

Pastor, L. and Veronesi, P. 2004. "Was There a Nasdaq Bubble in the Late 1990's," Journal of Financial Economics, 81 (1): 61-100.

Pastor, L. and Veronesi, P. 2005. "Technological Revolutions and Stock Prices," National Bureau of Economic Research w11876.

Schankerman, M. and Pakes, A. 1986. "Estimates of the Value of Patent Rights in European Countries during the Post-1950 Period," Economic Journal 97: 1-25.

Schmookler, J. 1966. “Invention and Economic Growth.” MA: Harvard University Press.

Sharpe, W., 1964 "Capital Asset Prices: A Theory of Market Equilibrium Under Conditions of Risk,” Journal of Finance, 19, 425-442.

Shiller, R.. 1987, “Investor Behavior in the October 1987 Stock Market Crash.” National Bureau of Economic Research, Working Paper no. 2446,.

Shiller, R., Kon-ya, F. and Tsutsui, Y.,1991 "Investor Behavior in the October 1987 Stock Market Crash: The case of Japan.” Journal of the Japanese and International Economies 5, 1- 13

Skinner, D. and Sloan, R. 2002. "Earnings Surprises, Growth Expectations, and Stock Returns or Don't Let an Earnings Torpedo Sink Your Portfolio" Review of Accounting Studies, 7, 289-312, 2002

Stein, J., 1987. “Information Externalities and Welfare Speculation.” Journal of Political Economy. 95, 1123-45 
Trajtenberg, M., 1990, "A Penny For Your Quotes: Patent Citations and the Value of Innovations,” The RAND Journal of Economics 21, 172-187. 
Table 3.1

\section{Summary Distribution of Earnings per Size by Portfolios}

At the end of each month stocks are ranked in ascending order on the basis of the past 3 months of firm issued patents and held for K months. 10 decile equally-weighted portfolios of stocks are formed. Stocks in the top decile (decile 1) are stocks with high patents and stocks in the bottom decile (decile 10) are firms with low patents. The results are based on the data sample that merges CRSP, COMPUSTAT and patent data, and the period of the sample used is 1970:01 - 2001:12. Summary results of average earnings per size distributed among the 10 decile portfolio are presented in the Table. Compustat data item 172 is used as earnings and it is defined as the net income in thousands of dollars. Size is estimated as the market value of stocks, measured in June of each year.

\begin{tabular}{|c|c|c|c|c|c|c|c|c|c|c|}
\hline $\mathrm{J}=3$ & High & & & & & & & & & Low \\
\hline$K=3$ & 0.4266 & 0.2422 & 0.1909 & 0.1355 & 0.0938 & 0.0621 & 0.0489 & 0.0204 & 0.015 & 0.0089 \\
\hline$K=6$ & 0.4215 & 0.2266 & 0.1951 & 0.1211 & 0.0916 & 0.0615 & 0.045 & 0.0211 & 0.0113 & 0.0081 \\
\hline$K=9$ & 0.4199 & 0.2122 & 0.2003 & 0.1133 & 0.0908 & 0.0601 & 0.0471 & 0.0208 & 0.0129 & 0.0079 \\
\hline$K=12$ & 0.4154 & 0.2112 & 0.1901 & 0.1127 & 0.0911 & 0.0591 & 0.0419 & 0.0201 & 0.0145 & 0.0073 \\
\hline
\end{tabular}

Table 3.2

\section{Summary Distribution of patents among momentum Portfolios}

At the end of each month stocks are ranked in ascending order on the basis of the past 12 months of firm returns and held for K months. 10 decile equally-weighted portfolios of stocks are formed. Stocks in the top decile (decile 1) are stocks with high returns and stocks in the bottom decile (decile 10) are firms with low returns. The High-Low represents the zero-cost portfolio. The results are based on the data sample that merges CRSP, COMPUSTAT and patent data, and the period of the sample used is 1970:01 - 2001:12.

The summary results of average monthly patents issued to firms and distribution among the 10 decile portfolios.

\begin{tabular}{|c|c|c|c|c|c|c|c|c|c|c|}
\hline $\mathrm{J}=12$ & High & & & & & & & & \multicolumn{2}{|c|}{ Low } \\
\hline$K=3$ & 29.6 & 10.8 & 5.9 & 3.7 & 2.5 & 1.6 & 1.1 & 0.8 & 0.3 & 0.6 \\
\hline$K=6$ & 29.8 & 11.2 & 4.8 & 3.1 & 2.1 & 1.4 & 1.1 & 0.7 & 0.2 & 0.6 \\
\hline$K=9$ & 28.5 & 9.6 & 5.2 & 2.9 & 1.9 & 1.4 & 1.0 & 0.7 & 0.2 & 0.6 \\
\hline$K=12$ & 28.1 & 7.5 & 4.0 & 2.7 & 1.8 & 1.4 & 1.0 & 0.7 & 0.2 & 0.6 \\
\hline
\end{tabular}


Table 3.3

\section{Average Returns of Patent Portfolios}

At the end of each month stocks are ranked in ascending order on the basis of the past $J$ months of firm issued patents and held for $K$ months. 10 decile equally-weighted portfolios of stocks are formed. Stocks in the top decile (decile 1) are stocks with high patents and stocks in the bottom decile (decile 10) are firms with low patents. The High-Low represents the zero-cost portfolio. The results are based on the data sample that merges CRSP, COMPUSTAT and patent data, and the period of the sample used is 1970:01 - 2001:12. The average monthly returns of these portfolios are presented in this Table.

\begin{tabular}{|c|c|c|c|c|c|c|}
\hline & \multicolumn{2}{|c|}{ High } & \multicolumn{2}{|c|}{ Low } & \multicolumn{2}{|c|}{ HIGH - LOW } \\
\hline$J=3$ & Ret & T-Stat & Ret & T-Stat & Ret & T-Stat \\
\hline$K=3$ & 0.0233 & 4.05 & 0.0134 & 1.80 & 0.0099 & 1.96 \\
\hline$K=6$ & 0.0113 & 2.31 & 0.0093 & 0.64 & 0.0020 & 0.98 \\
\hline$K=9$ & 0.0103 & 2.99 & 0.0012 & 1.37 & 0.0091 & 1.29 \\
\hline$K=12$ & 0.0097 & 2.62 & 0.0053 & 1.38 & 0.0044 & 1.03 \\
\hline \multicolumn{7}{|l|}{$\mathrm{J}=6$} \\
\hline$K=3$ & 0.0179 & 3.92 & 0.0127 & 1.68 & 0.0052 & 2.11 \\
\hline$K=6$ & 0.0113 & 3.33 & 0.0107 & 1.40 & 0.0006 & 1.99 \\
\hline$K=9$ & 0.0114 & 2.74 & 0.0081 & 0.35 & 0.0033 & 1.15 \\
\hline$K=12$ & 0.0109 & 3.21 & 0.0065 & 1.33 & 0.0044 & 1.56 \\
\hline \multicolumn{7}{|l|}{$J=9$} \\
\hline$K=3$ & 0.0174 & 3.48 & 0.0139 & 1.73 & 0.0035 & 1.84 \\
\hline$K=6$ & 0.0130 & 3.71 & 0.0078 & 1.47 & 0.0052 & 2.17 \\
\hline$K=9$ & 0.0116 & 3.33 & 0.0069 & 1.42 & 0.0047 & 1.17 \\
\hline$K=12$ & 0.0106 & 3.59 & 0.0039 & 1.46 & 0.0067 & 1.25 \\
\hline \multicolumn{7}{|l|}{$\mathrm{J}=12$} \\
\hline$K=3$ & 0.0155 & 3.62 & 0.0121 & 1.52 & 0.0034 & 1.91 \\
\hline$K=6$ & 0.0079 & 3.51 & 0.0087 & 1.33 & -0.0007 & -1.07 \\
\hline$K=9$ & 0.0077 & 3.27 & 0.0080 & 1.38 & -0.0003 & -0.74 \\
\hline $\mathrm{K}=12$ & 0.0109 & 3.45 & 0.0054 & 1.40 & 0.0055 & 1.31 \\
\hline
\end{tabular}


Table 3.4

\section{Average Returns of Patent Portfolios}

At the end of each month stocks are ranked in ascending order on the basis of the past $J$ months of firm issued patents and held for $K$ months. 10 decile equally-weighted portfolios of stocks are formed. Stocks in the top decile (decile 1) are stocks with high patents and stocks in the bottom decile (decile 10) are firms with low patents. The High-Low represents the zero-cost portfolio. The results are based on the data sample that merges CRSP, COMPUSTAT and patent data, and the period of the sample used is 1970:01 - 2001:12. The average monthly returns of these portfolios are presented in this table.

\begin{tabular}{|c|c|c|c|c|c|c|c|c|c|c|c|}
\hline$J=3$ & High & & & & & & & & & Low & High - Low \\
\hline$K=3$ & 0.0233 & 0.0133 & 0.0131 & 0.0130 & 0.0131 & 0.0132 & 0.0143 & 0.0132 & 0.0118 & 0.0134 & 0.0099 \\
\hline$K=6$ & 0.0113 & 0.0075 & 0.0093 & 0.0090 & 0.0066 & 0.0092 & 0.0096 & 0.0069 & 0.0083 & 0.0093 & 0.0020 \\
\hline$K=9$ & 0.0103 & 0.0114 & 0.0071 & 0.0075 & 0.0104 & 0.0071 & 0.0082 & 0.0108 & 0.0065 & 0.0012 & 0.0091 \\
\hline$K=12$ & 0.0097 & 0.0068 & -0.0047 & -0.0090 & 0.0057 & -0.0050 & -0.0082 & 0.0063 & -0.0055 & 0.0053 & 0.0044 \\
\hline $\mathrm{J}=6$ & High & & & & & & & & & & \\
\hline$K=3$ & 0.0179 & 0.0137 & 0.0137 & -0.0058 & 0.0129 & 0.0129 & -0.0057 & 0.0137 & 0.0120 & 0.0127 & 0.0052 \\
\hline$K=6$ & 0.0113 & 0.0072 & 0.0068 & -0.0047 & 0.0064 & 0.0064 & -0.0046 & 0.0072 & 0.0056 & 0.0107 & 0.0006 \\
\hline$K=9$ & 0.0114 & 0.0069 & 0.0089 & -0.0057 & 0.0061 & 0.0084 & -0.0054 & 0.0070 & 0.0078 & 0.0081 & 0.0033 \\
\hline$K=12$ & 0.0109 & 0.0086 & 0.0215 & 0.0073 & 0.0076 & 0.0212 & 0.0078 & 0.0084 & 0.0205 & 0.0065 & 0.0044 \\
\hline \multicolumn{12}{|l|}{$J=9$} \\
\hline$K=3$ & 0.0174 & 0.0170 & 0.0145 & -0.0176 & 0.0053 & 0.0142 & -0.0057 & 0.0104 & 0.0082 & 0.0139 & 0.0035 \\
\hline$K=6$ & 0.0130 & 0.0090 & 0.0092 & -0.0053 & 0.0080 & 0.0087 & -0.0049 & 0.0091 & 0.0077 & 0.0078 & 0.0052 \\
\hline$K=9$ & 0.0116 & 0.0080 & 0.0097 & 0.0092 & 0.0069 & 0.0094 & 0.0098 & 0.0079 & 0.0084 & 0.0069 & 0.0047 \\
\hline$K=12$ & 0.0106 & 0.0084 & 0.0055 & 0.0088 & 0.0074 & 0.0054 & 0.0095 & 0.0082 & 0.0044 & 0.0039 & 0.0067 \\
\hline \multicolumn{12}{|l|}{$\mathrm{J}=12$} \\
\hline$K=3$ & 0.0155 & 0.0148 & 0.0074 & -0.0018 & 0.0088 & 0.0073 & -0.0016 & 0.0100 & 0.0058 & 0.0121 & 0.0034 \\
\hline$K=6$ & 0.0079 & 0.0093 & 0.0082 & 0.0077 & 0.0083 & 0.0080 & 0.0083 & 0.0091 & 0.0067 & 0.0087 & -0.0007 \\
\hline$K=9$ & 0.0077 & 0.0074 & 0.0089 & 0.0076 & 0.0062 & 0.0089 & 0.0081 & 0.0069 & 0.0078 & 0.0080 & -0.0003 \\
\hline$K=12$ & 0.0109 & 0.0057 & 0.0077 & 0.0095 & 0.0044 & 0.0077 & 0.0102 & 0.0051 & 0.0067 & 0.0054 & 0.0055 \\
\hline
\end{tabular}


Table 3.5

\section{Uncorrected Average Returns and Corrected Average Returns from Patent Trading Strategy}

At the end of each month stocks are ranked in ascending order on the basis of the past 3 months of firm issued patents and held for 3 months. 10 decile equally-weighted portfolios of stocks are formed. Stocks in the top decile (decile 1) are stocks with high patents and stocks in the bottom decile (decile 10) are firms with low patents. The High-Low represents the zero-cost portfolio. The results are based on the data sample that merges CRSP, COMPUSTAT and patent data, and the period of the sample used is 1970:01 - 2001:12. Panel A present results of raw average returns, uncorrected for risk. Exret is the estimated average returns minus risk free rate for the 10 decile portfolios and the zero-cost portfolios. Panel B present results from the time series regression of portfolio returns minus risk free rate against excess market returns and a constant term. Exmkt is the aggregate market returns from Kenneth French’s data library minus the risk free rate.

\begin{tabular}{|c|c|}
\hline \multicolumn{2}{|l|}{ Panel A } \\
\hline & Exret \\
\hline High & 0.022 \\
\hline 2 & 0.016 \\
\hline 3 & 0.017 \\
\hline 4 & 0.016 \\
\hline 5 & 0.016 \\
\hline 6 & 0.016 \\
\hline 7 & 0.018 \\
\hline 8 & 0.015 \\
\hline 9 & 0.016 \\
\hline Low & 0.014 \\
\hline High - Low & 0.008 \\
\hline
\end{tabular}

\begin{tabular}{|c|c|c|}
\hline \multirow[b]{2}{*}{$B$} & \multicolumn{2}{|c|}{ Coefficients } \\
\hline & Constant & Exmkt \\
\hline High & 0.020 & 0.997 \\
\hline 2 & 0.016 & 0.948 \\
\hline 3 & 0.016 & 0.957 \\
\hline 4 & 0.016 & 0.970 \\
\hline 5 & 0.015 & 0.948 \\
\hline 6 & 0.016 & 0.953 \\
\hline 7 & 0.017 & 0.936 \\
\hline 8 & 0.016 & 0.888 \\
\hline 9 & 0.015 & 0.844 \\
\hline Low & 0.012 & 0.897 \\
\hline High - Low & 0.008 & 0.100 \\
\hline
\end{tabular}

\begin{tabular}{rr}
\hline \multicolumn{2}{c}{ T-values } \\
Constant & Exmkt \\
\hline \hline 9.41 & 8.79 \\
7.51 & 7.43 \\
7.80 & 7.64 \\
6.49 & 7.42 \\
7.77 & 8.09 \\
8.60 & 8.54 \\
7.70 & 8.27 \\
7.54 & 8.47 \\
7.51 & 7.81 \\
5.59 & 7.50 \\
\hline 5.05 & 2.91 \\
\hline \hline
\end{tabular}


Table 3.6

\section{Average Returns from Patent Trading Strategy Corrected for Fama-French Three Factors}

At the end of each month stocks are ranked in ascending order on the basis of the past 3 months of firm issued patents and held for 3 months. 10 decile equally-weighted portfolios of stocks are formed. Stocks in the top decile (decile 1) are stocks with high patents and stocks in the bottom decile (decile 10) are firms with low patents. The High-Low represents the zero-cost portfolio. The results are based on the data sample that merges CRSP, COMPUSTAT and patent data, and the period of the sample used is 1970:01 - 2001:12. Results presented is from the time series regression of portfolio returns minus risk free rate against excess market returns, Fama-French size and value factors, and a constant term. Exmkt is the aggregate market returns from Kenneth French's data library minus the risk free rate. SMB and HML are the size and the value factor from Kenneth French's data library.

\begin{tabular}{|c|c|c|c|c|}
\hline & \multicolumn{4}{|c|}{ Coefficients } \\
\hline & Constant & Exmkt & $S M B$ & $H M L$ \\
\hline High & 0.021 & 0.981 & 0.425 & -0.294 \\
\hline 2 & 0.015 & 0.802 & 0.228 & -0.336 \\
\hline 3 & 0.017 & 0.778 & 0.205 & -0.487 \\
\hline 4 & 0.015 & 0.853 & -0.009 & -0.421 \\
\hline 5 & 0.015 & 0.834 & 0.083 & -0.328 \\
\hline 6 & 0.016 & 0.754 & 0.152 & -0.428 \\
\hline 7 & 0.017 & 0.861 & -0.127 & -0.435 \\
\hline 8 & 0.015 & 0.852 & -0.070 & -0.364 \\
\hline 9 & 0.015 & 0.783 & -0.177 & -0.435 \\
\hline Low & 0.014 & 0.732 & -0.122 & -0.631 \\
\hline High - Low & 0.007 & 0.249 & 0.547 & -0.925 \\
\hline
\end{tabular}

\begin{tabular}{rrrr}
\hline \multicolumn{5}{c}{ T-value } \\
Constant & Exmkt & \multicolumn{1}{c}{ SMB } & \multicolumn{1}{c}{ HML } \\
\hline \hline 9.33 & 6.49 & 1.92 & -1.06 \\
7.32 & 5.80 & 1.26 & -1.61 \\
7.43 & 5.49 & 1.09 & -2.28 \\
6.60 & 6.48 & -0.07 & -2.11 \\
7.64 & 6.81 & 0.54 & -1.74 \\
9.18 & 6.18 & 0.97 & -2.34 \\
7.75 & 6.66 & -0.75 & -2.23 \\
8.39 & 7.40 & -0.50 & -2.03 \\
7.76 & 6.47 & -1.11 & -2.28 \\
6.47 & 5.89 & -0.74 & -3.35 \\
\hline 5.65 & 3.23 & 2.20 & -3.32 \\
\hline \hline
\end{tabular}


Table 3.7

\section{Average Returns from Patent Trading Strategy Corrected for Fama-French Three Factors and Momentum Factor}

At the end of each month stocks are ranked in ascending order on the basis of the past 3 months of firm issued patents and held for 3 months. 10 decile equally-weighted portfolios of stocks are formed. Stocks in the top decile (decile 1) are stocks with high patents and stocks in the bottom decile (decile 10) are firms with low patents. The High-Low represents the zero-cost portfolio. The results are based on the data sample that merges CRSP, COMPUSTAT and patent data, and the period of the sample used is 1970:01 - 2001:12. Results presented is from the time series regression of portfolio returns minus risk free rate against excess market returns, Fama-French size, value and momentum factors, and a constant term. Exmkt is the aggregate market returns from Kenneth French's data library minus the risk free rate. SMB, HML and MOM are the size, value and momentum factors from Kenneth French's data library.

\begin{tabular}{|c|c|c|c|c|c|}
\hline & \multicolumn{5}{|c|}{ Coefficients } \\
\hline & Constant & Exmkt & $S M B$ & $H M L$ & MOM \\
\hline High & 0.015 & 0.743 & 0.129 & -0.456 & 0.949 \\
\hline 2 & 0.010 & 0.647 & 0.043 & -0.435 & 0.847 \\
\hline 3 & 0.011 & 0.657 & 0.056 & -0.564 & 0.679 \\
\hline 4 & 0.008 & 0.720 & -0.166 & -0.506 & 0.724 \\
\hline 5 & 0.009 & 0.723 & -0.070 & -0.414 & 0.699 \\
\hline 6 & 0.012 & 0.641 & 0.019 & -0.501 & 0.723 \\
\hline 7 & 0.011 & 0.757 & -0.244 & -0.502 & 0.715 \\
\hline 8 & 0.011 & 0.760 & -0.174 & -0.423 & 0.590 \\
\hline 9 & 0.011 & 0.700 & -0.269 & -0.488 & 0.489 \\
\hline Low & 0.012 & 0.747 & -0.094 & -0.621 & 0.344 \\
\hline High - Low & 0.003 & -0.004 & 0.223 & 0.165 & 0.605 \\
\hline
\end{tabular}

\begin{tabular}{rrrrr}
\hline \multicolumn{5}{c}{ T-value } \\
Constant & Exmkt & \multicolumn{1}{c}{ SMB } & \multicolumn{1}{c}{ HML } & MOM \\
\hline \hline 6.80 & 5.86 & 0.67 & -2.00 & 10.54 \\
5.04 & 5.07 & 0.25 & -2.27 & 8.56 \\
5.57 & 4.86 & 0.28 & -2.81 & 6.45 \\
4.47 & 5.79 & -1.02 & -2.72 & 7.51 \\
5.43 & 6.13 & -0.44 & -2.36 & 7.99 \\
7.19 & 5.50 & 0.15 & -2.90 & 6.82 \\
5.94 & 6.04 & -1.49 & -2.67 & 5.71 \\
6.58 & 6.81 & -1.25 & -2.46 & 5.73 \\
6.14 & 5.90 & -1.73 & -2.64 & 4.80 \\
6.46 & 5.96 & -0.57 & -3.30 & 1.61 \\
\hline 3.00 & -2.14 & 1.88 & 1.48 & 3.27 \\
\hline \hline
\end{tabular}


Table 3.8

\section{Average Returns from Patent Trading Strategy Corrected for Fama-French Three Factors and Patent Risk Factor}

At the end of each month stocks are ranked in ascending order on the basis of the past 3 months of firm issued patents and held for 3 months. 10 decile equally-weighted portfolios of stocks are formed. Stocks in the top decile (decile 1) are stocks with high patents and stocks in the bottom decile (decile 10) are firms with low patents. The High-Low represents the zero-cost portfolio. The results are based on the data sample that merges CRSP, COMPUSTAT and patent data, and the period of the sample used is 1970:01 - 2001:12. Patfact is the patent risk factor estimated by subtracting the average of the bottom $30 \%$ of portfolios formed based on past firm issued patents from the average of the top 30\% of portfolios. Results presented are from the time series regression of the portfolio returns minus risk free rate against excess market returns, size and value factors, patent risk factors and a constant term. Exmkt is the aggregate market returns from Kenneth French's data library minus the risk free rate. SMB and HML are the size and the value factors from Kenneth French's data library.

\begin{tabular}{|c|c|c|c|c|c|}
\hline & \multicolumn{5}{|c|}{ Coefficients } \\
\hline & Constant & Exmkt & $S M B$ & $H M L$ & Patfact \\
\hline High & 0.014 & 0.713 & 0.054 & -0.445 & 0.935 \\
\hline 2 & 0.011 & 0.665 & 0.009 & -0.425 & 0.897 \\
\hline 3 & 0.012 & 0.667 & 0.029 & -0.559 & 0.817 \\
\hline 4 & 0.011 & 0.750 & -0.173 & -0.488 & 0.716 \\
\hline 5 & 0.011 & 0.750 & -0.084 & -0.398 & 0.661 \\
\hline 6 & 0.013 & 0.664 & 0.010 & -0.486 & 0.846 \\
\hline 7 & 0.014 & 0.789 & -0.241 & -0.482 & 0.756 \\
\hline 8 & 0.013 & 0.780 & -0.184 & -0.411 & 0.614 \\
\hline 9 & 0.013 & 0.727 & -0.266 & -0.471 & 0.517 \\
\hline Low & 0.013 & 0.775 & -0.053 & -0.603 & 0.454 \\
\hline High - Low & 0.001 & -0.062 & 0.107 & 0.158 & 0.481 \\
\hline
\end{tabular}

\begin{tabular}{rrrrr}
\hline \multicolumn{5}{c}{ T-value } \\
Constant & Exmkt & SMB & HML & Patfact \\
\hline \hline 7.17 & 6.19 & 0.31 & -2.03 & 9.83 \\
5.27 & 5.25 & 0.06 & -2.23 & 8.82 \\
5.70 & 4.96 & 0.13 & -2.79 & 6.77 \\
4.86 & 5.97 & -1.05 & -2.59 & 6.68 \\
5.79 & 6.32 & -0.53 & -2.24 & 7.38 \\
7.53 & 5.68 & 0.08 & -2.78 & 6.21 \\
6.37 & 6.23 & -1.45 & -2.53 & 4.60 \\
6.89 & 6.96 & -1.31 & -2.37 & 5.30 \\
6.54 & 6.08 & -1.68 & -2.52 & 3.80 \\
7.07 & 6.24 & -0.32 & -3.22 & 2.85 \\
\hline 3.59 & -1.46 & 1.27 & 1.40 & 3.64 \\
\hline \hline
\end{tabular}


Table 3.9

\section{Average Returns from Patent Trading Strategy Corrected for Fama-French Three Factors, Momentum Factor and Patent Risk Factor}

At the end of each month stocks are ranked in ascending order on the basis of the past 3 months of firm issued patents and held for 3 months. 10 decile equally-weighted portfolios of stocks are formed. Stocks in the top decile (decile 1) are stocks with high patents and stocks in the bottom decile (decile 10) are firms with low patents. The High-Low represents the zero-cost portfolio. The results are based on the data sample that merges CRSP, COMPUSTAT and patent data, and the period of the sample used is 1970:01 - 2001:12. Patfact is the patent risk factor estimated by subtracting the average of the bottom $30 \%$ of portfolios formed based on past firm issued patents from the average of the top 30\% of portfolios. Results presented are from the time series regression of the portfolio returns minus risk free rate against excess market returns, size and value factors, momentum factor, patent risk factors and a constant term. M-beta is the estimated market beta from the regression. SMB, HML and MOM are the size, value and momentum factors taken from Kenneth French data library.

\begin{tabular}{lr|rrrrrr}
\hline & & \multicolumn{6}{|c}{ Coefficients } \\
& & Constant & Exmkt & SMB & HML & MOM & Patfact \\
\hline \hline \multirow{2}{*}{ High } & & 0.016 & 0.868 & 0.043 & -0.607 & 0.535 & 0.928 \\
& 2 & 0.011 & 0.594 & 0.012 & -0.393 & 0.415 & 0.859 \\
& 3 & 0.013 & 0.638 & 0.093 & -0.519 & 0.244 & 0.726 \\
& 4 & 0.013 & 0.714 & -0.230 & -0.507 & 0.618 & 0.491 \\
& 5 & 0.011 & 0.662 & -0.051 & -0.458 & 0.552 & 0.544 \\
& 6 & 0.013 & 0.590 & 0.036 & -0.532 & 0.486 & 0.567 \\
& 7 & 0.014 & 0.722 & -0.236 & -0.505 & 0.626 & 0.412 \\
& 8 & 0.013 & 0.747 & -0.243 & -0.354 & 0.405 & 0.482 \\
Low & 9 & 0.012 & 0.657 & -0.250 & -0.352 & 0.509 & 0.257 \\
\hline \multicolumn{2}{l|}{ High-Low } & 0.013 & 0.717 & -0.034 & -0.594 & 0.477 & 0.228 \\
\hline \hline
\end{tabular}

\begin{tabular}{rrrrrr}
\hline \multicolumn{6}{c}{$T$-value } \\
Constant & Exmkt & SMB & HML & MOM & Patfact \\
\hline \hline 6.68 & 5.91 & 0.23 & -2.76 & 3.41 & 8.81 \\
4.15 & 4.68 & 0.08 & -2.07 & 3.07 & 6.62 \\
5.05 & 4.56 & 0.51 & -2.48 & 1.63 & 5.42 \\
3.35 & 5.80 & -1.43 & -2.75 & 4.70 & 4.30 \\
4.85 & 5.80 & -0.34 & -2.68 & 4.53 & 4.92 \\
6.52 & 5.29 & 0.25 & -3.18 & 4.08 & 4.04 \\
5.28 & 5.91 & -1.48 & -2.77 & 4.80 & 2.46 \\
5.91 & 7.03 & -1.75 & -2.23 & 3.57 & 3.31 \\
5.04 & 5.86 & -1.71 & -2.10 & 4.25 & 2.01 \\
6.13 & 6.02 & -0.22 & -3.33 & 3.75 & 2.24 \\
\hline 3.29 & 2.63 & 1.01 & -0.15 & 0.92 & 3.04 \\
\hline \hline
\end{tabular}


Table 3.10

\section{Average Returns from Patent Trading Strategy Corrected for Patent Risk Factor}

At the end of each month stocks are ranked in ascending order on the basis of the past 3 months of firm issued patents and held for 3 months. 10 decile equally-weighted portfolios of stocks are formed. Stocks in the top decile (decile 1) are stocks with high patents and stocks in the bottom decile (decile 10) are firms with low patents. The High-Low represents the zero-cost portfolio. The results are based on the data sample that merges CRSP, COMPUSTAT and patent data, and the period of the sample used is 1970:01 - 2001:12. Patfact is the patent risk factor estimated by subtracting the average of the bottom $30 \%$ of portfolios formed based on past firm issued patents from the average of the top 30\% of portfolios. Results presented are from the time series regression of portfolio returns minus risk free rate against patent risk factors and a constant term.

\begin{tabular}{lr|cc}
\hline & & \multicolumn{2}{|c}{ Coefficients } \\
& & Constant & Patfact \\
\hline \hline High & & 0.013 & 0.798 \\
& 2 & 0.010 & 0.760 \\
& 3 & 0.011 & 0.714 \\
& 4 & 0.010 & 0.611 \\
& 5 & 0.010 & 0.604 \\
& 6 & 0.012 & 0.547 \\
& 7 & 0.013 & 0.589 \\
& 8 & 0.012 & 0.419 \\
& 9 & 0.012 & 0.226 \\
Low & & 0.012 & 0.272 \\
\hline High - Low & 0.001 & 0.526 \\
\hline \hline
\end{tabular}

\begin{tabular}{rr}
\hline \multicolumn{2}{c}{ T-value } \\
Constant & Patfact \\
\hline \hline 6.15 & 6.89 \\
4.24 & 8.89 \\
4.57 & 6.89 \\
3.84 & 7.19 \\
4.71 & 7.95 \\
6.16 & 6.89 \\
5.32 & 5.18 \\
5.68 & 5.89 \\
5.43 & 4.38 \\
5.64 & 1.59 \\
\hline 2.04 & 3.79 \\
\hline \hline
\end{tabular}




\section{Table 3.11}

\section{Average Returns from Patent Trading Strategy Corrected for Market and Patent Risk Factor}

At the end of each month stocks are ranked in ascending order on the basis of the past 3 months of firm issued patents and held for 3 months. 10 decile equally-weighted portfolios of stocks are formed. Stocks in the top decile (decile 1) are stocks with high patents and stocks in the bottom decile (decile 10) are firms with low patents. The High-Low represents the zero-cost portfolio. The results are based on the data sample that merges CRSP, COMPUSTAT and patent data, and the period of the sample used is 1970:01 - 2001:12. Patfact is the patent risk factor estimated by subtracting the average of the bottom $30 \%$ of portfolios formed based on past firm issued patents from the average of the top 30\% of portfolios. Results presented are from the time series regression of portfolio returns minus risk free rate against excess market returns, patent risk factors and a constant term. Exmkt is the aggregate market returns from Kenneth French's data library minus the risk free rate.

\begin{tabular}{lr|rcc}
\hline & & \multicolumn{3}{|c}{ Coefficients } \\
& & Constant & Exmkt & Paffact \\
\hline \hline High & & 0.014 & 0.902 & 0.940 \\
& 2 & 0.010 & 0.721 & 0.896 \\
& 3 & 0.012 & 0.749 & 0.770 \\
& 4 & 0.011 & 0.801 & 0.726 \\
& 5 & 0.011 & 0.809 & 0.704 \\
& 6 & 0.012 & 0.742 & 0.683 \\
& 7 & 0.014 & 0.839 & 0.736 \\
& 8 & 0.013 & 0.809 & 0.695 \\
& 9 & 0.013 & 0.754 & 0.497 \\
Low & & 0.013 & 0.856 & 0.461 \\
\hline \multicolumn{1}{l|}{ High-Low } & 0.001 & 0.046 & 0.479 \\
\hline \hline
\end{tabular}

\begin{tabular}{rrr}
\hline \multicolumn{3}{c}{ T-value } \\
Constant & Exmkt & Patfact \\
\hline \hline 6.92 & 7.18 & 8.85 \\
5.10 & 6.01 & 8.84 \\
5.45 & 5.87 & 6.80 \\
4.67 & 6.76 & 6.58 \\
5.58 & 7.22 & 7.36 \\
7.23 & 6.73 & 6.21 \\
6.20 & 7.01 & 4.49 \\
6.80 & 7.67 & 5.18 \\
6.46 & 6.69 & 3.68 \\
6.76 & 7.31 & 2.89 \\
\hline 3.60 & 2.95 & 3.47 \\
\hline \hline
\end{tabular}


Table 3.12

\section{Uncorrected Average Returns and Corrected Average Returns from Momentum Trading Strategy}

At the end of each month stocks are ranked in ascending order on the basis of the past 12 months of firm returns and held for 6 months. 10 decile equally-weighted portfolios of stocks are formed. Stocks in the top decile (decile 1) are stocks with high returns and stocks in the bottom decile (decile 10) are firms with low returns. The High-Low represents the zero-cost portfolio. The results are based on the data sample that merges CRSP, COMPUSTAT and patent data, and the period of the sample used is 1970:01 - 2001:12. Panel A present results of raw average returns, uncorrected for risk. Exret is the estimated average returns minus risk free rate for the 10 decile portfolios and the zero cost portfolios. Panel B present results from the time series regression of portfolio returns minus risk free rate against excess market returns and a constant term. Exmkt is the aggregate market returns from Kenneth French's data library minus the risk free rate.

\begin{tabular}{ll|l}
\multicolumn{2}{l}{ Panel } & \multicolumn{2}{l}{ A } & \multicolumn{2}{l}{ Exret } \\
\hline \hline High & & 0.026 \\
& 2 & 0.023 \\
& 3 & 0.021 \\
& 4 & 0.017 \\
& 5 & 0.016 \\
& 6 & 0.017 \\
& 7 & 0.017 \\
& 8 & 0.015 \\
& 9 & 0.017 \\
Low & & 0.015 \\
\hline High - Low & 0.010 \\
\hline \hline
\end{tabular}

\begin{tabular}{lr|rr}
\hline \multicolumn{2}{l|}{$\begin{array}{l}\text { Panel } \\
\text { B }\end{array}$} & \multicolumn{2}{c}{ Coefficients } \\
High & & 0.025 & 0.963 \\
& 2 & 0.023 & 1.004 \\
& 3 & 0.021 & 0.991 \\
& 4 & 0.018 & 0.984 \\
& 5 & 0.016 & 0.978 \\
& 6 & 0.016 & 1.013 \\
& 7 & 0.016 & 0.961 \\
& 8 & 0.016 & 0.927 \\
& 9 & 0.016 & 0.937 \\
Low & & 0.012 & 0.959 \\
\hline High - Low & 0.013 & 0.004 \\
\hline \hline \multicolumn{2}{l}{}
\end{tabular}

\begin{tabular}{rr}
\hline \multicolumn{2}{c}{ T-values } \\
Constant & Exmkt \\
\hline \hline 8.16 & 8.47 \\
7.55 & 7.73 \\
7.83 & 7.94 \\
7.06 & 7.16 \\
7.50 & 7.72 \\
7.69 & 8.27 \\
7.43 & 7.98 \\
6.79 & 7.72 \\
7.36 & 7.75 \\
6.13 & 7.39 \\
\hline 4.94 & 4.79 \\
\hline \hline
\end{tabular}


Table 3.13

\section{Average Returns from Momentum Trading Strategy Corrected for Fama-French Three Factors}

At the end of each month stocks are ranked in ascending order on the basis of the past 12 months of firm returns and held for 6 months. 10 decile equally-weighted portfolios of stocks are formed. Stocks in the top decile (decile 1) are stocks with high returns and stocks in the bottom decile (decile 10) are firms with low returns. The High-Low represents the zero-cost portfolio. The results are based on the data sample that merges CRSP, COMPUSTAT and patent data, and the period of the sample used is 1970:01 - 2001:12. Results presented is from the time series regression of portfolio returns minus risk free rate against excess market returns, Fama-French size and value factors, and a constant term. Exmkt is the aggregate market returns from Kenneth French's data library minus the risk free rate. SMB and HML are the size and the value factors from Kenneth French's data library.

\begin{tabular}{lr|rccc}
\hline & & \multicolumn{4}{|c}{ Coefficients } \\
& & Constant & Exmkt & SMB & HML \\
\hline \hline High & & 0.026 & 0.973 & 0.451 & -0.309 \\
& 2 & 0.022 & 0.919 & 0.364 & -0.416 \\
& 3 & 0.020 & 0.899 & 0.330 & -0.487 \\
& 4 & 0.015 & 0.920 & 0.280 & -0.437 \\
& 5 & 0.016 & 0.927 & 0.277 & -0.369 \\
& 6 & 0.017 & 0.895 & 0.318 & -0.424 \\
& 7 & 0.016 & 0.936 & 0.186 & -0.459 \\
& 8 & 0.015 & 0.922 & 0.241 & -0.444 \\
& 9 & 0.016 & 0.903 & 0.155 & -0.512 \\
Low & & 0.014 & 0.873 & 0.179 & -0.555 \\
\hline \multicolumn{1}{l|}{ High - Low } & 0.012 & 0.100 & 0.272 & 0.246 \\
\hline \hline \multicolumn{4}{l}{} \\
& & & & &
\end{tabular}

\begin{tabular}{rrrr}
\hline \multicolumn{5}{c}{ T-values } \\
Constant & Exmkt & SMB & HML \\
\hline \hline 8.19 & 7.74 & 1.98 & -0.66 \\
7.48 & 7.53 & 1.43 & -1.94 \\
7.49 & 7.35 & 0.88 & -2.77 \\
7.23 & 7.66 & 0.37 & -2.58 \\
7.45 & 7.98 & 0.45 & -2.27 \\
8.26 & 7.61 & 0.87 & -2.58 \\
7.57 & 7.82 & -0.68 & -2.63 \\
7.81 & 8.02 & -0.39 & -2.69 \\
7.78 & 7.68 & -0.87 & -2.96 \\
6.91 & 7.41 & -0.72 & -3.22 \\
\hline 5.89 & 6.07 & 3.66 & 3.87 \\
\hline \hline
\end{tabular}


Table 3.14

\section{Average Returns from Momentum Trading Strategy Corrected for Patent Risk Factor}

At the end of each month stocks are ranked in ascending order on the basis of the past 12 months of firm returns and held for 6 months. 10 decile equally-weighted portfolios of stocks are formed. Stocks in the top decile (decile 1) are stocks with high returns and stocks in the bottom decile (decile 10) are firms with low returns. The High-Low represents the zero-cost portfolio. The results are based on the data sample that merges CRSP, COMPUSTAT and patent data, and the period of the sample used is 1970:01 - 2001:12. Patfact is the patent risk factor estimated by subtracting the average of the bottom $30 \%$ of portfolios formed based on past firm issued patents from the average of the top 30\% of portfolios. Results presented are from the time series regression of portfolio returns minus risk free rate against patent risk factors and a constant term.

\begin{tabular}{lr|rr}
\hline & & \multicolumn{2}{|c}{ Coefficients } \\
& & Constant & Patfact \\
\hline \hline High & & 0.011 & 0.912 \\
& 2 & 0.009 & 0.828 \\
& 3 & 0.009 & 0.757 \\
& 4 & 0.007 & 0.662 \\
& 5 & 0.009 & 0.629 \\
& 6 & 0.012 & 0.664 \\
& 7 & 0.012 & 0.619 \\
& 8 & 0.012 & 0.474 \\
& 9 & 0.011 & 0.331 \\
Low & & 0.012 & 0.343 \\
\hline \multicolumn{1}{l|}{ High-Low } & -0.001 & 0.569 \\
\hline \hline
\end{tabular}

\begin{tabular}{rr}
\hline \multicolumn{2}{c}{$T$-values } \\
Constant & Patfact \\
\hline \hline 6.22 & 8.73 \\
4.84 & 8.88 \\
5.01 & 7.54 \\
4.59 & 7.64 \\
5.00 & 8.05 \\
6.70 & 6.90 \\
5.70 & 5.13 \\
6.08 & 5.22 \\
6.19 & 4.14 \\
6.16 & 2.04 \\
\hline-0.46 & 4.74 \\
\hline \hline
\end{tabular}


Table 3.15

\section{Average Returns from Momentum Trading Strategy Corrected for Fama-French Three Factors and Patent Risk Factor}

At the end of each month stocks are ranked in ascending order on the basis of the past 12 months of firm returns and held for 6 months. 10 decile equally-weighted portfolios of stocks are formed. Stocks in the top decile (decile 1) are stocks with high returns and stocks in the bottom decile (decile 10) are firms with low returns. The High-Low represents the zero-cost portfolio. The results are based on the data sample that merges CRSP, COMPUSTAT and patent data, and the period of the sample used is 1970:01 - 2001:12. Patfact is the patent risk factor estimated by subtracting the average of the bottom $30 \%$ of portfolios formed based on past firm issued patents from the average of the top 30\% of portfolios. Results presented are from the time series regression of the portfolio returns minus risk free rate against excess market returns, size and value factors, patent risk factors and a constant term. Exmkt is the aggregate market returns from Kenneth French's data library minus the risk free rate. SMB and HML are the size and the value factors from Kenneth French's data library.

\begin{tabular}{lr|rrrrr}
\hline & & \multicolumn{5}{|c}{ Coefficients } \\
& & Constant & Exmkt & SMB & HML & Patfact \\
\hline \hline High & & 0.012 & 0.826 & 0.230 & -0.248 & 0.928 \\
& 2 & 0.009 & 0.768 & 0.115 & -0.437 & 0.828 \\
& 3 & 0.009 & 0.736 & 0.061 & -0.574 & 0.737 \\
& 4 & 0.007 & 0.783 & -0.031 & -0.471 & 0.662 \\
& 5 & 0.009 & 0.819 & -0.034 & -0.335 & 0.633 \\
& 6 & 0.012 & 0.740 & 0.057 & -0.439 & 0.664 \\
& 7 & 0.012 & 0.834 & -0.190 & -0.488 & 0.662 \\
& 8 & 0.012 & 0.809 & -0.074 & -0.471 & 0.497 \\
& 9 & 0.011 & 0.776 & -0.239 & -0.603 & 0.331 \\
Low & & 0.011 & 0.766 & -0.109 & -0.656 & 0.344 \\
\hline \multicolumn{2}{l|}{ High- Low } & 0.001 & 0.061 & 0.339 & 0.408 & 0.584 \\
\hline \hline
\end{tabular}

\begin{tabular}{rrrrr}
\hline \multicolumn{5}{c}{ T-Value } \\
Constant & Exmkt & \multicolumn{1}{c}{ SMB } & \multicolumn{1}{c}{ HML } & Patfact \\
\hline \hline 7.66 & 6.32 & 1.16 & -1.05 & 8.73 \\
4.32 & 5.78 & 0.64 & -2.21 & 8.88 \\
6.44 & 5.44 & 0.29 & -2.85 & 7.54 \\
5.93 & 6.05 & -0.20 & -2.42 & 7.64 \\
4.33 & 6.72 & -0.18 & -1.80 & 8.05 \\
8.07 & 5.97 & 0.37 & -2.38 & 6.90 \\
6.82 & 6.41 & -1.12 & -2.41 & 5.13 \\
4.81 & 6.81 & -0.55 & -2.54 & 5.22 \\
4.83 & 6.15 & -1.43 & -3.04 & 4.14 \\
6.48 & 5.98 & -0.64 & -3.38 & 2.04 \\
\hline 3.39 & 2.86 & 2.42 & 3.33 & 4.54 \\
\hline \hline
\end{tabular}


Table 3.16

\section{Average Returns from Momentum Trading Strategy Corrected for Fama-French Three Factors and Momentum Factor}

At the end of each month stocks are ranked in ascending order on the basis of the past 12 months of firm returns and held for 6 months. 10 decile equally-weighted portfolios of stocks are formed. Stocks in the top decile (decile 1) are stocks with high returns and stocks in the bottom decile (decile 10) are firms with low returns. The High-Low represents the zero-cost portfolio. The results are based on the data sample that merges CRSP, COMPUSTAT and patent data, and the period of the sample used is 1970:01 - 2001:12. Results presented are from the time series regression of the portfolio returns minus risk free rate against excess market returns, size and value factors, patent risk factors and a constant term. Exmkt is the aggregate market returns from Kenneth French's data library minus the risk free rate. SMB, HML and MOM are the size, value and momentum factors taken from Kenneth French data library.

\begin{tabular}{|c|c|c|c|c|c|}
\hline & \multicolumn{5}{|c|}{ Coefficients } \\
\hline & Constant & Exmkt & $S M B$ & $H M L$ & MOM \\
\hline High & 0.015 & 0.743 & 0.129 & -0.456 & 0.949 \\
\hline 2 & 0.010 & 0.647 & 0.043 & -0.435 & 0.847 \\
\hline 3 & 0.011 & 0.657 & 0.056 & -0.564 & 0.679 \\
\hline 4 & 0.008 & 0.720 & -0.166 & -0.506 & 0.724 \\
\hline 5 & 0.009 & 0.723 & -0.070 & -0.414 & 0.699 \\
\hline 6 & 0.012 & 0.641 & 0.019 & -0.501 & 0.723 \\
\hline 7 & 0.011 & 0.757 & -0.244 & -0.502 & 0.715 \\
\hline 8 & 0.011 & 0.760 & -0.174 & -0.423 & 0.590 \\
\hline 9 & 0.011 & 0.700 & -0.269 & -0.488 & 0.489 \\
\hline Low & 0.012 & 0.747 & -0.094 & -0.621 & 0.344 \\
\hline High - Low & 0.003 & -0.004 & 0.223 & 0.165 & 0.605 \\
\hline
\end{tabular}

\begin{tabular}{rrrrr}
\hline \multicolumn{5}{c}{ T-Value } \\
Constant & Exmkt & \multicolumn{1}{c}{ SMB } & \multicolumn{1}{c}{ HML } & MOM \\
\hline \hline 7.06 & 5.57 & 0.67 & -1.52 & 6.14 \\
4.79 & 4.62 & 0.25 & -1.56 & 4.24 \\
5.63 & 4.54 & 0.28 & -1.94 & 2.96 \\
3.92 & 5.79 & -1.02 & -2.25 & 3.17 \\
5.49 & 5.78 & -0.44 & -2.16 & 4.03 \\
7.16 & 5.29 & 0.15 & -2.18 & 3.74 \\
5.78 & 5.90 & -1.49 & -2.27 & 2.54 \\
6.57 & 7.02 & -1.25 & -1.71 & 2.50 \\
5.58 & 5.85 & -1.73 & -1.61 & 2.00 \\
6.16 & 5.77 & -0.57 & -2.14 & 0.64 \\
\hline 3.41 & -1.39 & 1.88 & 0.52 & 3.20 \\
\hline \hline
\end{tabular}


Table 3.17

\section{Average Returns from Momentum Trading Strategy Corrected for Fama-French Three Factors, Momentum and Patent Risk Factors}

At the end of each month stocks are ranked in ascending order on the basis of the past 12 months of firm returns and held for 6 months. 10 decile equally-weighted portfolios of stocks are formed. Stocks in the top decile (decile 1) are stocks with high returns and stocks in the bottom decile (decile 10) are firms with low returns. The High-Low represents the zero-cost portfolio. The results are based on the data sample that merges CRSP, COMPUSTAT and patent data, and the period of the sample used is 1970:01 - 2001:12. Patfact is the patent risk factor estimated by subtracting the average of the bottom $30 \%$ of portfolios formed based on past firm issued patents from the average of the top 30\% of portfolios. Results presented are from the time series regression of the portfolio returns minus risk free rate against excess market returns, size and value factors, patent risk factors and a constant term. Exmkt is the aggregate market returns from Kenneth French's data library minus the risk free rate. SMB, HML and MOM are the size, value and momentum factors taken from Kenneth French data library.

\begin{tabular}{|c|c|c|c|c|c|c|}
\hline & \multicolumn{6}{|c|}{ Coefficients } \\
\hline & Constant & Exmkt & $S M B$ & $H M L$ & MOM & Patfact \\
\hline High & 0.013 & 0.786 & 0.052 & -0.462 & 0.725 & 0.894 \\
\hline 2 & 0.010 & 0.644 & 0.008 & -0.438 & 0.655 & 0.859 \\
\hline 3 & 0.011 & 0.655 & 0.028 & -0.567 & 0.522 & 0.706 \\
\hline 4 & 0.009 & 0.719 & -0.176 & -0.507 & 0.669 & 0.491 \\
\hline 5 & 0.010 & 0.722 & -0.086 & -0.415 & 0.612 & 0.548 \\
\hline 6 & 0.011 & 0.639 & 0.008 & -0.502 & 0.662 & 0.567 \\
\hline 7 & 0.010 & 0.757 & -0.243 & -0.502 & 0.718 & 0.455 \\
\hline 8 & 0.009 & 0.759 & -0.186 & -0.424 & 0.522 & 0.506 \\
\hline 9 & 0.010 & 0.701 & -0.268 & -0.488 & 0.496 & 0.257 \\
\hline Low & 0.011 & 0.750 & -0.055 & -0.618 & 0.456 & 0.229 \\
\hline High - Low & 0.002 & 0.036 & 0.106 & 0.156 & 0.270 & 0.665 \\
\hline
\end{tabular}

\begin{tabular}{rrrrrr}
\hline \multicolumn{6}{c}{ T-value } \\
Constant & Exmkt & \multicolumn{1}{c}{ SMB } & \multicolumn{1}{c}{ HML } & MOM & Patfact \\
\hline \hline 7.09 & 5.90 & 0.23 & -2.77 & 3.42 & 7.85 \\
4.62 & 4.66 & 0.08 & -2.07 & 3.08 & 4.11 \\
5.48 & 4.55 & 0.51 & -2.48 & 1.64 & 3.04 \\
3.84 & 5.78 & -1.43 & -2.76 & 4.71 & 1.21 \\
5.37 & 5.78 & -0.34 & -2.68 & 4.54 & 2.06 \\
7.06 & 5.28 & 0.25 & -3.19 & 4.09 & 1.50 \\
5.77 & 5.89 & -1.48 & -2.77 & 4.81 & 0.07 \\
6.47 & 7.01 & -1.75 & -2.23 & 3.58 & 1.73 \\
5.57 & 5.84 & -1.71 & -2.11 & 4.26 & 0.16 \\
6.63 & 6.00 & -0.22 & -3.34 & 3.76 & 1.84 \\
\hline 2.46 & 1.15 & 1.25 & 1.09 & 0.94 & 4.01 \\
\hline \hline
\end{tabular}


Table 3.18

\section{Average Returns from Momentum Trading Strategy Corrected Market and Patent Risk Factors}

At the end of each month stocks are ranked in ascending order on the basis of the past 12 months of firm returns and held for 6 months. 10 decile equally-weighted portfolios of stocks are formed. Stocks in the top decile (decile 1) are stocks with high returns and stocks in the bottom decile (decile 10) are firms with low returns. The High-Low represents the zero-cost portfolio. The results are based on the data sample that merges CRSP, COMPUSTAT and patent data, and the period of the sample used is 1970:01 - 2001:12. Patfact is the patent risk factor estimated by subtracting the average of the bottom $30 \%$ of portfolios formed based on past firm issued patents from the average of the top 30\% of portfolios. Results presented are from the time series regression of the portfolio returns minus risk free rate against excess market returns, size and value factors, patent risk factors and a constant term. Exmkt is the aggregate market returns from Kenneth French's data library minus the risk free rate.

\begin{tabular}{|c|c|c|c|}
\hline & \multicolumn{3}{|c|}{ Coefficients } \\
\hline & Constant & Exmkt & Patfact \\
\hline High & 0.012 & 0.962 & 0.824 \\
\hline 2 & 0.009 & 0.823 & 0.688 \\
\hline 3 & 0.010 & 0.823 & 0.586 \\
\hline 4 & 0.009 & 0.892 & 0.626 \\
\hline 5 & 0.009 & 0.826 & 0.545 \\
\hline 6 & 0.011 & 0.831 & 0.367 \\
\hline 7 & 0.010 & 0.895 & 0.419 \\
\hline 8 & 0.010 & 0.850 & 0.462 \\
\hline 9 & 0.011 & 0.835 & 0.284 \\
\hline Low & 0.011 & 0.914 & 0.306 \\
\hline High - Low & 0.001 & 0.048 & 0.518 \\
\hline
\end{tabular}

\begin{tabular}{rrr}
\hline \multicolumn{3}{c}{ T-value } \\
Constant & Exmkt & Patfact \\
\hline \hline 7.30 & 8.21 & 7.93 \\
4.91 & 6.50 & 8.56 \\
5.39 & 6.56 & 5.80 \\
4.32 & 7.73 & 5.77 \\
5.79 & 7.95 & 6.94 \\
7.24 & 7.74 & 5.84 \\
6.30 & 7.84 & 4.13 \\
7.00 & 8.74 & 5.46 \\
6.21 & 7.43 & 3.50 \\
6.76 & 8.48 & 3.14 \\
\hline 3.84 & 2.20 & 5.19 \\
\hline \hline
\end{tabular}




\section{Robustness Tables}

Table 3.19

\section{Robustness: Average Returns of Patent Portfolios with T-Statistics}

At the end of each month stocks are ranked in ascending order on the basis of the past $\mathrm{J}$ - month citations of issued patents and held for K months. 10 decile equally-weighted portfolios of stocks are formed. Stocks in the top decile (HIGH) are stocks with high patent citations and stocks in the bottom decile (LOW) are firms with low patent citations. The High-Low represents the zero-cost portfolio. The results are based on the data sample that merges CRSP, COMPUSTAT and patent data, and the period of the sample used is 1970:01 - 2001:12. The value of J and K for the different strategies is indicated in the first column. The average monthly excess returns of the portfolios and the t-statistics are presented in the table

\begin{tabular}{|c|c|c|c|c|c|c|}
\hline & \multicolumn{2}{|c|}{ High } & \multicolumn{2}{|c|}{ Low } & \multicolumn{2}{|c|}{ High - Low } \\
\hline$J=3$ & Ret & T-Stat & Ret & T-Stat & Ret & T-Stat \\
\hline$C=3$ & 0.0155 & 3.507 & 0.0130 & 1.414 & 0.0025 & 2.030 \\
\hline$C=6$ & 0.0132 & 2.439 & 0.0140 & 0.956 & -0.0008 & -0.084 \\
\hline$C=9$ & 0.0102 & 2.455 & 0.0089 & 0.708 & 0.0013 & 0.150 \\
\hline$C=12$ & 0.0104 & 2.052 & 0.0081 & 0.615 & 0.0023 & 1.070 \\
\hline \multicolumn{7}{|l|}{$\mathrm{J}=6$} \\
\hline$C=3$ & 0.0121 & 3.414 & 0.0087 & 1.314 & 0.0034 & 1.970 \\
\hline$C=6$ & 0.0102 & 2.844 & 0.0073 & 0.864 & 0.0029 & 1.150 \\
\hline$C=9$ & 0.0089 & 2.956 & 0.0108 & 0.649 & -0.0019 & -0.843 \\
\hline$C=12$ & 0.0080 & 2.655 & 0.0065 & 0.599 & 0.0015 & 1.480 \\
\hline \multicolumn{7}{|l|}{$\mathrm{J}=9$} \\
\hline$C=3$ & 0.0121 & 2.958 & 0.0093 & 1.324 & 0.0028 & 2.015 \\
\hline$C=6$ & 0.0094 & 3.191 & 0.0076 & 0.874 & 0.0018 & 1.151 \\
\hline$C=9$ & 0.0110 & 2.774 & 0.0104 & 0.681 & 0.0006 & 0.725 \\
\hline$C=12$ & 0.0096 & 2.976 & 0.0084 & 0.679 & 0.0012 & 1.544 \\
\hline \multicolumn{7}{|l|}{$\mathrm{J}=12$} \\
\hline$C=3$ & 0.0115 & 3.159 & 0.0087 & 1.179 & 0.0028 & 1.902 \\
\hline$C=6$ & 0.0087 & 3.040 & 0.0067 & 0.807 & 0.0020 & 1.011 \\
\hline$C=9$ & 0.0086 & 2.722 & 0.0079 & 0.662 & 0.0007 & 0.179 \\
\hline$C=12$ & 0.0089 & 2.863 & 0.0072 & 0.639 & 0.0017 & 1.219 \\
\hline
\end{tabular}


Table 3.20

\section{Robustness: Uncorrected Average Returns and Corrected Average Returns from Citation Trading Strategy}

At the end of each month stocks are ranked in ascending order on the basis of the past 3 months of firm citations and held for 3 months. 10 decile equally-weighted portfolios of stocks are formed. Stocks in the top decile (decile 1) are stocks with high citations and stocks in the bottom decile (decile 10) are firms with low citations. The High-Low represents the zero cost portfolio. The results are based on the data sample that merges CRSP, COMPUSTAT and patent data, and the period of the sample used is 1970:01 - 2001:12. Panel A present results of raw average returns, uncorrected for risk. Exret is the estimated average returns minus risk free rate for the 10 decile portfolios and the zero cost portfolios. Panel B present results from the time series regression of portfolio returns minus risk free rate against excess market returns and a constant term. Exmkt is the aggregate market returns from Kenneth French's data library minus the risk free rate.

\begin{tabular}{lr|c}
\multicolumn{2}{l}{ Panel A } \\
\multicolumn{4}{l}{ High } & & \multicolumn{1}{l}{ Exret } \\
\hline \hline & 2 & 0.0155 \\
& 3 & 0.0156 \\
& 4 & 0.0154 \\
& 5 & 0.0156 \\
& 6 & 0.0148 \\
& 7 & 0.0171 \\
& 8 & 0.0152 \\
& 9 & 0.0149 \\
Low & & 0.0175 \\
\hline High - Low & 0.0130 \\
\hline \hline
\end{tabular}

\begin{tabular}{lr|rr}
\hline \multicolumn{1}{l|}{ Panel B } & \multicolumn{2}{c}{ Coefficients } \\
& & Constant & Exmkt \\
\hline \hline High & & 0.0124 & 0.872 \\
& 2 & 0.0123 & 0.901 \\
& 3 & 0.0121 & 0.866 \\
& 4 & 0.0123 & 0.775 \\
& 5 & 0.0118 & 0.836 \\
& 6 & 0.0131 & 0.826 \\
& 7 & 0.0122 & 0.810 \\
& 8 & 0.0119 & 0.720 \\
& 9 & 0.0132 & 0.743 \\
Low & & 0.0102 & 0.642 \\
\hline High - Low & 0.0022 & 1.030 \\
\hline \hline \multicolumn{2}{l}{}
\end{tabular}

\begin{tabular}{rr}
\hline \multicolumn{2}{c}{$T$-values } \\
Constant & Exmkt \\
\hline \hline 7.50 & 7.82 \\
7.95 & 7.21 \\
7.09 & 7.73 \\
6.47 & 5.77 \\
7.68 & 7.19 \\
7.19 & 7.92 \\
8.26 & 7.19 \\
7.04 & 8.58 \\
6.96 & 7.59 \\
4.54 & 6.85 \\
\hline 2.52 & 1.67 \\
\hline \hline
\end{tabular}


Table 3.21

\section{Robustness: Average Returns from Citation Trading Strategy Corrected for Fama- French Three Factors}

At the end of each month stocks are ranked in ascending order on the basis of the past 3 months of firm citations and held for 3 months. 10 decile equally-weighted portfolios of stocks are formed. Stocks in the top decile (decile 1) are stocks with high citations and stocks in the bottom decile (decile 10) are firms with low citations. The High-Low represents the zero-cost portfolio. The results are based on the data sample that merges CRSP, COMPUSTAT and patent data, and the period of the sample used is 1970:01 - 2001:12. Results presented are from the time series regression of the portfolio returns minus risk free rate against excess market returns, size and value factors, and a constant term. Exmkt is the aggregate market returns from Kenneth French's data library minus the risk free rate. SMB and HML are the size and the value factor from Kenneth French's data library.

\begin{tabular}{lr|rrrr}
\hline & & \multicolumn{4}{|c}{ Coefficients } \\
& & \multicolumn{1}{|c}{ Constant } & Exmkt & \multicolumn{1}{l}{ SMB } & \multicolumn{1}{l}{ HML } \\
\hline \hline High & & 0.012 & 1.027 & 0.475 & 0.204 \\
& 2 & 0.011 & 0.866 & 0.413 & -0.502 \\
& 3 & 0.011 & 0.881 & 0.282 & -0.431 \\
& 4 & 0.010 & 0.966 & 0.216 & -0.468 \\
& 5 & 0.010 & 0.845 & 0.159 & -0.424 \\
& 6 & 0.013 & 0.943 & 0.143 & -0.409 \\
& 7 & 0.011 & 0.818 & -0.109 & -0.416 \\
& 8 & 0.010 & 0.872 & 0.053 & -0.575 \\
& 9 & 0.008 & 0.907 & -0.291 & -0.632 \\
Low & & 0.009 & 0.941 & -0.194 & -0.663 \\
\hline \multicolumn{2}{l|}{ High - Low } & 0.003 & 0.086 & 0.669 & 0.867 \\
\hline \hline
\end{tabular}

\begin{tabular}{rrrr}
\hline Constant & \multicolumn{4}{c}{$\begin{array}{c}\text { T-values } \\
\text { Exmkt }\end{array}$} & \multicolumn{1}{c}{ SMB } & \multicolumn{1}{l}{ HML } \\
\hline \hline 7.70 & 6.32 & 1.82 & 0.33 \\
6.90 & 6.20 & 1.40 & -2.22 \\
7.32 & 6.09 & 0.76 & -2.85 \\
6.10 & 5.97 & 1.02 & -2.25 \\
7.41 & 7.20 & 0.48 & -1.32 \\
7.64 & 6.47 & 0.85 & -2.02 \\
7.79 & 6.40 & -0.69 & -2.31 \\
7.14 & 6.79 & 0.35 & -2.83 \\
7.64 & 6.40 & -1.26 & -3.03 \\
6.48 & 5.59 & -1.13 & -4.03 \\
\hline 2.27 & 2.95 & 3.74 & 3.59 \\
\hline \hline
\end{tabular}


Table 3.22

\section{Robustness: Average Returns from Momentum Trading Strategy Corrected for Patent Risk Factor}

At the end of each month stocks are ranked in ascending order on the basis of the past 3 months of firm patent citations and held for 3 months. 10 decile equally-weighted portfolios of stocks are formed. Stocks in the top decile (decile 1) are stocks with high citations and stocks in the bottom decile (decile 10) are firms with low citations. The High-Low represents the zero-cost portfolio. The results are based on the data sample that merges CRSP, COMPUSTAT and patent data, and the period of the sample used is 1970:01 2001:12. Patfact is the patent risk factor estimated by subtracting the average of the bottom 30\% of portfolios formed based on past firm issued patents from the average of the top $30 \%$ of portfolios. Results presented are from the time series regression of portfolio returns minus risk free rate against patent risk factors and a constant term.

\begin{tabular}{lr|rr}
\hline & & \multicolumn{2}{|c}{ Coefficients } \\
& & Constant & Patfact \\
\hline \hline High & & 0.0085 & 0.758 \\
& 2 & 0.0084 & 0.619 \\
& 3 & 0.0084 & 0.577 \\
& 4 & 0.0081 & 0.529 \\
& 5 & 0.0074 & 0.467 \\
& 6 & 0.0087 & 0.262 \\
& 7 & 0.0070 & 0.169 \\
& 8 & 0.0064 & 0.223 \\
& 9 & 0.0093 & 0.110 \\
Low & & 0.0087 & 0.128 \\
\hline High - Low & -0.0002 & 0.630 \\
\hline \hline
\end{tabular}

\begin{tabular}{rr}
\hline \multicolumn{2}{c}{ T-values } \\
Constant & Patfact \\
\hline \hline 5.66 & 7.97 \\
4.57 & 9.10 \\
4.47 & 7.69 \\
4.50 & 8.00 \\
4.51 & 7.67 \\
6.22 & 6.95 \\
5.27 & 6.13 \\
2.45 & 5.50 \\
3.91 & 4.41 \\
2.53 & 0.98 \\
\hline-2.50 & 3.18 \\
\hline \hline
\end{tabular}


Table 3.23

\section{Robustness: Average Returns from Patent Trading Strategy Corrected for Market Risk and Patent Risk Factor}

At the end of each month stocks are ranked in ascending order on the basis of the past 3 months of firm patent citations and held for 3 months. 10 decile equally-weighted portfolios of stocks are formed. Stocks in the top decile (decile 1) are stocks with high citations and stocks in the bottom decile (decile 10) are firms with low citations. The High-Low represents the zero-cost portfolio. The results are based on the data sample that merges CRSP, COMPUSTAT and patent data, and the period of the sample used is 1970:01 2001:12. Patfact is the patent risk factor estimated by subtracting the average of the bottom $30 \%$ of portfolios formed based on past firm issued patents from the average of the top $30 \%$ of portfolios. Results presented are from the time series regression of portfolio returns minus risk free rate against excess market returns, patent risk factors and a constant term. Exmkt is the aggregate market returns from Kenneth French's data library minus the risk free rate.

\begin{tabular}{lr|rrr}
\hline & & \multicolumn{3}{|c}{ Coefficients } \\
& & Constant & Exmkt & Patfact \\
\hline \hline High & & 0.008 & 0.826 & 0.682 \\
& 2 & 0.008 & 0.901 & 0.478 \\
& 3 & 0.008 & 0.821 & 0.431 \\
& 4 & 0.008 & 0.907 & 0.518 \\
& 5 & 0.007 & 0.819 & 0.352 \\
& 6 & 0.009 & 0.870 & 0.203 \\
& 7 & 0.008 & 0.907 & 0.174 \\
& 8 & 0.008 & 0.855 & 0.171 \\
& 9 & 0.009 & 0.907 & 0.056 \\
Low & & 0.009 & 0.902 & 0.124 \\
\hline \multicolumn{1}{l|}{ High-Low } & -0.001 & -0.076 & 0.558 \\
\hline \hline
\end{tabular}

\begin{tabular}{rrr}
\hline \multicolumn{3}{c}{ T-values } \\
Constant & Exmkt & Patfact \\
\hline \hline 5.33 & 7.09 & 10.89 \\
4.62 & 8.21 & 9.68 \\
4.29 & 7.81 & 9.57 \\
4.72 & 7.38 & 8.75 \\
4.33 & 8.13 & 8.45 \\
6.22 & 7.42 & 7.24 \\
5.16 & 7.67 & 5.09 \\
3.29 & 8.07 & 4.00 \\
3.15 & 7.92 & 3.61 \\
2.41 & 8.11 & 2.38 \\
\hline-3.37 & -0.92 & 4.38 \\
\hline \hline
\end{tabular}


Table 3.24

\section{Robustness: Sub-period Monthly Excess Returns}

At the end of each month stocks are ranked in ascending order on the basis of the past 3 months of firm issued patents and held for $\mathrm{J}=3,6$ months. 10 decile equally-weighted portfolios of stocks are formed. Stocks in the top decile (decile 1) are stocks with high patents and stocks in the bottom decile (decile 10) are firms with low patents. The High-Low represents the zero-cost portfolio. The results are based on the data sample that merges CRSP, COMPUSTAT and patent data, and the period of the sample used is 1970:01 - 2001:12. The table presents the zero-cost excess returns for the 12 calendar months.

\begin{tabular}{|l|cr|l|cr|}
\hline & \multicolumn{2}{|c|}{$\mathrm{J}=3$} & & \multicolumn{2}{c|}{$\mathrm{J}=6$} \\
& Returns & T-values & & Returns & T-values \\
\hline January & 0.0155 & 2.49 & & 0.0131 & 1.61 \\
February & 0.0045 & 1.08 & & 0.0008 & 0.37 \\
March & 0.0014 & 1.92 & & 0.0014 & 1.42 \\
April & 0.0018 & 2.41 & & 0.0009 & 0.72 \\
May & 0.0093 & 1.83 & & 0.0019 & 1.17 \\
June & 0.0043 & 0.91 & & 0.0012 & 1.05 \\
July & 0.0042 & 0.48 & & 0.0021 & 0.88 \\
August & 0.0128 & 2.11 & & 0.0017 & 1.45 \\
September & 0.0115 & 1.94 & & 0.0025 & 1.20 \\
October & 0.0152 & 2.73 & & 0.0118 & 1.95 \\
November & 0.0187 & 3.78 & & 0.0141 & 3.89 \\
December & 0.0179 & 3.17 & & 0.0119 & 4.19 \\
\hline
\end{tabular}


Figure 3.1

\section{Monthly Cumulative Abnormal Returns Adjusted for Kenneth French Aggregate Market Returns}

At the end of each month stocks are ranked in ascending order on the basis of past 3 months of firm issued patents and held for $K$ months. 10 decile equally-weighted portfolios of stocks are formed. Stocks in the top decile (HIGH) are stocks with high patents and stocks in the bottom decile (LOW) are firms with low patents. The results are based on the data sample that merges CRSP, COMPUSTAT and patent data, and the period of the sample used is 1970:01 - 2001:12. Monthly cumulative abnormal returns are estimated for the 10 decile portfolios for $K=0-60$. The estimated abnormal returns are in excess of aggregate market return data from Kenneth French data library

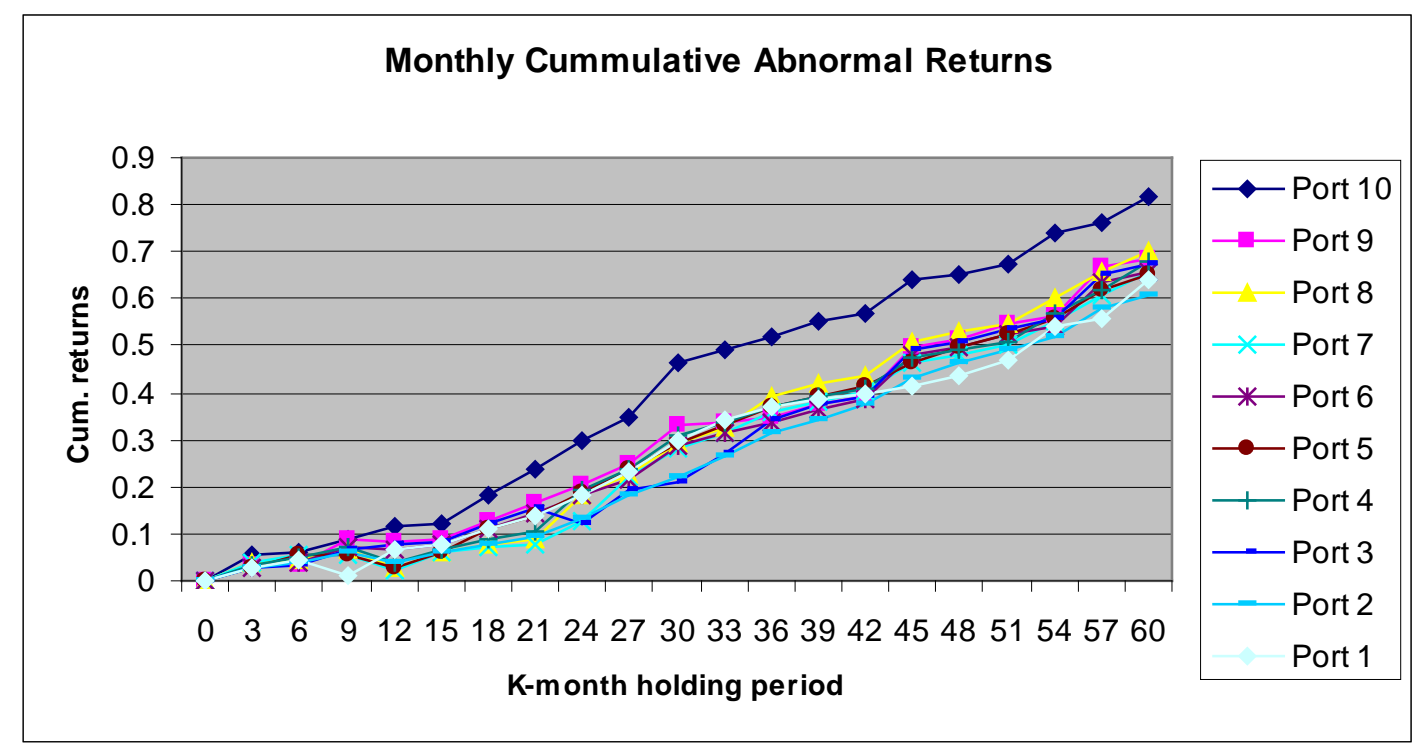


Figure 3.2

\section{Monthly Cumulative Abnormal Returns Adjusted for Sample Estimated Aggregate Market Returns}

At the end of each month stocks are ranked in ascending order on the basis of past 3 months of firm issued patents and held for $K$ months. 10 decile equally-weighted portfolios of stocks are formed. Stocks in the top decile (HIGH) are stocks with high patents and stocks in the bottom decile (LOW) are firms with low patents. The results are based on the data sample that merges CRSP, COMPUSTAT and patent data, and the period of the sample used is 1970:01 - 2001:12. Monthly cumulative abnormal returns are estimated for the 10 decile portfolios for $K=0-60$. The estimated abnormal returns are in excess of aggregate market returns. Aggregate market returns are estimated from the data sample used for the paper

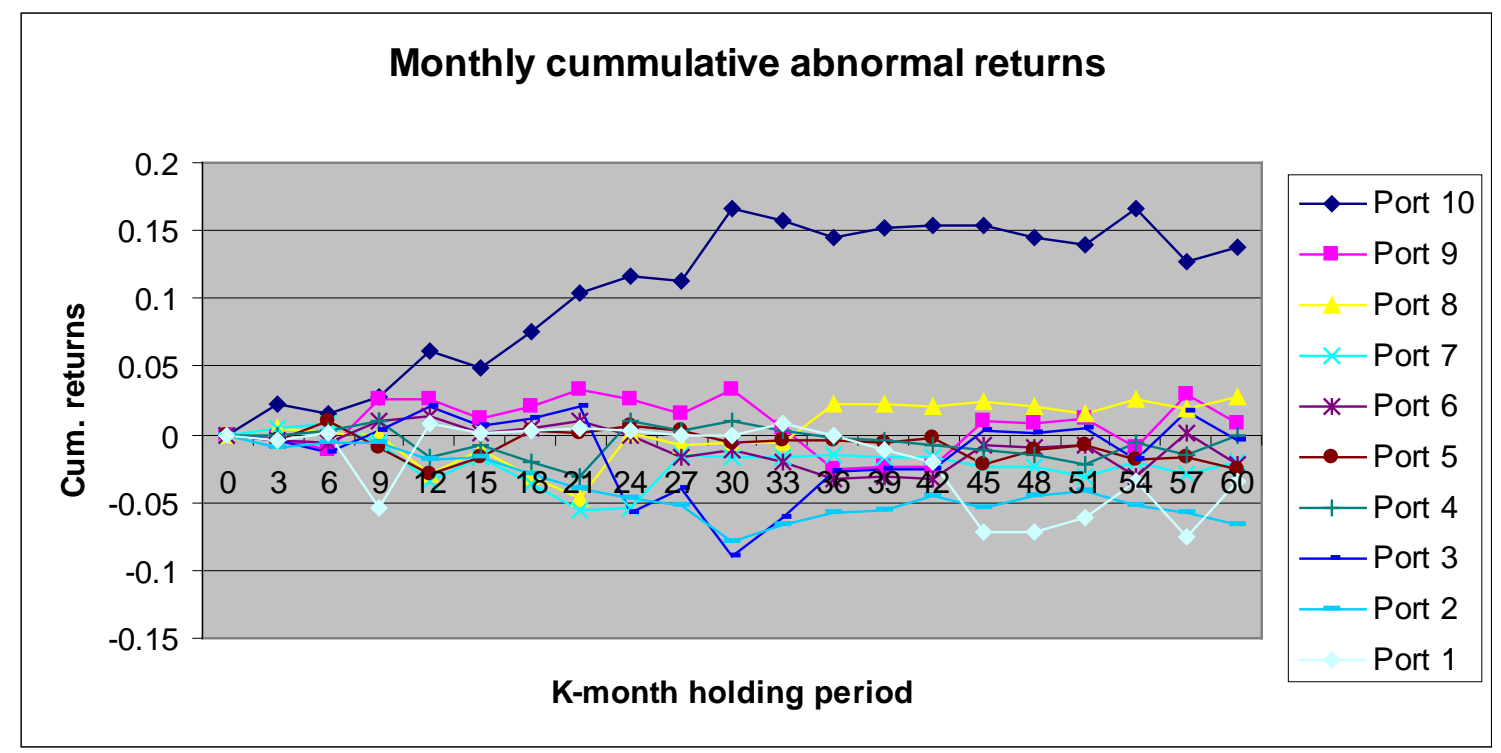


Appendix. 3A

List of the top tier of firms in the sample ranked by aggregate number of patent for the period 1970:01 - 2001:12.

\begin{tabular}{|c|c|c|c|c|c|c|c|}
\hline No. & $\mathrm{SIC}$ & CUSIP & COMPANAY NAME & $\begin{array}{l}\text { AGG. } \\
\text { PATENTS }\end{array}$ & $\begin{array}{l}\text { AVE. } \\
\text { RETURNS } \\
\end{array}$ & $\begin{array}{l}\text { AVE. IND. } \\
\text { PORTFOLIO } \\
\text { RET. } \\
\end{array}$ & INDUSTRY \\
\hline 1 & 7370 & 45920010 & INTL BUSINESS MACHINES & 35,927 & 0.0101 & 0.0124 & Business Services \\
\hline 2 & 3600 & 36960410 & GENERAL ELECTRIC CO-PRE & 29,482 & 0.0116 & 0.0126 & Electrical Eq. \\
\hline 3 & 3577 & 13800630 & CANON INC -ADR & 24,433 & 0.0137 & 0.0089 & Computers \\
\hline 4 & 3570 & 43357850 & HITACHI LTD -ADR & 22,963 & 0.0187 & 0.0089 & Computers \\
\hline 5 & 3861 & 27746110 & EASTMAN KODAK CO & 18,320 & 0.0168 & 0.0094 & Household Goods \\
\hline 6 & 3571 & 62905020 & NEC CORP -ADR & 18,260 & 0.0077 & 0.0089 & Computers \\
\hline 7 & 3663 & 62007610 & MOTOROLA INC & 16,369 & 0.0139 & 0.0120 & Electronic Eq \\
\hline 8 & 9997 & 82619750 & SIEMENS AG -ADR & 15,785 & 0.0168 & & \\
\hline 9 & 4813 & 00206R10 & AT\&T INC & 15,704 & 0.0134 & 0.0112 & Communications \\
\hline 10 & 3651 & 83569930 & SONY CORP -ADR & 15,016 & 0.0140 & 0.0085 & Recreational \\
\hline 11 & 2820 & 26353410 & DU PONT (E I) DE NEMOUR & 14,715 & 0.0081 & 0.0105 & Chemicals \\
\hline 12 & 2800 & 07273030 & BAYER AG -ADR & 14,092 & 0.0221 & 0.0105 & Chemicals \\
\hline 13 & 3577 & 98412110 & XEROX CORP & 13,616 & 0.0113 & 0.0089 & Computers \\
\hline 14 & 3861 & $35958 N 10$ & FUJI PHOTO FILM -ADR & 13,221 & 0.0059 & 0.0094 & Household Goods \\
\hline 15 & 3711 & 37044210 & GENERAL MOTORS CORP-PRE & 12,281 & 0.0078 & 0.0095 & Automobiles \\
\hline 16 & 3585 & $12490 K 10$ & WESTINGHOUSE ELEC-PRE F & 12,035 & 0.0125 & 0.0096 & Machinery \\
\hline 17 & 3674 & 88250810 & TEXAS INSTRUMENTS INC & 11,113 & 0.0159 & 0.0120 & Electronic Eq \\
\hline 18 & 2821 & 26054310 & DOW CHEMICAL & 10,472 & 0.0113 & 0.0105 & Chemicals \\
\hline 19 & 2800 & 05526250 & BASF AG -ADR & 10,915 & 0.0186 & 0.0105 & Chemicals \\
\hline 20 & 3570 & 42823610 & HEWLETT-PACKARD CO & 9,309 & 0.0160 & 0.0089 & Computers \\
\hline 21 & 2670 & 88579Y10 & $3 \mathrm{M} \mathrm{CO}$ & 8,935 & 0.0102 & 0.0106 & Paper Business \\
\hline 22 & 2800 & 43439030 & HOECHST AG -ADR & 7,944 & 0.0051 & 0.0105 & Chemicals \\
\hline 23 & 3600 & 74928510 & RCA CORP & 7,912 & 0.0116 & 0.0126 & Electrical Eq. \\
\hline 24 & 3674 & 59511210 & MICRON TECHNOLOGY INC & 7,314 & 0.0225 & 0.0120 & Electronic Eq \\
\hline 25 & 2911 & 60708000 & MOBIL OIL CORP & 7,109 & 0.0139 & 0.0117 & Oil \\
\hline 26 & 3711 & 65474440 & NISSAN MOTOR CO LTD -A & 6,939 & 0.0097 & 0.0095 & Automobiles \\
\hline 27 & 7373 & 90921410 & UNISYS CORP & 6,595 & 0.0106 & 0.0124 & Business Services \\
\hline 28 & 1311 & 82263500 & SHELL OIL CO & 6,551 & 0.0135 & 0.0117 & Oil \\
\hline 29 & 7373 & 54946310 & LUCENT TECHNOLOGIES INC & 6,319 & 0.0093 & 0.0124 & Business Services \\
\hline 30 & 2840 & 74271810 & PROCTER \& GAMBLE CO & 6,252 & 0.0117 & 0.0094 & Household Goods \\
\hline 31 & 3674 & 00790310 & ADVANCED MICRO DEVICES & 6,043 & 0.0189 & 0.0120 & Electronic Eq \\
\hline 32 & 3674 & 45814010 & INTEL CORP & 6,016 & 0.0219 & 0.0120 & Electronic Eq \\
\hline 33 & 3711 & 34537010 & FORD MOTOR CO & 5,835 & 0.0135 & 0.0095 & Automobiles \\
\hline 34 & 2870 & $61166 W 10$ & MONSANTO CO & 5,786 & 0.0310 & 0.0105 & Chemiclas \\
\hline 35 & 3720 & 91301710 & UNITED TECHNOLOGIES COR & 5,686 & 0.0140 & 0.0127 & Aircraft \\
\hline 36 & 3531 & 14912310 & CATERPILLAR INC-PRE FAS & 5,646 & 0.0123 & 0.0096 & Machinery \\
\hline 37 & 2800 & 02532110 & AMERICAN CYANAMID CO & 5,105 & 0.0119 & 0.0105 & Chemicals \\
\hline 38 & 2834 & 58933110 & MERCK \& CO & 5,013 & 0.0140 & 0.0126 & Drugs \\
\hline 39 & 3350 & 90320010 & UOP INC & 4,750 & 0.0086 & 0.0078 & Steel \\
\hline
\end{tabular}




\begin{tabular}{|c|c|c|c|c|c|c|c|}
\hline No. & $\mathrm{SIC}$ & CUSIP & COMPANAY NAME & $\begin{array}{l}\text { AGG. } \\
\text { PATENTS }\end{array}$ & $\begin{array}{l}\text { AVE. } \\
\text { RETURNS } \\
\end{array}$ & $\begin{array}{l}\text { AVE. IND. } \\
\text { PORTFOLIO } \\
\text { RET. }\end{array}$ & INDUSTRY \\
\hline 40 & 3822 & 43850610 & HONEYWELL INC & 4,671 & 0.0132 & 0.0105 & Measuring \\
\hline 41 & 2860 & 90558100 & UNION CARBIDE CORP & 4,594 & 0.0121 & 0.0105 & Chemicals \\
\hline 42 & 2911 & 88169410 & TEXACO INC & 4,390 & 0.0101 & 0.0117 & Oil \\
\hline 43 & 3714 & 27805810 & EATON CORP & 4,068 & 0.0133 & 0.0095 & Automobiles \\
\hline 44 & 3721 & 09702310 & BOEING CO & 3,972 & 0.0160 & 0.0127 & Aircraft \\
\hline 45 & 2851 & 69350610 & PPG INDUSTRIES INC & 3,825 & 0.0123 & 0.0105 & Chemicals \\
\hline 46 & 3714 & 87264910 & TRW INC & 3,803 & 0.0120 & 0.0095 & Automobiles \\
\hline 47 & 3678 & 03189710 & AMP INC & 3,665 & 0.0146 & 0.0120 & Electronic Eq \\
\hline 48 & 2834 & 53245710 & LILLY (ELI) \& CO & 3,616 & 0.0117 & 0.0126 & Drugs \\
\hline 49 & 3640 & 36299900 & GTE PRODUCTS CORP & 3,522 & 0.0109 & 0.0126 & Electrical \\
\hline 50 & 2800 & 30249130 & FMC CORP & 3,516 & 0.0131 & 0.0105 & Chemicals \\
\hline 51 & 3011 & 38255010 & GOODYEAR TIRE \& RUBBER & 3,391 & 0.0096 & 0.0095 & Automobiles \\
\hline 52 & 3679 & 21935010 & CORNING INC & 3,355 & 0.0139 & 0.0120 & Electronic Eq \\
\hline 53 & 7011 & 45091210 & ITT CORPORATION & 3,160 & 0.0206 & 0.0103 & Resturants \\
\hline 54 & 3579 & 80303830 & SANYO ELECTRIC CO LTD & 3,057 & 0.0022 & 0.0089 & Computers \\
\hline 55 & 2834 & 71708110 & PFIZER INC & 2,977 & 0.0128 & 0.0126 & Drugs \\
\hline 56 & 3571 & 86681010 & SUN MICROSYSTEMS INC & 2,949 & 0.0211 & 0.0089 & Computers \\
\hline 57 & 3578 & 62886000 & NCR CORP & 2,890 & 0.0141 & 0.0089 & Computers \\
\hline 58 & 3714 & 08168900 & BENDIX CORP & 2,825 & 0.0131 & 0.0095 & Automobiles \\
\hline 59 & 2810 & 38388F10 & GRACE (W R) \& CO & 2,812 & 0.0406 & 0.0105 & Chemicals \\
\hline 60 & 3812 & 75511150 & RAYTHEON CO & 2,705 & 0.0139 & 0.0120 & Electronic Eq \\
\hline 61 & 3523 & 24419910 & DEERE \& CO & 2,698 & 0.0143 & 0.0096 & Machnery \\
\hline 62 & 2834 & 00282410 & ABBOTT LABORATORIES & 2,697 & 0.0145 & 0.0126 & Drugs \\
\hline 63 & 2834 & 80658520 & SCHERING AG -ADR & 2,645 & 0.0149 & 0.0126 & Drugs \\
\hline 64 & 3674 & 63764010 & NATIONAL SEMICONDUCTOR & 2,627 & 0.0214 & 0.0120 & Electronic Eq \\
\hline 65 & 3350 & 68066520 & OLIN CORP & 2,619 & 0.0116 & 0.0078 & Steel \\
\hline 66 & 2911 & 03190400 & AMOCO CO & 2,526 & 0.0142 & 0.0117 & Oil \\
\hline 67 & 2844 & 19416210 & COLGATE-PALMOLIVE CO & 2,480 & 0.0132 & 0.0094 & Household Goods \\
\hline 68 & 2911 & 04882510 & ATLANTIC RICHFIELD CO & 2,441 & 0.0137 & 0.0117 & Oil \\
\hline 69 & 2834 & 93448810 & WARNER-LAMBERT CO & 2,381 & 0.0159 & 0.0126 & Drugs \\
\hline 70 & 7372 & 59491810 & MICROSOFT CORP & 2,321 & 0.0294 & 0.0124 & Business Services \\
\hline 71 & 3570 & 25384910 & DIGITAL EQUIPMENT & 2,269 & 0.0160 & 0.0089 & Computers \\
\hline 72 & 2821 & 77537110 & ROHM AND HAAS CO & 2,248 & 0.0115 & 0.0105 & Chemicals \\
\hline 73 & 3559 & 03822210 & APPLIED MATERIALS INC & 2,243 & 0.0253 & 0.0096 & Machnery \\
\hline 74 & 2810 & 00915810 & AIR PRODUCTS \& CHEMICAL & 2,208 & 0.0134 & 0.0105 & Chemicals \\
\hline 75 & 2834 & 85224510 & SQUIBB CORP & 2,146 & 0.0158 & 0.0126 & Drugs \\
\hline
\end{tabular}

Appendix. 3B

Student t-statistics of the returns of the top tier firms in the sample compared to the industry returns.

$$
\text { Mean }=\frac{\sum_{i=1}^{n}\left(\bar{r}_{i I}-\bar{R}_{I}\right)}{n}
$$




$$
=0.00376
$$

Where $\bar{r}_{i I}$ is the average return over the sample period for an individual firm $i$ listed under industry $I . \bar{R}_{I}$ is the average return over the sample period for industry $I$

$$
\text { T-Statistics }=\frac{\text { mean }}{\sigma / \sqrt{n}}
$$




\section{Chapter 4. Money Illusion in the Stock Market: International Evidence.}

\subsection{Introduction}

Money illusion ${ }^{28}$ refers to the phenomenon according to which people confuse nominal dollar amounts with real purchasing power. Macroeconomics theory ${ }^{29}$ often stipulates that nominal variables cannot influence real variables. It is then inconceivable to expect investors to err when it comes to stock pricing, discounting real cash flows by nominal required returns. According to the Modigliani-Cohn hypothesis, investors make this exact mistake. Cohen, Polk and Vuolteenaho (2005) perform an empirical test to show that the US stock market investors suffer from money illusion. That is, during periods of rising inflation, stocks are over-valued and during periods of falling inflation, stocks are undervalued. Fama (1981) substantiates the pricing anomaly by providing evidence to show the inverse relation between real stock values, representing ownership of the income generated by real asset, and nominal inflation. However, Balvers and Huang (2009) present contradictory evidence to suggest that there is no money illusion in the US stock market. They show that once real money growth is accounted for in the Cohen et al. (2005) model lagged inflation has no explanatory power for the cross section of returns.

There is broad recognition in the literature of global financial market interdependence. Eun and Shim (1989) examine the interdependence of the nine largest international financial markets. They find evidence of market interdependence, and also, that the US financial market exerts strong influence on the other financial markets. Hamao et al. (1990) provided evidence to show the transmission of stock market shocks from New York to Tokyo and London and from London to Tokyo, but not from Tokyo either to New York or London. In view of market interdependence, do international finance markets also suffer from money illusion as hypothesized by Modigliani and Cohn? This chapter addresses this question by looking at two classes of markets. First, the question is addressed to the developed financial markets. Technological advancement

\footnotetext{
${ }^{28}$ The term “money illusion” was coined by John Maynard Keynes early in the twentieth century. In 1928 Irving Fisher gave the subject a thorough treatment in his book "The Money Illusion".

${ }^{29}$ Classical dichotomy in macroeconomics is a feature of many classical and new classical theories of macroeconomics. However, the Keynesians sticky price models reject the classical dichotomy.
} 
and communication inter-connectivity enables information to be transmitted swiftly between developed countries. Second, the question is addressed to emerging financial markets. These two market groups are addressed separately because the level of market integration among developed markets and among emerging markets is different. The chapter presents some evidence to show that the international developed markets suffer from some degree of money illusion. Some individual countries may appear to be insulated from money illusion, but on average, the international markets may suffer from money illusion. At the same time the results may offer support to Balvers and Huang (2009) who argue that what looks to be the effect of money illusion may in fact be the equilibrium asset pricing impact of money growth on the transaction-cost adjusted marginal value of wealth. The evidence on emerging markets may not be enough to conclude that emerging markets suffer from money illusion.

The remaining sections of the chapter are organized as follows: Section II provides the literature review and model description, where the research question is defined. Section III presents the data used for the chapter. Section IV provides the empirical results. Section V presents the robustness of the research findings. Section VI concludes the chapter.

\subsection{Literature Review and Model Description}

To what extent are financial markets influenced by the macroeconomy? Efforts have been made to model the linkage of stock prices to consumption through the first order conditions of individual investors, as noted for instance by Balvers and Huang (2009). The 'Fed Model', the leading model for equity valuation, relates the yield on stocks to the yield on bonds [Asness (2003)]. Thus the model pitches stocks, representing ownership of the income generated by real assets, against nominal bonds as two competing assets in the financial markets. If the yield on bonds rises, then for stocks to stay competitive, the yield on stocks must also rise. Empirical work by Asness (2000, 2003) suggests that inflation is the main influence on bond yield. Thus during periods of rising inflation, the yield on bonds will rise to keep pace with inflation as suggested by Asness (2000). Now if inflation drives nominal bond yield and bond yield co-moves with stock yield then indirectly, stock yields are being driven by inflation as the Fed Model seems to suggest. 
However, inflation is a nominal variable and the stock yield is the return on real cash flow from investment. Modiglani and Cohn (1979) hypothesized that stock market investors may be suffering from money illusion. The investors discount real cash flows by nominal discount rates. The reality of this is that the time variation of inflation may lead to the market's subjective expectation of the equity premium to systematically deviate from rational expectation [Cohen, Polk and Vuolteenaho (2005)]. Cohen, Polk and Vuolteenaho (2005) present evidence to show that the US stock market investor suffers from money illusion of this sort.

The main purpose of this chapter is to investigate whether international financial markets suffer from money illusion. The literature documents significant co-movement in stock prices across countries. Eun and Shim (1989), Hamao et al. (1990) and, Karolyi and Stultz (1996) not only provide evidence of co-movements, but also argue that the US market exerts significant influence on other stock markets. $\mathrm{Ng}$ et al. (1991) and $\mathrm{Ng}$ (2000) find significant spillovers among the Pacific Rim countries, and Booth et al. (1997) provide evidence for price and volatility spillovers among the Scandinavian countries.

\subsubsection{Hypotheses}

This chapter contributes to the literature by investigating whether stock market interdependence provides a transmission channel for the transfer of investor irrationality across countries. If the US market exerts significant influence on other stock markets [Eun and Shim (1989)], and if the US market suffers from money illusion [Cohen, Polk and Vuolteenaho (2005)], then the expectation is that the international market must also suffer from money illusion. The scope of the investigation in this chapter extends beyond developed markets to include emerging markets. Two hypotheses are proposed:

\section{Hypothesis 1}

Developed international financial markets suffer from money illusion of the nature described by Modigliani and Cohen.

Market liberalization and increased sales of securitized financial assets across the international markets offer the platform for the transmission of market mistakes. 
Worldwide improvements in information processing enable market movements in one domestic market to be instantly transmitted across countries, and they end up affecting domestic markets of other countries. For example, for stocks in the UK to stay competitive to increases in yields of US stocks, UK stock prices must also fall. Failure of UK stock yield to rise and stay competitive with US stocks may lead to capital outflow from the UK to the US. To prevent potential capital outflow, UK stock yields must also rise.

This chapter addresses money illusion not only in developed markets, but also in emerging markets. Emerging economies and their markets are faced with different sets of economic challenges compared to those of developed markets. Notable and of direct bearing on this chapter, is monetary policy. Central banks of developed markets tend to be more independent of government inflationary demands. Monetary policies by central bank are independent of central government influence. The central goal of a central bank's monetary policy is price stability, and the credibility of the central bank to deliver on that depends on how independent the bank is from central government influence. A number of papers attribute central bank credibility to their independence. Notable among them are Posen (2000) and Mishkin (2000). Both argue that independent central banks can resist inflationary demands of governments and its policies are inherently more credible. Rogoff (1985) argues that the inflationary bias problem can be solved if monetary policy is conducted by those who are inflation-averse.

\section{Hypothesis 2}

Emerging financial markets do not suffer from money illusion of the nature described by Modigliani and Cohen.

Kim et al. (1998) and Almeida et al. (2004) argue that increased financial integration makes countries vulnerable to contagion from both within the region and outside the region. As argued above, competition among integrated markets may serve as the channel

for money illusion to affect markets. Emerging markets are less integrated with the international finance market. Given friction in capital account convertibility and limitations in the flow of information, emerging markets may not be very sensitive to 
stock price movements in the developed markets. In effect, this hypothesis proposes that emerging market do not suffer from money illusion as hypothesized by Modigliani and Cohen.

\subsubsection{Model}

An alternative model is presented in this chapter that builds on the Cohen, Polk and Vuolteenaho (2005) model. The modification ${ }^{30}$ allows for either a one-pass $^{31}$ or two-pass empirical evaluation of the testable implication of money illusion. The model allows for the complex three-pass method to be side-stepped. The Capital Asset Pricing Model (CAPM) formulation is outlined in the model by Cohen, Polk and Vuolteenaho (2005). As outlined in Cohen, Polk and Vuolteenaho (2005), I make the assumption that stock market investors discount the present value of real cash flow by a nominal discount rate, appealing to the 'Fed Model', that makes the same mistake, but has been proven to perform consistently well over the years in developed markets. I consider the Gordon growth model for valuing stocks and impose the assumption of money illusion. So for a given firm $i$, you can write;

$$
P_{i t}^{E}=\frac{E_{t} D_{i t+1}}{k_{i t}^{E}-\hat{g}_{i t}}
$$

Where $k_{i}^{E}$ is the required nominal return and $\hat{g}_{i}$ is the constant projected growth rate of cash flows or dividends, and $D_{t}$ is dividends at time $t$. The growth rate of cash flow may potentially not be constant due to time variation in inflation. In the Gordon growth model dividend growth is assumed to be a constant $g$ (based on the long term average inflation rate $\bar{\pi}$ ). If the market could make a perfect prediction of inflation, then observed inflation $\pi$ must be equal to the expectation inflation $(\bar{\pi})$. Otherwise, the growth rate of dividends would be subjected to time variation in expected inflation. The difficulty in estimating the long term future growth rate of dividends makes agents assume a constant growth rate $g$. I also assume an imperfect money illusion; typically not all investors are irrational. Then the variation factor is assumed to be a linear function of the deviation of observed inflation from the expected.

\footnotetext{
${ }^{30}$ Empirical model is developed and published in the lecture notes of Ronald Balvers, West Virginia University. http://www.be.wvu.edu/divecon/econ/balvers/

${ }^{31}$ One-pass is a one stage CAPM regression analysis.
} 


$$
\hat{g}_{i}=g_{i}-f(\pi-\bar{\pi})
$$

Now if we have a perfect money illusion, thus all investors suffer from this phenomenon, then the expression $f(\pi)=\pi-\bar{\pi}$ must be satisfied. However under the assumption that there is an imperfect money illusion because some investors are rational and others are irrational, it would be a reasonable assumption to set $f(\pi-\bar{\pi})=\gamma(\pi-\bar{\pi})$, with $0<\gamma<1$. Due to the stickiness and persistent nature of inflation, it is easy to use the rule of thumb, where expected inflation is estimated based on the recent past inflation [Friedman-Phelps (1968)]. This chapter adopts the backward-looking approach where expected inflation is estimated to follow a random walk [Ball (2000) and Atkeson and Ohanian (2001)]. From equation (1) the expected yield is calculated as

$$
\frac{E_{t} D_{i t+1}}{P_{i t}^{E}}=k_{i t}^{E}-\hat{g}_{i t}
$$

And by definition, the expected capital gain

$$
\frac{\left(E_{t} P_{i t-1}-P_{i t}\right)}{P_{i t}^{E}}=g_{i t}
$$

Then the dividend yield and capital gain may be combined to find an expression for the expected return given as,

$$
\hat{\mu}_{i t}=k_{i t}^{E}+f_{i}\left(\pi_{t}\right)
$$

Thus you get an important result that suggests that the mean return for any stock $i$. exceeds the required return on the stock by the same proportion which depends positively on inflation. If the same assumption is made as Cohen, Polk and Vuolteenaho (2005) that the required return satisfies the CAPM, then you can write

$$
k_{i t}^{E}-r_{f}^{n}=\beta_{i}\left(k_{m t}^{E}-r_{f}^{n}\right)
$$

Where $r_{f}^{n}$ is the risk free rate, $\beta_{i}$ is the stock's market beta, which according to the CAPM is the sole relevant measure of risk, and $k_{m}^{E}$ is the required return on the market 
portfolio. Then from equation (3.5), an extension could be made to derive the mean return of the aggregate market portfolio and substituted into equation (3.6).

$$
\hat{\mu}_{i t}-r_{f}^{n}=\beta_{i}\left(\hat{\mu}_{m t}-r_{f}^{n}\right)+\left(1-\beta_{i}\right) f_{i}\left(\pi_{t}\right)
$$

Now since $f\left(\pi_{t}\right)=\gamma\left(\pi_{t}-\bar{\pi}_{t}\right)$, then the stock alpha, the part of expected return unexplained by the CAPM is given as $\alpha_{i}=\left(1-\beta_{i}\right) \gamma\left(\pi_{i t}-\bar{\pi}_{i t}\right)$. The model leads to four testable implications for the presence of money illusion. Case 1 is for $\left(\pi_{i t}-\bar{\pi}_{i t}\right)<0$ and $\beta_{i}>1$ then $\alpha_{i}$ must be positive and significant. Case 2 is for $\left(\pi_{i t}-\bar{\pi}_{i t}\right)<0$ and $\beta_{i}<1$, the $\alpha_{i}$ must be negative and significant. Case 3 is for $\left(\pi_{i t}-\bar{\pi}_{i t}\right)>0$ and $\beta_{i}>1$, the $\alpha_{i}$ must be negative and significant. Case 4 is for $\left(\pi_{i t}-\bar{\pi}_{i t}\right)>0$ and $\beta_{i}<1$, the $\alpha_{i}$ must be positive and significant. If empirical tests of all the four cases are satisfied, this would lead to a conclusion that the international financial markets suffer from money illusion. The intuitive explanation of the theory is that during periods of rising inflation (positive inflation shock), stocks with beta less than one (case 4) would be over-priced and during periods of falling inflation (negative inflation shock), stocks with beta less than one (case 2) would be under-priced. Similarly, during periods of rising inflation, stocks with beta greater than one (case 3) would be under-priced and during periods of falling inflation, stocks with beta greater than one (case 1) would be over-priced.

If there is mispricing as the theory suggests, then some rational agents could profit because this may provide an arbitrage opportunity. A few rational investors would buy stocks when they are underpriced during times of rising inflation and sell during time of falling inflation. As noted in Cohen, Polk and Vuolteenaho (2005) this would not be the case. They cite the slow adjustment process of price correction which would not make this easy. If price adjustment process is slow, then the adjustment process introduces additional uncertainty. Arbitrage profit is possible under the assumption of constant risk. In this case, more uncertainty rules out the possibility of an arbitrage profit.

The single pass regression in equation (4.7) is run to test the implication of money illusion in international markets. From the 4 cases listed above, two sets of regressions are run. The country portfolios are partitioned into two periods of negative inflation shocks and positive inflation shocks. Separate regressions are run for the two periods, and 
from the results, the 4 cases are evaluated by identifying countries with beta greater than one and countries with beta less than one. Fama-McBeth (1973) suggests the use of rolling beta estimation with a trailing window of 60 months in portfolio formation and also out of sample portfolio beta estimation. This is to increase the noise-to-variability ratio and also to reduce measurement errors. However, the estimation method used in this paper follows Black, Jensen and Scholes (1972), where the portfolios are the country market returns. I have a relatively short sample period and as a result I impose the assumption of constant beta for the sample period. I use the Black, Jensen and Scholes (1972) estimation method to test the implication of money illusion by running a single pass regression of equation (4.7).

Under the first hypothesis, developed markets suffer from money illusion. On the basis of the theoretical result investors wrongly specify the dividend yield $\left(\hat{g}_{i}\right)$ on stocks. Intuitively, this mis-specification could be explained through domestic sources or through foreign sources. Developed markets have well-developed bond markets that could compete with the stock market. Using the example of the Fed Model as argued by Campbell and Vuolteenaho (2004), $\hat{g}_{i}$ may be subject to an inflation factor that is driven by bond yields. Similarly, money illusion could be a result of foreign sources through market interdependence. The implication is that, for developed markets if $\beta_{i}>1$, then $\alpha_{i}=\left(1-\beta_{i}\right) \gamma\left(\pi_{i t}-\bar{\pi}_{i t}\right)<0$ and significant for $\pi_{i t}>\bar{\pi}_{i t}$ where $\gamma$ is a positive constant. Similarly, if $\beta_{i}<1$, then $\alpha_{i}=\left(1-\beta_{i}\right) \gamma\left(\pi_{i t}-\bar{\pi}_{i t}\right)>0$ and significant for $\pi_{i t}>\bar{\pi}_{i t}$. The second hypothesis stipulates that emerging markets may not suffer from money illusion since they are not fully integrated with international financial markets. Intuitively, it could be argued that the bond markets ${ }^{32}$ of emerging countries are not developed enough for bonds and stocks to effectively compete for investments. Hence, from the theoretical model, $\hat{g}_{i}$ may not be subject to the inflation factor that is driven by bond yield, both local and foreign. The model implication is that, for emerging markets, the four cases listed above would not hold.

\footnotetext{
${ }^{32}$ G8 2007 Finance ministers meeting. Potsdam May 19 ${ }^{\text {th }}$ 2007. Document title: Action plan for developing local bond market in emerging markets economies and developing countries. http://www.g7.utoronto.ca/finance/g8finance-bond.pdf
} 
The first pass regression [equation 3.7], estimates alphas, the part of the risk premium unexplained by the market risk premium and asset specific beta, in our case country betas. Alphas are to be interpreted as the abnormal return of an asset. Hence, the estimated alphas should capture the information concerning money illusion if present. These test implications are similar to that of Cohen, Polk and Vuolteenaho (2005). When inflation is high, rational equity premium expectation is higher than the market's subjective expectation and as such the stock market is under-valued.

\subsection{Data}

The financial market data for developed countries used in this chapter is taken from the Morgan Stanley Capital International $\left(\mathrm{MSCI}^{33}\right)$ data. The MSCI data compiles monthly country indices, which include dividends for developed markets, and the sample used in this chapter spans the period from January 1970 to December 2005. A sample of sixteen countries $^{34}$ is selected from the MSCI data on the basis of countries with data spanning the specified period ${ }^{35}$ January 1970 to December 2005. The financial data for emerging markets are from the emerging market database (EMDB). This is a Monthly Stock Series that combines the International finance corporation (IFC) version, which has data up to October 1997, and Standard and Poor's version, with data up to May 2001. Emerging market dataset has firm-specific data from 30 countries covering an unbalanced period from 1982 to 2000. This number is reduced to 16 countries by including countries with firm level data of 500 or more, and country portfolios are formed for each country for the period 1987 to 2000. MSCI compiles data of country indices for emerging countries. However, using MSCI emerging market data would reduce the sample period and the number of countries included.

Log differencing is used to compute the nominal monthly returns from the price indices (including dividends) in both MSCI and emerging market data. Data are usually converted from nominal returns to real returns by subtracting inflation. However, since

\footnotetext{
${ }^{33}$ MSCI monthly indices are constructed using every listed security in a market free float adjusted, classified in accordance with Global Industry Standard and screened by size, liquidity and minimum float

${ }^{34}$ The MSCI sample consist of US, UK, Germany, Austria, Italy, France, Norway, Belgium, Japan, Netherlands, Denmark, Spain, Sweden, Switzerland, Canada and Singapore

${ }^{35}$ The focus of this paper is to evaluate the presence of money illusion in developed and emerging market. Since contrasting the two markets is not the objective, the difference in the two data periods is not an issue of concern. However, I include in the robustness results for the developed market from 1987:01 - 2005:12.
} 
excess returns are used, the inflation rate cancels out. The Consumer Price Index (CPI) data is taken from the International Financial Statistics (IFS) data CD. Log differencing is used to compute the monthly inflation rate for all countries in the sample. All prices are dollar quoted; hence there is no need for currency conversion. I use the risk free rate of the US as a common risk free rate for all the countries, since prices are in US dollar and the analysis is taken from the perspective of an investor in the US.

There are many formulations of expected inflation, but the advantage of the backward looking version stems from the empirical success and the persistent nature of inflation. A number of authors model inflation as a random walk [eg. Atkeson and Ohanian (2001) and Ball (2000)]. From the estimated long-run inflation, the deviation of actual inflation from the expected long-run are computed. This is to measure inflation surprises and test the implication of money illusion. Actual inflation is computed by taken the log difference in the CPI. The sample is partitioned into periods of high and periods of low inflation and the regression model in equation 7 is run.

\subsection{Empirical Results:}

\subsubsection{Summary Results}

Inflation is the prominent variable of interest when evaluating money illusion. Cohen, Polk and Vuolteenaho (2005) explain that during periods of high inflation, stock returns are under valued and during periods of low inflation, stock returns are over-valued. I estimate inflation shock (surprise) variables. Inflation surprises are estimated by taking the monthly difference in actual inflation and expected inflation. Periods of positive inflation shocks are grouped together and analyzed separately from periods of negative inflation shock. Actual inflation is computed from Consumer Price Index (CPI) data and expected inflation is estimated using the past one year inflation rate. The summary results in Table 4.1 show that on average, Italy and United Kingdom experience relative higher negative inflation shocks as compared to the rest of the developed countries. On the other hand, German, Italy, Japan, United Kingdom, Sweden and Singapore experience higher positive inflation shocks. Italy and United Kingdom may be showing up in both the high negative and positive shock groups because of more variability in their inflation data. 
Table 4.2 presents results of average monthly stock returns of developed markets. Results in Table 4.2 are based on MSCI international data. Stocks in the Netherlands, Sweden and United Kingdom on average perform significantly better compared to other countries in the sample for the period of the study. Japan, Sweden, Italy, Spain, Austria, Norway, United Kingdom and Singapore show a relatively high standard error, an indication that those markets may be more risky. Comparing the summary results in the two tables (Table 4.1 and 4.2), it does not appear that there is a clear link between high inflation shock and return variability. Countries with moderate levels of inflation perform relatively well. This may be an indication that some moderate level of inflation may be good for a country’s financial market.

\subsubsection{Empirical Results on the Money Illusion for Developed markets}

The main focus of this chapter is to evaluate whether the international financial markets suffer from money illusion as is proven to be the case for the US market. In this subsection, the empirical implication of money illusion is evaluated for developed markets in the data sample used for this chapter. The results are based on the empirical model in equation (4.7) and the four empirical implications (Cases 1, 2, 3 and 4) are examined. For example, if observed inflation is less than the expected inflation, then the presence of money illusion would imply that if the coefficient on excess world returns (Ex-World) is less than one, then the coefficient of country inflation (Inf-Alpha) must be negative and significant (Case 3). Table 4.3 examines the empirical implications of Case 1 and Case 2. Seven countries fall under Case 1, since the estimated beta for these countries is greater than one. According to Case one, for the money illusion condition to be satisfied, then the mean Inf-Alpha coefficient for these countries must be positive and significant. The correct sign is observed for the Case 1 results but it is not significant. The mean InfAlpha coefficient for Case 2, according to the empirical implication must be negative and significant to satisfy the presence of money illusion is the other nine countries. This is observed to be the case from the results in Table 4.3.

Table 3.4 examines the implication for Case 3 and Case 4 for developed markets. From the results, nine countries have estimated beta greater than one. According to Case 3, Inf-Alpha must be negative and significant to satisfy the presence of money illusion. The mean inflation coefficient (Inf-Alpha) has the expected sign and it is significant at 
the $95 \%$ confidence level. The mean results for Case 4 have the opposite sign required for money illusion. Overall, three of the cases have the required sign and among them two are significant at the $95 \%$ confidence level. Only one case, Case 4 has the opposite sign but is economically small.

\subsubsection{Empirical Results on the Money Illusion for Emerging Markets}

The second hypothesis proposes that emerging markets may not suffer from money illusion since they are not fully integrated with the international financial markets. Ng, Chang and Chou (1991) argue that evidence of a spillover effect is present only if international investment restrictions are relaxed between developed and developing markets.

The empirical model $\hat{\mu}_{i t}-r_{f}^{n}=\beta_{i}\left(\hat{\mu}_{m t}-r_{f}^{n}\right)+\left(1-\beta_{i}\right) f_{i}\left(\pi_{t}\right)$ is run using emerging markets data and the results are presented in Table 4.5 and 4.6. The four empirical implications are evaluated to determine the presence of money illusion in emerging markets. Table 4.5 presents results from the regression analysis using negative inflation shocks. The results show that all the countries in the sample have estimated beta less than one. Thus the results exclude the empirical implication of Case 1 . Case 2 is therefore the mean coefficient of all the countries in the sample. According to the requirement for money illusion under Case 2, on average the results show that money illusion is present. Table 4.6 reports results of the regression analysis using positive inflation shock. Similar to the results in Table 4.5, Table 4.6 shows that the estimated betas for the countries in the sample are all less than one. The results make it impossible to evaluate Case 3 for the presence of money illusion and only Case 4 is examined. For the presence of money illusion under Case 4 to be satisfied, the mean coefficient of the inflation variable must be positive and significant. The results show that the required sign to demonstrate the presence of money illusion is satisfied but not significant.

Since only Cases 2 and 4 are present in the results in this sub-section and of these cases only Case 2 is significant, there may not be sufficient evidence to suggest money illusion in emerging markets.

\subsection{Robustness}


In this section I examine minor adjustment to the proposed hypotheses in this chapter. I include Fama-French size and value factors in the empirical model. According to Fama and French (1993), size and value premia may matter for asset pricing. Tables 4.7 and 4.8 present results for the developed nations. Table 4.7 evaluates the empirical implication of money illusion for periods of negative inflation shocks by looking at Case 1 and Case 2 . Case 1 has the right sign but the mean coefficient is not significant. Case 2 has the right sign and it is significant at 95\% confidence level. Table 4.8 presents the analysis over periods of positive inflation shocks for developed nations. The results show that both Case 3 and Case 4 are negative and significant. The presence of money illusion requires Case 3 to be negative and Case 4 to be positive. These results are consistent with the results in the main study. The evidence shows that of the four cases, three satisfy the expected sign with two being significant at 95\% confidence level.

Robustness checks are conducted for the emerging market countries. The FamaFrench size and vaule factors are included in the empirical model in equation 4.7. There are no significant changes in the results as compared to the results in the main presentation. In both Tables 4.9 and 4.10, the estimated betas for the countries in the sample are less than one. This eliminates Case 1 and Case 3. Results presented in Table 3.9 and 3.10 have Case 2 and Case 4 respectively. The result for Case 2 in Table 4.9 endorses the presence of money illusion, and the result is significant. The results for Case 4 in Table 4.10 have the expected sign, but it is not significant.

The focus of this chapter is to evaluate the presence of money illusion in developed and emerging markets. Since contrasting the two markets is not the objective for this research, the difference in the time periods of the two data sets may not be an important issue of great concern. However, I present results for the developed market from 1987:01 - 2005:12. The results in Table 4.11 show no significant difference to the results for the data period 1970:01 - 2005:12. Thus periods of negative inflation shocks, the expected results for case 1 and case 2 under the hypothesis are significant and they both have the require sign for the regression coefficients. Table 4.12 present results for periods with positive inflation shocks from 1987:01 - 2005:12. The observed signs of the results both for case 3 and case 4 are consistent with the model requirement for the presence of money illusion in the stock market. This shows an improvement over the 
results covering the period 1970:01 - 2005:12. However, in both case 3 and case 4, the results are not significant.

The findings in the robustness section show that minor changes in the main assumption do not affect the outcome of the results. There is reasonable evidence to support the presence of money illusion in developed markets. However, not enough evidence is presented to support money illusion in emerging markets.

\subsection{Conclusion}

In general there is reasonable evidence to suggest the presence of money illusion in developed markets as demonstrated by the results in this chapter. As discussed, more market integration of the international financial market provides for easy flow of capital from one country to the other. If stocks in one market are viewed by investors as not offering a competitive yield, investors would re-allocate their investments to markets offering competitive yields. Competition among markets may present the linkage for money illusion to affect international markets.

However, emerging markets may suffer from relatively more frictions in the flow of capital and information between countries. In the presence of friction and information problems, emerging market stocks may not react competitively to stock price movements of other markets. In effect, the lack of frictionless integration may insulate emerging markets from the spillover of money illusion from foreign sources. Also, the bond markets in emerging markets are not well developed to ensure bond - stock competition that may influence domestically generated money illusion. 


\subsection{References}

Almeida, H., M. C. and. Weisbach, M. 2004, "The Cash Flow Sensitivity of Cash," Journal of Finance 59, 1777-1804.

Asness, C. S. 2003. “Fight the Fed Model.” Journal of Portfolio Management 30, 11-24.

Asness, C. S. 2000."Stocks versus Bonds: Explaining the Equity Risk Premium.” Financial Analysts Journal, 56, 96-113

Atkeson, A. and Ohanian, L. E. 2001 "Are Phillips Curves Useful for Forecasting Inflation?” Federal Reserve Bank of Minneapolis Quarterly Review, 25, 2-11.

Ball, L. 2000 “Near-Rationality and Inflation in two Monetary Regimes”, Working Paper \# 7988

Balvers, R. J. and Haung, D. 2009, "Money and the C-CAPM” Journal of Financial and Quantitative Analysis, 44, 337-368

Black, P., M. C. Jensen, and M. Scholes, 1972, “The Capital Asset Pricing Model: Some Empirical Tests,” in M. C. Jensen (ed.), Studies in the Theory of Capital Markets, Praeger, New York, 79-121.

Booth, G.G., Martikainen, T. and Tse, Y. 1997, "Price and Volatility Spillovers in Scandinavian Stock Markets,” Journal of Banking \& Finance, 21, 811-823

Campbell, J. Y. and Vuolteenaho, T. 2004. “Inflation illusion and stock Prices”, American Economic Review, 94, 19-23.

Cohen, R., Polk, B. C. and Vuolteenaho, T., 2005. "Money illusion in the Stock Market: The Modigliani-Cohn Hypothesis”. Quarterly Journal of Economics, 689 - 668

Eun, C.S. and Shim, S. 1989, “International Transmission of Stock Market Movements”. The Journal of Financial and Quantitative Analysis, 24, 241-256

Fama, E. P.. and J. D. MacBeth, 1973, “Risk, Return, and Equilibrium: Empirical Tests,” Journal of Political Economy, 71,607-636.

Fama, E., 1981, “Stock returns, real activity, inflation, and money”, American Economic Review, 71, 545-564.

Fama, E. F. and French, K. R, 1993 "Common risk factors in the returns on stocks and bonds”, Journal of Financial Economics 33,55-84

Friedman, M. 1968. "The Role of Monetary Policy". American Economic Review 58, 117. 
Hamao, Y.R., Masulis, R. W. and.Ng, V. N. 1990, "Correlations in Price Changes and Volatility Across International Stock Markets”. Review of Financial Studies, 3, 281-307

Karolyi, G.A. and Stultz, R. M. 1996, "Why Do Markets Move Together? An Investigation of U.S.- Japan Stock Return Comovements”. The Journal of Finance, 51, 951-986

Kim, C., Mauer, D and Sherman, A. 1998. "The Determinants of Corporate Liquidity: Theory and Evidence”. Journal of Financial and Quantitative Analysis, 33, 335359.

Lintner, J., 1965, "The Valuation of Risk Assets and the Selection of Risky Investments in Stocks," Review of Economics and Statistics,. 14, 13-37.

Mishkin, F. 2000, “Inflation Targeting in Emerging Market Countries”, NBER, Working Paper Series” No 7618.

Modigliani, F. and Cohn, R. 1979 "Inflation, Rational Valuation and the market”, Financial Analysts Journal 35, 24-44

Ng, A. 2000. "Volatility Spillover Effects from Japan and the U.S. to the Pacific Basin." Journal of International Money and Finance,.19, 207-233.

Ng, V., Chang, R. P. and Chow, R. 1991. "An Examination of the Behavior of International Stock Market Volatility" in S.G. Rhee and R.P. Chang (eds.), Pacific-basic Capital Markets Research. 245-260, Amsterdam: North-Holland.

Phelps, E. S. 1968. "Money-Wage Dynamics and Labor-Market Equilibrium”. Journal of Political Economy 76, 678-711.

Posen A 1995, "Central Bank Independence and Disinflation Credibility: A Missing Link?” Reserve Bank of New York Staff Papers.

Rogoff, K. 1985, “The Optimal Degree of Commitment to an Intermediate Monetary Target”, Quarterly Journal of Economics, 100,1169-1190.

Sharpe, W. F., 1964. "Capital Asset Prices: A Theory of Market Equlibrium under Conditions of Risk," Journal of Finance, 19,. 425-442.

Stultz, R.M., 1996, “A Rethinking Risk Management”, Journal of Applied corporate Finance, 8-23. 


\section{Table 4.1}

\section{Average Inflation for All Data Period and Average Inflation for Periods of Positive and Negative Inflation Shocks}

Summary results of average (annualized) inflation level of countries in the data sample for the period 1970:012005:12. All inflation represents the annualized monthly average for all the time period of the data. Negative shock segment represent the annualized monthly average for periods of negative inflation shocks and positive shock represent the annualized monthly average for periods with positive inflation shocks. Inflation for each of the 16 countries is computed by estimating the annual percentage change in Consumer Price Index (CPI) for each month and average across the data period $(1970$ - 2005).

\begin{tabular}{l|rrr}
\hline & All Inflation & Negative Shock & Positive Shock \\
\hline \hline Germany & 2.515 & 2.492 & 3.529 \\
Austria & 3.779 & 3.105 & 4.590 \\
Belgium & 3.845 & 3.794 & 4.791 \\
Canada & 4.872 & 4.123 & 5.609 \\
Denmark & 5.447 & 4.782 & 6.163 \\
France & 5.364 & 4.599 & 6.347 \\
Italy & 8.179 & 7.159 & 9.467 \\
Japan & 3.490 & 3.463 & 5.711 \\
Netherlands & 3.902 & 3.739 & 4.393 \\
Norway & 5.654 & 5.131 & 6.480 \\
Singapore & 3.106 & 2.715 & 4.517 \\
Spain & 8.565 & 7.841 & 9.421 \\
Sweden & 5.733 & 5.100 & 6.881 \\
Switzerland & 3.104 & 2.320 & 3.934 \\
United Kingdom & 7.030 & 5.587 & 8.394 \\
United States & 4.799 & 3.958 & 5.631 \\
\hline \hline \multicolumn{4}{l}{}
\end{tabular}




\section{Table 4.2}

\section{Mean Excess Returns of data from Morgan Stanley Capital International}

Table reports the average market returns for the 16 countries in the data sample. The market returns are used as the country portfolios and are estimated from Morgan Stanley Capital International (MSCI) price indices with dividends. The sample data for the sixteen developed countries span the period 1970:01 2005:12.

\begin{tabular}{l|rrrr}
\hline & \multicolumn{1}{|l}{ Mean } & Std. Err. & \multicolumn{1}{l}{ [95\% Confidence Interval] } \\
\hline Austria & 0.76 & 0.342 & 0.087 & 1.432 \\
Belgium & 0.88 & 0.2843 & 0.320 & 1.438 \\
France & 0.81 & 0.3378 & 0.143 & 1.472 \\
Italy & 0.62 & 0.3884 & -0.146 & 1.382 \\
Netherlands & 0.89 & 0.2714 & 0.359 & 1.426 \\
Norway & 0.76 & 0.3783 & 0.018 & 1.506 \\
Singapore & 0.79 & 0.4079 & -0.010 & 1.594 \\
Spain & 0.55 & 0.3402 & -0.124 & 1.214 \\
Sweden & 0.94 & 0.348 & 0.258 & 1.626 \\
Switzerland & 0.71 & 0.268 & 0.183 & 1.237 \\
United Kingdom & 0.98 & 0.3338 & 0.318 & 1.631 \\
Japan & 0.57 & 0.3375 & -0.092 & 1.235 \\
Germany & 0.63 & 0.3083 & 0.025 & 1.237 \\
United States & 0.68 & 0.2315 & 0.223 & 1.133 \\
\hline
\end{tabular}




\section{Table 4.3}

\section{Regression Results for Developed Countries Using Negative Inflation Shocks}

Table presents a time series regression of excess return of country portfolios against world excess returns (ExWorld) and inflation shock variable (Inf-Alpha). Country portfolios are estimated from Morgan Stanley Capital International (MSCI) price indices with dividends. One year lagged inflation is used as the estimate of expected inflation and the difference between observed inflation and expected inflation is the inflation shock variable. The sample data covers sixteen developed countries over the period 1970:01 - 2005:12. The results in the table are based on regression $\hat{\mu}_{i t}-r_{f}^{n}=\beta_{i}\left(\hat{\mu}_{m t}-r_{f}^{n}\right)+\left(1-\beta_{i}\right) f_{i}\left(\pi_{t}\right)$ covering periods with negative inflation shock.

Case 1 is the mean coefficients of all the countries where for $\left(\pi_{i t}-\bar{\pi}_{i t}\right)<0$ and $\beta_{i}>1$, and Case 2 is the mean coefficients of all the countries where for $\left(\pi_{i t}-\bar{\pi}_{i t}\right)<0$ and $\beta_{i}<1$.

\begin{tabular}{l|rrrr}
\hline Negative Shock & \multicolumn{2}{|c}{ Coefficients } & \multicolumn{2}{c}{ T-values } \\
\hline \hline Germany & Ex-World & Inf-Alpha & Ex-World & Inf-Alpha \\
Austria & 0.866 & -0.0845 & 8.38 & -1.59 \\
Belgium & 0.541 & 0.0014 & 5.37 & 0.76 \\
Canada & 1.004 & -0.0095 & 10.87 & -1.64 \\
Denmark & 0.689 & -0.0532 & 9.15 & -0.60 \\
France & 0.829 & 0.0018 & 8.22 & 2.06 \\
Italy & 1.030 & -0.0074 & 11.45 & -0.47 \\
Japan & 1.001 & 0.0696 & 7.16 & -0.07 \\
Netherlands & 1.029 & -0.0087 & 11.84 & -1.07 \\
United States & 0.866 & -0.0235 & 11.22 & -0.22 \\
United Kingdom & 0.927 & 0.0010 & 14.44 & 1.32 \\
Norway & 0.992 & -0.0110 & 11.09 & -0.20 \\
Spain & 1.017 & -0.0016 & 8.28 & -1.02 \\
Sweden & 1.015 & 0.0132 & 9.73 & 1.24 \\
Switzerland & 0.987 & -0.0303 & 8.34 & -2.95 \\
Singapore & 0.810 & -0.0101 & 10.08 & -1.02 \\
\hline \hline Average & 1.003 & -0.0028 & 8.17 & -0.53 \\
Case 1 & & & & \\
Case 2 & 1.014 & 0.0075 & 221.08 & 0.70 \\
\hline \hline
\end{tabular}




\section{Table 4.4}

\section{Regression Results for Developed Countries Using Positive Inflation Shocks}

Table presents a time series regression of excess return of country portfolios against world excess returns (ExWorld) and inflation shock variable (Inf-Alpha). Country portfolios are estimated from Morgan Stanley Capital International (MSCI) price indices with dividends. One year lagged inflation is used as the estimate of expected inflation and the difference between observed inflation and expected inflation is the inflation shock variable. The sample data covers sixteen developed countries over the period 1970:01 - 2005:12. The results in the table are based on regression $\hat{\mu}_{i t}-r_{f}^{n}=\beta_{i}\left(\hat{\mu}_{m t}-r_{f}^{n}\right)+\left(1-\beta_{i}\right) f_{i}\left(\pi_{t}\right)$ covering periods with positive inflation shock.

Case 3 is the mean coefficients of all the countries where for $\left(\pi_{i t}-\bar{\pi}_{i t}\right)>0$ and $\beta_{i}>1$, and Case 4 is the mean coefficients of all the countries where for $\left(\pi_{i t}-\bar{\pi}_{i t}\right)>0$ and $\beta_{i}<1$.

\begin{tabular}{l|rrrr}
\hline Positive Shock & \multicolumn{2}{|c}{ Coefficients } & \multicolumn{2}{c}{ T-values } \\
\hline \hline Germany & Ex-World & Inf-Alpha & Ex-World & Inf-Alpha \\
Austria & 1.068 & 0.0057 & 11.74 & 1.16 \\
Belgium & 0.622 & -0.0042 & 5.78 & -0.21 \\
Canada & 0.982 & 0.0031 & 10.19 & 0.59 \\
Denmark & 1.039 & 0.0013 & 13.77 & 0.97 \\
France & 0.786 & -0.0024 & 8.48 & -2.64 \\
Italy & 1.057 & -0.0153 & 12.05 & -1.05 \\
Japan & 0.948 & -0.0062 & 8.01 & -0.76 \\
Netherlands & 0.985 & -0.0017 & 10.17 & -2.53 \\
United States & 1.076 & -0.0203 & 14.89 & -1.49 \\
United Kingdom & 1.004 & -0.0264 & 16.56 & -3.17 \\
Norway & 1.013 & 0.0061 & 13.67 & 0.77 \\
Spain & 0.844 & -0.0012 & 7.10 & -1.15 \\
Sweden & 0.786 & -0.0029 & 8.26 & -3.46 \\
Switzerland & 1.038 & 0.0032 & 11.68 & 0.30 \\
Singapore & 1.007 & -0.0189 & 11.78 & -1.43 \\
\hline \hline \multirow{2}{*}{ Average } & 1.088 & -0.0526 & 9.74 & -0.88 \\
Case 3 & & & & \\
Case 4 & 1.043 & -0.0209 & 101.36 & $-1.95{ }^{\circledR}$ \\
\hline \hline
\end{tabular}

\footnotetext{
${ }^{\circledR}$ Result is influenced significantly by outliers in Singapore’s observed inflation minus the expected inflation.
} 


\section{$\underline{\text { Table } 4.5}$}

\section{Regression Results for Emerging Countries Using Negative Inflation Shocks}

Table presents a time series regression of excess return of country portfolios against world excess returns (ExWorld) and inflation shock variable (Inf-Alpha). Country portfolios are estimated from the Emerging Market Database (EMDB) stock series with dividends. One year lagged inflation is used as the estimate of expected inflation and the difference between observed inflation and expected inflation is the inflation shock variable. The sample data covers sixteen developed countries over the period 1987:01 - 2005:12. The results in the table are based on regression $\hat{\mu}_{i t}-r_{f}^{n}=\beta_{i}\left(\hat{\mu}_{m t}-r_{f}^{n}\right)+\left(1-\beta_{i}\right) f_{i}\left(\pi_{t}\right)$ covering periods with negative inflation shock. Case 1 is the mean coefficients of all the countries where for $\left(\pi_{i t}-\bar{\pi}_{i t}\right)<0$ and $\beta_{i}>1$, and Case 2 is the mean coefficients of all the countries where for $\left(\pi_{i t}-\bar{\pi}_{i t}\right)<0$ and $\beta_{i}<1$.

\begin{tabular}{l|cccc}
\hline Negative Shock & \multicolumn{2}{|c}{ Coefficients } & \multicolumn{2}{c}{ T-values } \\
\hline \hline Argentina & Ex-World & Inf-Alpha & Ex-World & Inf-Alpha \\
Chile & 0.480 & -0.0011 & 2.48 & -3.22 \\
Colombia & 0.203 & -0.0014 & 1.80 & -1.18 \\
Greece & 0.101 & -0.0068 & 0.68 & -0.38 \\
India & 0.507 & -0.0051 & 3.21 & -2.51 \\
Jordan & -0.142 & -0.0021 & -0.96 & -1.45 \\
S. Korea & 0.111 & 0.0012 & 2.02 & 0.31 \\
Malaysia & 0.363 & -0.0053 & 2.90 & -2.65 \\
Mexico & 0.547 & -0.0052 & 4.34 & -1.19 \\
Nigeria & 0.577 & -0.0047 & 4.08 & -2.07 \\
Pakistan & -0.001 & -0.0049 & -0.01 & -3.73 \\
Philippines & -0.109 & -0.0266 & -0.59 & -0.96 \\
Thailand & 0.435 & 0.0022 & 3.77 & 1.97 \\
Turkey & 0.491 & 0.0004 & 3.58 & 0.02 \\
Venezuela & 0.833 & -0.0086 & 3.54 & -0.96 \\
Zimbabwe & -0.011 & -0.0014 & -0.05 & -2.91 \\
\hline \hline \multirow{2}{*}{ Average } & 0.040 & -0.0042 & 0.38 & -5.86 \\
Case 2 & & & & \\
& 0.277 & -0.0046 & & \\
& & & & \\
\hline \hline
\end{tabular}




\section{Table 4.6}

\section{Regression Results for Emerging Countries Using Positive Inflation Shocks}

Table presents a time series regression of excess return of country portfolios against world excess returns (ExWorld) and inflation shock variable (Inf-Alpha). Country portfolios are estimated from the Emerging Market Database (EMDB) stock series with dividends. One year lagged inflation is used as the estimate of expected inflation and the difference between observed inflation and expected inflation is the inflation shock variable. The sample data covers sixteen developed countries over the period 1987:01 - 2005:12. The results in the table are based on regression $\hat{\mu}_{i t}-r_{f}^{n}=\beta_{i}\left(\hat{u}_{m t}-r_{f}^{n}\right)+\left(1-\beta_{i}\right) f_{i}\left(\pi_{t}\right)$ covering periods with positive inflation shock. Case 3 is the mean coefficients of all the countries where for $\left(\pi_{i t}-\bar{\pi}_{i t}\right)>0$ and $\beta_{i}>1$, and Case 4 is the mean coefficients of all the countries where for $\left(\pi_{i t}-\bar{\pi}_{i t}\right)>0$ and $\beta_{i}<1$.

\begin{tabular}{|c|c|c|c|c|}
\hline \multirow[t]{2}{*}{ Positive Shock } & \multicolumn{2}{|c|}{ Coefficients } & \multicolumn{2}{|c|}{ T-values } \\
\hline & Ex-World & Inf-Alpha & Ex-World & Inf-Alpha \\
\hline Argentina & -0.008 & 0.0019 & -0.02 & 3.46 \\
\hline Chile & 0.144 & 0.0024 & 2.17 & 2.83 \\
\hline Colombia & 0.009 & -0.0027 & 0.06 & -1.17 \\
\hline Greece & 0.180 & 0.0074 & 1.26 & 2.69 \\
\hline India & 0.042 & -0.0044 & 0.26 & -2.36 \\
\hline Jordan & 0.058 & -0.0012 & 1.00 & -4.00 \\
\hline S. Korea & 0.599 & 0.0015 & 3.63 & 0.52 \\
\hline Malaysia & 0.600 & -0.0021 & 4.83 & -0.54 \\
\hline Mexico & 0.783 & 0.0014 & 4.56 & 2.91 \\
\hline Nigeria & 0.283 & -0.0008 & 1.24 & -0.14 \\
\hline Pakistan & 0.186 & 0.0068 & 1.94 & 0.50 \\
\hline Philippines & 0.647 & 0.0048 & 4.14 & 0.28 \\
\hline Thailand & 0.760 & -0.0051 & 5.38 & -1.70 \\
\hline Turkey & -0.209 & 0.0085 & -0.72 & 1.03 \\
\hline Venezuela & 0.062 & -0.0023 & 0.32 & -0.56 \\
\hline Zimbabwe & 0.313 & -0.0032 & 2.30 & -0.57 \\
\hline \multicolumn{5}{|l|}{ Average } \\
\hline Case 4 & 0.278 & 0.0008 & 3.63 & 0.76 \\
\hline
\end{tabular}




\section{Table 4.7}

\section{Regression Results for Developed Countries Using Negative Inflation Shocks with Fama-French 3 Factor Correction}

Table presents a time series regression of excess return of country portfolios against world excess returns (ExWorld) and inflation shock variable (Inf-Alpha). Country portfolios are estimated from Morgan Stanley Capital International (MSCI) price indices with dividends. One year lagged inflation is used as the estimate of expected inflation and the difference between observed inflation and expected inflation is the inflation shock variable. The sample data covers sixteen developed countries over the period 1970:01 - 2005:12. The results in the table are based on regression $\hat{\mu}_{i t}-r_{f}^{n}=\beta_{i}\left(\hat{\mu}_{m t}-r_{f}^{n}\right)+\left(1-\beta_{i}\right) f_{i}\left(\pi_{t}\right)$ covering periods with negative inflation shock. SMB and HML are the Fama-French size and value factors. Case 1 is the mean coefficients of all the countries where for $\left(\pi_{i t}-\bar{\pi}_{i t}\right)<0$ and $\beta_{i}>1$, and Case 2 is the mean coefficients of all the countries where for $\left(\pi_{i t}-\bar{\pi}_{i t}\right)<0$ and $\beta_{i}<1$.

\begin{tabular}{|c|c|c|c|c|c|c|c|c|}
\hline \multirow[t]{2}{*}{ Negative Shock } & \multicolumn{4}{|c|}{ Coefficients } & \multicolumn{4}{|c|}{ T-values } \\
\hline & Ex-World & SMB & $\mathrm{HML}$ & Inf-Alpha & Ex-World & SMB & $\mathrm{HML}$ & Inf-Alpha \\
\hline Germany & 0.902 & 0.006 & 0.073 & -0.077 & 8.28 & 0.10 & 1.11 & -1.43 \\
\hline Austria & 0.585 & 0.017 & 0.090 & 0.002 & 5.49 & 0.30 & 1.41 & 0.98 \\
\hline Belgium & 1.012 & -0.007 & 0.158 & -0.008 & 11.23 & -0.13 & 2.63 & -1.45 \\
\hline Canada & 0.693 & 0.026 & 0.021 & -0.045 & 8.70 & 0.61 & 0.43 & -0.49 \\
\hline Denmark & 0.908 & -0.072 & 0.112 & 0.002 & 8.60 & -1.24 & 1.74 & 2.34 \\
\hline France & 1.037 & -0.119 & 0.059 & -0.004 & 11.45 & -1.84 & 0.81 & -0.26 \\
\hline Italy & 1.013 & -0.042 & 0.196 & 0.024 & 7.60 & -0.51 & 2.19 & 0.22 \\
\hline Japan & 1.029 & 0.049 & 0.012 & -0.008 & 11.14 & 0.77 & 0.17 & -0.97 \\
\hline Netherlands & 0.915 & 0.029 & 0.110 & 0.006 & 11.30 & 0.65 & 2.26 & 0.06 \\
\hline United States & 0.891 & -0.037 & -0.089 & 0.007 & 13.20 & -1.00 & -2.18 & 0.89 \\
\hline United Kingdom & 0.991 & 0.021 & 0.011 & -0.008 & 10.51 & 0.41 & 0.19 & -0.14 \\
\hline Norway & 1.021 & 0.056 & 0.111 & -0.001 & 8.13 & 0.69 & 1.25 & -0.91 \\
\hline Spain & 1.019 & 0.034 & 0.081 & 0.014 & 9.49 & 0.50 & 1.08 & 1.32 \\
\hline Sweden & 1.000 & 0.146 & 0.104 & -0.028 & 8.03 & 2.18 & 1.40 & -2.71 \\
\hline Switzerland & 0.843 & 0.025 & 0.078 & -0.075 & 9.96 & 0.54 & 1.52 & -0.74 \\
\hline Singapore & 1.003 & 0.087 & 0.047 & -0.002 & 7.73 & 1.20 & 0.58 & -0.38 \\
\hline \multicolumn{9}{|l|}{ Average } \\
\hline Case 1 & 1.019 & 0.008 & 0.095 & 0.002 & 240.90 & 0.31 & 3.89 & 0.42 \\
\hline Case 2 & 0.859 & 0.018 & 0.057 & -0.024 & 18.89 & 0.91 & 2.58 & -2.10 \\
\hline
\end{tabular}




\section{Table 4.8}

\section{Regression Results for Developed Countries Using Positive Inflation Shocks with Fama-French 3 Factor Correction}

Table presents a time series regression of excess return of country portfolios against world excess returns (ExWorld) and inflation shock variable (Inf-Alpha). Country portfolios are estimated from Morgan Stanley Capital International (MSCI) price indices with dividends. One year lagged inflation is used as the estimate of expected inflation and the difference between observed inflation and expected inflation is the inflation shock variable. The sample data covers sixteen developed countries over the period 1970:01 - 2005:12. The results in the table are based on regression $\hat{\mu}_{i t}-r_{f}^{n}=\beta_{i}\left(\hat{\mu}_{m t}-r_{f}^{n}\right)+\left(1-\beta_{i}\right) f_{i}\left(\pi_{t}\right)$ covering periods with positive inflation shock. SMB and HML are the Fama-French size and value factors. Case 3 is the mean coefficients of all the countries where for $\left(\pi_{i t}-\bar{\pi}_{i t}\right)>0$ and $\beta_{i}>1$, and Case 4 is the mean coefficients of all the countries where for $\left(\pi_{i t}-\bar{\pi}_{i t}\right)>0$ and $\beta_{i}<1$.

\begin{tabular}{|c|c|c|c|c|c|c|c|c|}
\hline \multirow[t]{2}{*}{ Positive Shock } & \multicolumn{4}{|c|}{ Coefficients } & \multicolumn{4}{|c|}{ T-values } \\
\hline & Ex-World & SMB & $\mathrm{HML}$ & Inf-Alpha & Ex-World & SMB & $\mathrm{HML}$ & Inf-Alpha \\
\hline Germany & 1.017 & 0.041 & -0.074 & 0.0065 & 10.66 & 0.72 & -1.17 & 1.31 \\
\hline Austria & 0.637 & 0.020 & 0.043 & -0.0058 & 5.62 & 0.32 & 0.63 & -0.29 \\
\hline Belgium & 1.003 & 0.098 & 0.150 & 0.0027 & 10.20 & 1.78 & 2.48 & 0.51 \\
\hline Canada & 1.022 & 0.057 & 0.001 & 0.0013 & 12.89 & 1.10 & 0.03 & 0.96 \\
\hline Denmark & 0.844 & -0.114 & 0.045 & -0.0025 & 8.71 & -2.15 & 0.78 & -2.70 \\
\hline France & 1.018 & 0.034 & 0.142 & -0.0180 & 12.07 & 0.58 & 2.15 & -1.23 \\
\hline Italy & 0.960 & 0.032 & 0.042 & -0.0067 & 7.70 & 0.47 & 0.56 & -0.82 \\
\hline Japan & 0.993 & 0.062 & 0.055 & -0.0017 & 9.77 & 1.11 & 0.89 & -2.58 \\
\hline Netherlands & 1.006 & 0.053 & 0.089 & -0.0218 & 14.55 & 1.16 & 1.78 & -1.60 \\
\hline United States & 1.002 & 0.061 & -0.124 & -0.0224 & 14.84 & 1.63 & -2.95 & -2.70 \\
\hline United Kingdom & 1.083 & 0.136 & 0.217 & 0.0040 & 13.69 & 2.03 & 2.93 & 0.51 \\
\hline Norway & 0.882 & -0.019 & 0.062 & -0.0013 & 7.03 & -0.28 & 0.82 & -1.23 \\
\hline Spain & 0.788 & -0.014 & -0.004 & -0.0029 & 7.87 & -0.26 & -0.06 & -3.39 \\
\hline Sweden & 1.025 & 0.056 & 0.008 & 0.0030 & 10.99 & 0.85 & 0.11 & 0.27 \\
\hline Switzerland & 1.010 & 0.017 & 0.057 & -0.0200 & 11.45 & 0.32 & 0.99 & -1.50 \\
\hline Singapore & 1.038 & 0.090 & -0.045 & $\begin{array}{r}-0.0497 \\
\end{array}$ & 8.95 & 1.10 & -0.50 & -0.83 \\
\hline \multicolumn{9}{|l|}{ Average } \\
\hline Case 3 & 1.024 & 0.061 & 0.030 & -0.0070 & 126.16 & 5.23 & 0.84 & $-1.82^{\circledR}$ \\
\hline Case 4 & 0.872 & 0.009 & 0.056 & -0.0026 & 17.67 & 0.36 & 3.20 & -3.83 \\
\hline
\end{tabular}

\footnotetext{
${ }^{\circledR}$ Result is influenced significantly by outliers in Singapore’s observed inflation minus the expected inflation.
} 


\section{$\underline{\text { Table } 4.9}$}

\section{Regression Results for Emerging Countries Using Negative Inflation Shocks with Fama-French 3 Factor Correction}

Table presents a time series regression of excess return of country portfolios against world excess returns (ExWorld) and inflation shock variable (Inf-Alpha). Country portfolios are estimated from the Emerging Market Database (EMDB) stock series with dividends. One year lagged inflation is used as the estimate of expected inflation and the difference between observed inflation and expected inflation is the inflation shock variable. The sample data covers sixteen developed countries over the period 1987:01 - 2005:12. The results in the table are based on regression $\hat{\mu}_{i t}-r_{f}^{n}=\beta_{i}\left(\hat{\mu}_{m t}-r_{f}^{n}\right)+\left(1-\beta_{i}\right) f_{i}\left(\pi_{t}\right)$ covering periods with negative inflation shock. SMB and HML are the Fama-French size and value factors. Case 1 is the mean coefficients of all the countries where for $\left(\pi_{i t}-\bar{\pi}_{i t}\right)<0$ and $\beta_{i}>1$, and Case 2 is the mean coefficients of all the countries where for $\left(\pi_{i t}-\bar{\pi}_{i t}\right)<0$ and $\beta_{i}<1$.

\begin{tabular}{|c|c|c|c|c|c|c|c|c|}
\hline \multirow[t]{2}{*}{ Negative Shock } & \multicolumn{4}{|c|}{ Coefficients } & \multicolumn{4}{|c|}{ T-values } \\
\hline & Ex-World & SMB & $\mathrm{HML}$ & Inf-Alpha & Ex-World & SMB & $\mathrm{HML}$ & Inf-Alpha \\
\hline Argentina & 0.512 & 0.388 & 0.172 & -0.0012 & 2.44 & 1.48 & 0.55 & -3.28 \\
\hline Chile & 0.221 & 0.274 & 0.105 & -0.0013 & 1.81 & 1.81 & 0.58 & -1.13 \\
\hline Colombia & 0.072 & 0.162 & -0.087 & -0.0047 & 0.44 & 0.79 & -0.36 & -0.26 \\
\hline Greece & 0.509 & 0.123 & 0.025 & -0.0051 & 2.94 & 0.57 & 0.10 & -2.48 \\
\hline India & -0.149 & 0.532 & 0.036 & -0.0015 & -0.95 & 2.69 & 0.15 & -1.05 \\
\hline Jordan & 0.123 & 0.060 & 0.055 & 0.0009 & 2.06 & 0.80 & 0.61 & 0.22 \\
\hline S. Korea & 0.274 & 0.123 & -0.304 & -0.0052 & 2.03 & 0.73 & -1.50 & -2.64 \\
\hline Malaysia & 0.604 & 0.308 & 0.248 & -0.0043 & 4.43 & 1.78 & 1.21 & -0.96 \\
\hline Mexico & 0.480 & 0.426 & -0.274 & -0.0052 & 3.22 & 2.28 & -1.22 & -2.36 \\
\hline Nigeria & -0.026 & -0.050 & -0.100 & -0.0047 & -0.43 & -0.65 & -1.08 & -3.58 \\
\hline Pakistan & -0.042 & 0.934 & 0.410 & -0.0033 & -0.22 & 3.87 & 1.42 & -1.25 \\
\hline Philippines & 0.551 & 0.074 & 0.426 & 0.0025 & 4.43 & 0.47 & 2.25 & 2.29 \\
\hline Thailand & 0.513 & -0.040 & 0.076 & -0.0005 & 3.44 & -0.21 & 0.34 & -0.02 \\
\hline Turkey & 0.787 & 0.175 & -0.131 & -0.0092 & 3.06 & 0.55 & -0.34 & -1.03 \\
\hline Venezuela & -0.107 & 0.195 & -0.311 & -0.0014 & -0.45 & 0.66 & -0.88 & -2.91 \\
\hline Zimbabwe & -0.008 & 0.074 & -0.161 & -0.0043 & -0.07 & 0.50 & -0.90 & -5.94 \\
\hline \multicolumn{9}{|l|}{ Average } \\
\hline Case 2 & 0.270 & 0.235 & 0.012 & -0.003 & 3.64 & 3.80 & 0.20 & -4.19 \\
\hline
\end{tabular}


$\underline{\text { Table } 4.10}$

\section{Regression Results for Emerging Countries Using Positive Inflation Shocks with Fama-French 3 Factor Correction}

Table presents a time series regression of excess return of country portfolios against world excess returns (ExWorld) and inflation shock variable (Inf-Alpha). Country portfolios are estimated from the Emerging Market Database (EMDB) stock series with dividends. One year lagged inflation is used as the estimate of expected inflation and the difference between observed inflation and expected inflation is the inflation shock variable. The sample data covers sixteen developed countries over the period 1987:01 - 2005:12. The results in the table are based on regression $\hat{\mu}_{i t}-r_{f}^{n}=\beta_{i}\left(\hat{\mu}_{m t}-r_{f}^{n}\right)+\left(1-\beta_{i}\right) f_{i}\left(\pi_{t}\right)$ covering periods with positive inflation shock. SMB and HML are the Fama-French size and value factors. Case 3 is the mean coefficients of all the countries where for $\left(\pi_{i t}-\bar{\pi}_{i t}\right)>0$ and $\beta_{i}>1$, and Case 4 is the mean coefficients of all the countries where for $\left(\pi_{i t}-\bar{\pi}_{i t}\right)>0$ and $\beta_{i}<1$.

\begin{tabular}{|c|c|c|c|c|c|c|c|c|}
\hline \multirow[t]{2}{*}{ Positive Shock } & \multicolumn{4}{|c|}{ Coefficients } & \multicolumn{4}{|c|}{ T-values } \\
\hline & Ex-World & SMB & $\mathrm{HML}$ & Inf-Alpha & Ex-World & SMB & $\mathrm{HML}$ & Inf-Alpha \\
\hline Argentina & 0.048 & 0.492 & 0.279 & 0.0020 & 0.14 & 1.12 & 0.53 & 3.54 \\
\hline Chile & 0.143 & 0.135 & 0.012 & 0.0026 & 1.97 & 1.47 & 0.11 & 2.99 \\
\hline Colombia & 0.003 & -0.157 & -0.044 & -0.0029 & 0.02 & -0.75 & -0.17 & -1.21 \\
\hline Greece & 0.180 & 0.113 & 0.018 & 0.0075 & 1.15 & 0.57 & 0.07 & 2.71 \\
\hline India & -0.029 & -0.220 & -0.297 & -0.0047 & -0.16 & -0.98 & -1.11 & -2.50 \\
\hline Jordan & 0.038 & -0.002 & -0.072 & -0.0012 & 0.61 & -0.03 & -0.76 & -3.99 \\
\hline S. Korea & 0.481 & -0.265 & -0.470 & 0.0019 & 2.68 & -1.18 & -1.74 & 0.63 \\
\hline Malaysia & 0.582 & 0.124 & -0.042 & -0.0019 & 4.30 & 0.73 & -0.21 & -0.49 \\
\hline Mexico & 0.799 & 0.105 & 0.076 & 0.0014 & 4.26 & 0.45 & 0.27 & 2.88 \\
\hline Nigeria & 0.364 & 0.189 & 0.315 & -0.0018 & 1.45 & 0.60 & 0.82 & -0.29 \\
\hline Pakistan & 0.174 & -0.008 & -0.045 & 0.0072 & 1.66 & -0.06 & -0.28 & 0.52 \\
\hline Philippines & 0.671 & 0.257 & 0.130 & 0.0056 & 3.94 & 1.20 & 0.51 & 0.33 \\
\hline Thailand & 0.723 & 0.117 & -0.114 & -0.0047 & 4.69 & 0.60 & -0.49 & -1.55 \\
\hline Turkey & -0.335 & -0.421 & -0.507 & 0.0097 & -1.05 & -1.06 & -1.06 & 1.15 \\
\hline Venezuela & -0.030 & -0.070 & -0.341 & -0.0023 & -0.14 & -0.26 & -1.07 & -0.56 \\
\hline Zimbabwe & 0.144 & -0.040 & -0.627 & -0.0050 & 1.00 & -0.22 & -2.87 & -0.90 \\
\hline \multicolumn{9}{|l|}{ Average } \\
\hline Case 4 & 0.247 & 0.022 & -0.108 & 0.001 & 3.07 & 0.39 & -1.59 & 0.72 \\
\hline
\end{tabular}




\section{Table 4.11}

\section{Regression Results for Developed Countries Using Negative Inflation Shocks}

Table presents a time series regression of excess return of country portfolios against world excess returns (ExWorld) and inflation shock variable (Inf-Alpha). Country portfolios are estimated from Morgan Stanley Capital International (MSCI) price indices with dividends. One year lagged inflation is used as the estimate of expected inflation and the difference between observed inflation and expected inflation is the inflation shock variable. The sample data covers sixteen developed countries over the period 1987:01 - 2005:12. The results in the table are based on regression $\hat{\mu}_{i t}-r_{f}^{n}=\beta_{i}\left(\hat{\mu}_{m t}-r_{f}^{n}\right)+\left(1-\beta_{i}\right) f_{i}\left(\pi_{t}\right)$ covering periods with negative inflation shock.

Case 1 is the mean coefficients of all the countries where for $\left(\pi_{i t}-\bar{\pi}_{i t}\right)<0$ and $\beta_{i}>1$, and Case 2 is the mean coefficients of all the countries where for $\left(\pi_{i t}-\bar{\pi}_{i t}\right)<0$ and $\beta_{i}<1$.

\begin{tabular}{l|rrrr}
\hline Negative Shock & \multicolumn{2}{|c}{ Coefficients } & \multicolumn{2}{c}{ T-values } \\
\hline & Ex-World & Inf-Alpha & Ex-World & Inf-Alpha \\
\hline \hline Germany & 0.875 & -0.0180 & 8.53 & -2.02 \\
Austria & 0.576 & 0.0017 & 5.39 & 0.93 \\
Belgium & 1.005 & 0.0180 & 9.50 & 0.18 \\
Canada & 0.691 & -0.0070 & 9.37 & -0.98 \\
Denmark & 0.917 & 0.0010 & 8.12 & 0.10 \\
France & 1.003 & 0.0042 & 12.36 & 0.26 \\
Italy & 1.001 & 0.0054 & 5.09 & 0.51 \\
Japan & 1.005 & 0.0092 & 10.90 & 0.48 \\
Netherlands & 0.955 & -0.0091 & 11.10 & -1.35 \\
United States & 0.892 & -0.0012 & 14.31 & -2.28 \\
United Kingdom & 0.996 & 0.0017 & 11.16 & 1.01 \\
Norway & 1.065 & -0.0212 & 8.32 & -2.02 \\
Spain & 1.011 & 0.0097 & 9.51 & 0.86 \\
Sweden & 1.006 & -0.0014 & 8.73 & -0.39 \\
Switzerland & 0.902 & -0.0097 & 10.14 & -0.18 \\
Singapore & 1.007 & 0.0041 & 8.24 & 0.77 \\
\hline \hline Average & & & 134.51 & 0.87 \\
Case 1 & 1.013 & 0.0035 & & \\
Case 2 & & & & \\
\hline \hline
\end{tabular}




\section{Table 4.12}

\section{Regression Results for Developed Countries Using Positive Inflation Shocks}

Table presents a time series regression of excess return of country portfolios against world excess returns (ExWorld) and inflation shock variable (Inf-Alpha). Country portfolios are estimated from Morgan Stanley Capital International (MSCI) price indices with dividends. One year lagged inflation is used as the estimate of expected inflation and the difference between observed inflation and expected inflation is the inflation shock variable. The sample data covers sixteen developed countries over the period 1987:01 - 2005:12. The results in the table are based on regression $\hat{\mu}_{i t}-r_{f}^{n}=\beta_{i}\left(\hat{\mu}_{m t}-r_{f}^{n}\right)+\left(1-\beta_{i}\right) f_{i}\left(\pi_{t}\right)$ covering periods with positive inflation shock. Case 3 is the mean coefficients of all the countries where for $\left(\pi_{i t}-\bar{\pi}_{i t}\right)>0$ and $\beta_{i}>1$, and Case 4 is the mean coefficients of all the countries where for $\left(\pi_{i t}-\bar{\pi}_{i t}\right)>0$ and $\beta_{i}<1$.

\begin{tabular}{l|rrrr}
\hline Positive Shock & \multicolumn{2}{|c}{ Coefficients } & \multicolumn{2}{c}{ T-values } \\
& \multicolumn{1}{|c}{ Ex- } & \multicolumn{1}{c}{ Ex-World } & Inf-Alpha \\
\hline \hline Germany & 1.168 & 0.0157 & 11.74 & 1.16 \\
Austria & 0.522 & -0.0142 & 5.78 & -0.21 \\
Belgium & 0.902 & 0.0231 & 10.19 & 0.59 \\
Canada & 1.089 & 0.0013 & 13.77 & 0.97 \\
Denmark & 0.864 & 0.0240 & 8.48 & -2.64 \\
France & 1.217 & -0.0153 & 12.05 & -1.05 \\
Italy & 0.895 & -0.0162 & 8.01 & -0.76 \\
Japan & 0.915 & 0.0170 & 10.17 & -2.53 \\
Netherlands & 1.176 & -0.0203 & 14.89 & -1.49 \\
United States & 1.104 & -0.0264 & 16.56 & -3.17 \\
United Kingdom & 1.131 & 0.0161 & 13.67 & 0.77 \\
Norway & 0.844 & 0.0120 & 7.10 & -1.15 \\
Spain & 0.857 & 0.0292 & 8.26 & -3.46 \\
Sweden & 1.138 & 0.0132 & 11.68 & 0.30 \\
Switzerland & 1.073 & -0.0189 & 11.78 & -1.43 \\
Singapore & 1.188 & -0.0153 & 9.74 & -0.88 \\
\hline \hline Average & & & & \\
Case 3 & 1.143 & -0.0055 & 70.99 & -0.97 \\
& & & & \\
Case 4 & 0.828 & 0.0107 & 15.92 & 1.53 \\
\hline \hline
\end{tabular}

John $\mathrm{H}$. 